\title{
BIODISPONIBILIDADE DO ÍON FOSFATO EM SOLOS SOB PASTAGENS CULTIVADAS NA REGIĀO DO CERRADO
}

\section{Edemar JoAQuim Corazza \\ Engenheiro Agrônomo}

Orientador: Prof. Dr. TAKASHI MURAOKA

\begin{abstract}
Tese apresentada à Escola Superior de Agricultura "Luiz de Queiroz", Universidade de São Paulo, para obtenção do título de Doutor em Agronomia, Área de Concentração: Solos e Nutrição de Plantas.
\end{abstract}

\author{
PIR ACICABA \\ Estado de São Paulo - Brasil
}

Fevereiro - 2002 


\section{Dados Internacionais de Catalogaçāo na Publicaçāo (CIP) DIVISÃO DE BIBLIOTECA E DOCUMENTAÇÃO -'ESALO/USP}

\section{Corazza, Edemar Joaquim}

Biodisponibilidade do ion fosfato em soios sob pastagens cultivadas na Regiäo do Cerrado / Edemar Joaquim Corazza. - - Piracicaba, 2002.

127 p. : il.

Tese (doutorado) - Escola Superior de Agricultura Luiz de Queiroz, 2002.

Bibliografia.



1. Brachiaria 2. Cerrado 3, Fósforo 4.; Pạstagens 5. Química do solo I. Título

CDD 633.2

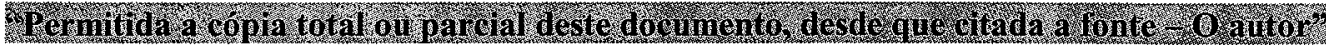




\section{DEDICATÓRIA}

Aos meus pais Albino ("in memoriam") e Maria,

pèlò amor e exemplo de vida,

dedico este trabalho. 


\section{AGRADECIMENTOS}

De maneira simples, mas sincera, queremos registrar a gratidão aos vários colaboradores e entidades, das quais, a experiência científica, os serviços técnicos e o apoio financeiro, nos permitiram desenvolver este trabalho.

Ao Prof. Dr. Takashi Muraoka pela orientação, amizade e apoio durante o período da realização deste trabalho.

Ao Pesquisador Dr. Michel Brossard pela orientação, discussão, amizade e estímulo na troca de idéias sobre a condução do trabalho.

Aos Pesquisadores Alexandre de Oliveira Barcellos, Lourival Vilela, Rui Veloso, pelas valiosas discussões sobre o tema.

Ao pesquisador Dr. Becquer pelas sugestões e comentários.

A Prof. Fátima Guimarães, pelas sugestões e discussões sobre o tema.

Ao Institut de recherche pour le developpement (IRD), pela concessão da bolsa de estudos.

À Escola Superior de Agricultura "Luiz de Queiroz" (ESALQ), Universidade de São Paulo (USP), pela oportunidade da realização do curso.

Ao Centro de Energia Nuclear na Agricultura (CENA), Universidade de São Paulo (USP), por permitir o uso do laboratório de Fertilidade do Solo para realização das análises deste trabalho.

À Embrapa Cerrados, por permitir o uso da sua base física para realização de parte deste trabalho.

À Verde Sol Agropecuária e Participações Ltda., pelo fornecimento da área, infraestrutura e apoio para a realização de um experimento de campo. 
À Usi-Fértil Indústria e Comércio de Fertilizantes Ltda., pela fornecimento do fosfato reativo de gafsa para as adubações de implantação e manutenção do experimento.

Ao Anderson, Felipe, Cristiano, Inês, Gelson, Valdemir, Ana Lúcia, amigos que contribuíram na elaboração dos experimentos e análises.

Aos funcionários Marileusa, Sandra, Henriqueta, João e Maria Aparecida do Laboratório de Fertilidade do Solo do CENA/USP, pelo auxílio nas análises laboratoriais.

À Roberta, pelo amor e compreensão.

À minha família pelo incentivo e apoio em todas as horas.

Aos meus amigos.

A todos aqueles que direta ou indiretamente, contribuíram para a realização deste trabalho. 


\section{SUMÁRIO}

Página

LISTA DE FIGURAS............................................................ $\mathrm{x}$

LISTA DE TABELAS...............................................................

CURRICULUM VITAE ............................................................ xiv

RESUMO ............................................................................... $\quad \mathrm{xV}$

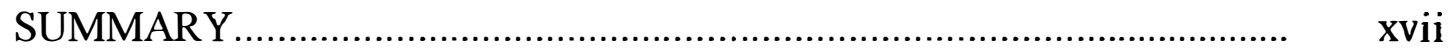

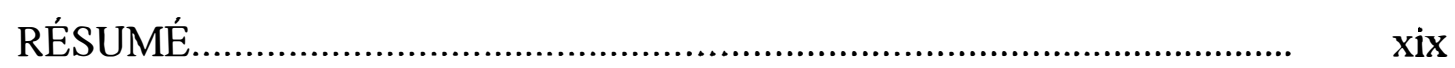



2 REVISÃO DE LITERATURA.................................................. 6

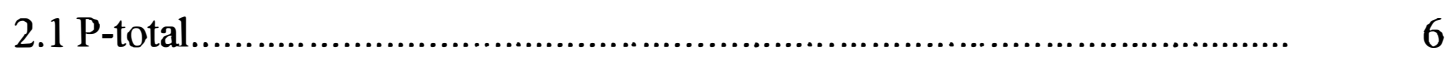

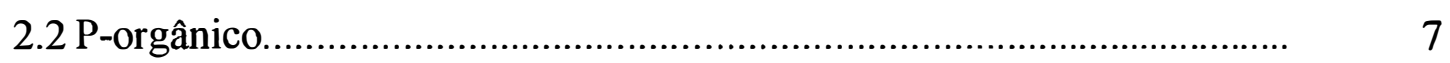

2.3 Critérios agronômicos de disponibilidade de P................................. 9

2.4 Métodos de extração de P-disponível............................................. 10

3 BIODISPONIBILIDADE POTENCIAL DE FOSFATO EM SOLOS SOB PASTAGENS CULTIVADAS TROPICAIS: UMA ABORDAGEM REGIONAL .............................................................................. 16

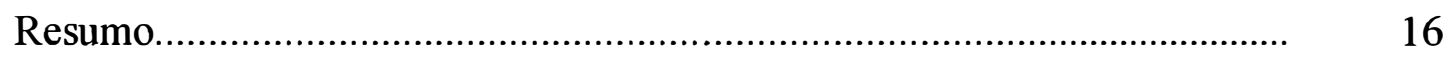

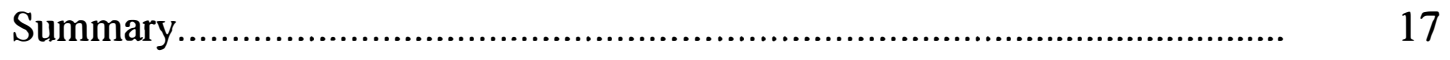

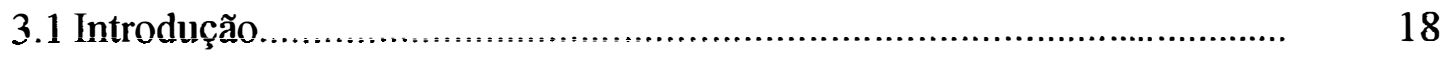

3.2 Material e Métodos..................................................................... 20

3.2.1 Áreas de amostragem................................................................ 20

3.2.2 Amostragens do solo........................................................ 21 


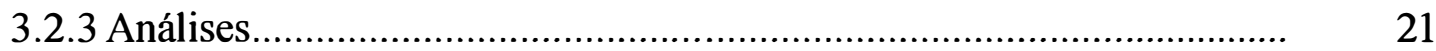

3.2.4 Determinação do fosfato isotopicamente trocável ................................. 22

3.2.5 Fórmulas básicas para o cálculo da quantidade de $\mathrm{P}$ isotopicamente trocável (Pit) de um sistema solo-solução e da quantidade de Pit a qualquer tempo t

3.2.6 Cálculo do tamanho dos compartimentos de fosfato do solo (Ep) do modelo multi-compartimental (Fardeau, 1993).............................................. 24

3.2.7 Análise estatística....................................................................... 25

3.3 Resultados e Discussão................................................................... 26

3.3.1 Análise em componentes principais (ACP) ......................................... 26

3.3.2 Dados experimentais das cinéticas de troca isotópica (CTI)................ 30

3.3.3 Fosfato isotopicamente trocável (Pit)................................................ 32

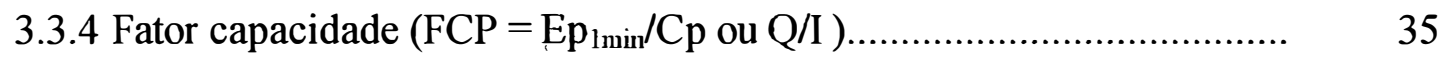

3.3.5 Biodisponibilidade de P no tempo.................................................. 37



4 BIODISPONIBILIDADE DE FOSFATO EM LATOSSOLO ARENOARGILOSO SOB Brachiaria sp. NO CERRADO....................................... 41

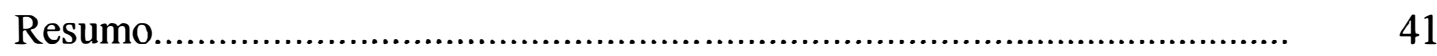

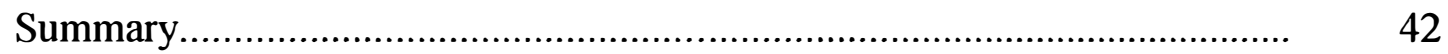



4.2 Material e Métodos........................................................................

4.2.1 Áreas de amostragem..........................................................................

4.2.2 Amostragens de solos.................................................................. 48



4.2.4 Determinação do fosfato isotopicamente trocável................................... 49

4.2.5 Cálculo da quantidade de P isotopicamente trocável (Pit) de um sistema solo solução (SSS) e da quantidade de Pit a qualquer tempo t.......... 49

4.2.6 Análise estatística........................................................................ 50



4.3.1 Contéudos de Pt e Po nos solos............................................................ $\quad 50$ 
4.3.2 Conteúdos de $\mathrm{Pr}, \mathrm{Ca}$ e $\mathrm{Mg}$

4.3.3 Cinéticas de troca isotópica (CTI) e cálculo do fosfato potencialmente biodisponível.......................................................... 52

4.4 Discussão.................................................................................. 53

4.5 Conclusões................................................................................. 58

5 VARIABILIDADE ESPACIAL DO FÓSFORO DO SOLO SOB Brachiaria brizantha DE BAIXA PRODUTIVIDADE.......................... 59

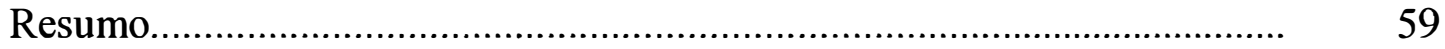

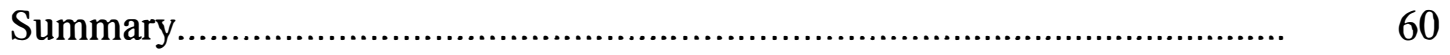

5.1 Introdução............................................................................... $\quad 61$

5.2 Material e Métodos...................................................................... 63

5.3 Resultados e Discussão............................................................ 67



6 UTILIZAÇÃO DO FÓSFORO DE FOSFATO NATURAL E SUPERFOSFATO POR Brachiaria brizantha E Stylosanthes guyanensis...

Resumo.

Summary.

6.1 Introdução

6.2 Material e Métodos.

6.2.1 Experimento de incubação.

6.2.2 Experimento na casa de vegetação.............................................. $\quad 79$



6.3.1 Experimento de incubação...................................................... $\quad 80$

6.3.2 Desenvolvimento e acúmulo de matéria seca das plantas.................. 81

6.3.3 Conteúdos de P na planta....................................................... 81

6.3.4 Conteúdos de P-resina $(\operatorname{Pr})$................................................ $\quad 84$

6.3.5 Colonização radicular por FMA............................................. 84

6.4 Discussão........................................................................ 84

6.5 Conclusões............................................................................... 87






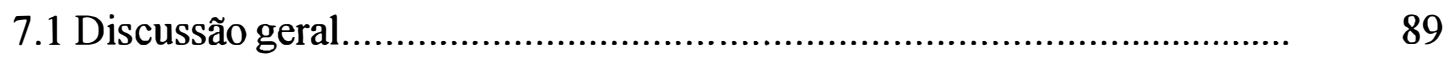

7.1.1 A oferta de fosfato pelo solo para manter o crescimento da planta

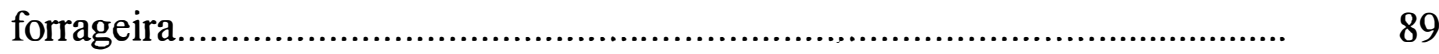

7.1.2 Oferta do P do solo avaliado pela resina............................................... $\quad 90$

7.1.3 Cinética de troca isotópica....................................................................... 91

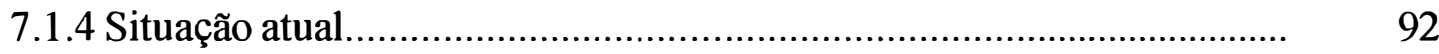

7.1.5 Perspectivas de pesquisas futuras............................................................. 93

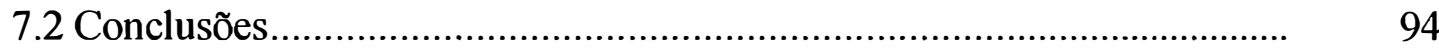

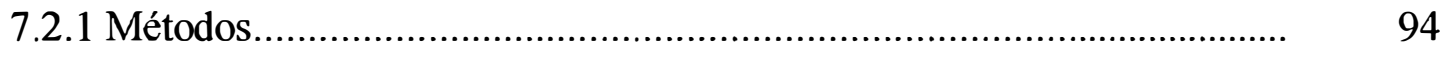

7.2.2 Escala

7.2.3 Resultados agronômicos............................................................... 96

REFERÊNCIAS BIBLIOGRÁFICAS..................................................... 97

APÊNDICES ..................................................................................... 113 


\section{LISTA DE FIGURAS}

Página

1 Ciclo simplificado do fósforo do solo num sistema de pastagem.

2 Representação esquemática do modelo multi-compartimental do fósforo trocável do solo (adaptado de Fardeau, 1993) (Ep = fósforo isotopicamente trocável).

3 Análise em componentes principais das cinéticas de troca isotópica..

4 Fosfato isotopicamente trocável (Ep) nos compartimentos da cinética de troca isotópica com todas as amostras.

5 Fosfato isotopicamente trocável (Ep) nos compartimentos da cinética de troca isotópica para as diferentes texturas de solo.

6 Oferta de $\mathrm{P}$ pelo solo e demanda de $\mathrm{P}$ pela planta para pastagem renovada (RM) e de manejo tradicional (TT) em função do tempo.

7 a) Croqui da área experimental com os tratamentos e respectivas subdivisões dos piquetes. b) Distribuição espacial dos 98 pontos de amostragens na área experimental. Escolhida aleatoriamente no T6 R2......

8 "Box-plots" dos conteúdos de $\mathrm{P}$ avaliado pelo método de resina nas divisórias dos tratamentos.

9 Correlação do fósforo (Pr) com a pendente (a) e semivariogramas escalonados dos dados originais e resíduos (b) para $\mathrm{O} P$ na touceira.

10 "Box-plot" dos conteúdos de fosfato (Pr) antes da fertilização (a) entre 
touceiras, na touceira e apos fertilização (b) em duas malhas de amostragem

11 Correlações entre o fósforo (Pr) entre touceiras (a) e na touceira (b) com o P na MV da forrageira.

12 "Box-plot" para P-resina (Pr) nas amostras compostas coletadas antes da implantação do experimento e de áreas adjacentes do cerrado e da fazenda vizinha (Fausto)

13 Conteúdos de $\mathrm{P}$-resina ( $\mathrm{Pr}$ ) e $\mathrm{pH} \mathrm{H}_{2} \mathrm{O}$ num período de incubação de 360 dias com superfosfato triplo (SFT) e fosfato reativo de gafsa (FRG), para os solos da Fazenda RJ (RJ) e Fazenda vizinha (Fa)

14 Conteúdos de cálcio e magnésio num período de incubação de 360 dias com superfosfato triplo (SFT) e fosfato reativo de gafsa (FRG) para os solos da Fazenda RJ (RJ) e Fazenda vizinha (Fa). 


\section{LISTA DE TABELAS}

Página

1 Características das áreas selecionadas.

2 Capacidade tampão do solo $\left(\mathrm{R} / \mathrm{r}_{1}\right)$, fosfato na solução do solo $(\mathrm{Cp})$, declividade da reta (n), P-total (Pt) e P-orgânico (Po) em diferentes solos e pastagens na Região do Cerrado.

3 Conteúdos de $\mathrm{P}$ calculados nos vários compartimentos trocáveis de acordo com o modelo multi-compartamental de Fardeau (1993).

4 Dados físicos e químicos do solo estudado.

5 Características das pastagens amostradas

6 Conteúdos de P-total (Pt), P-orgânico (Po) e P-resina (Pr), cálcio e magnésio dos extratos resina no cerradão, pastagens renovadas e de manejo tradicional

7 Conteúdos de $\mathrm{P}$ calculados nos vários compartimentos de troca de acordo com a análise multi-compartimental de Fardeau (1993).

8 Coeficientes de correlação de Pearson entre P-resina (Pr) e compartimentos de troca de fosfato $(\mathrm{Ep})(\mathrm{n}=27)$ de acordo com a análise multicompartimental de Fardeau (1993).

9 Caracterização da camada $0-10 \mathrm{~cm}$ do Latossolo Vermelho da área experimental

10 Resultados do poder tampão do solo $\left(\mathrm{R} / \mathrm{r}_{1}\right)$, concentração de íons fosfato na solução do solo $(\mathrm{Cp})$, declividade da reta (n), P-total (Pt) e P-orgânico (Po) 
das amostras compostas por tratamento.

11 Atributos químicos e físicos do Latossolo Vermelho-Escuro, na profundidade de $0-10 \mathrm{~cm}$.

12 Resultados relativos a planta cultivada em casa de vegetação (resultados das fontes em função das plantas utilizadas)

13 Conteúdos de $\mathrm{P}$ (Pr, Pt, Po) do solo e \% de raízes infectadas pelos FMAs (resultados das fontes em função das plantas utilizadas) 


\section{CURRICULUM VITAE}

EDEMAR JOAQUIM CORAZZA, filho de Albino Corazza Filho e Maria Corazza, nasceu em Espumoso, Rio Grande do Sul, em 15 de abril de 1967.

Graduou-se em Engenharia Agronômica, em 1990, pela Universidade Federal de Santa Maria, no período de 1991 a 1992 foi responsável técnico pela Medicampo Planejamento e Assistência Técnica Ltda., em Santo Antônio das Missões, Rio Grande do Sul.

Em 1992, foi convocado pela EMATER-PR para desempenhar a função de Extensionista Municipal - IV, em Nova Aurora, Paraná.

Em março de 1995, iniciou o curso de Mestrado em Agronomia, área de concentração Solos na Universidade de Brasília, concluindo-o em julho de 1997.

Em março de 1999, iniciou o curso de Doutorado em Solos e Nutrição de Plantas na Escola Superior de Agricultura "Luiz de Queiroz" (ESALQ), Universidade de São Paulo (USP), concluindo-o em abril de 2002. 


\title{
BIODISPONIBILIDADE DO ÍON FOSFATO EM SOLOS SOB PASTAGENS CULTIVADAS NA REGIÃO DO CERRADO
}

\author{
Autor: Edemar Joaquim Corazza \\ Orientador: Prof. Dr. Takashi Muraoka
}

\section{RESUMO}

O objetivo deste trabalho foi avaliar a biodisponibilidade do fosfato $(\mathrm{P})$ do solo sob pastagens cultivadas com Brachiaria spp. em diferentes situações de manejo e tipos de solo na Região do Cerrado. No Cerrado, que abrange um pouco mais de $24 \%$ do território brasileiro (207 milhões de hectares), as pastagens cultivadas ocupam 49,5 milhões de hectares, das quais, aproximadamente $80 \%$ apresentam-se com baixa produtividade. A baixa biodisponibilidade de $\mathrm{P}$ nos solos é apontada como uma das causas da perda da capacidade produtiva dessas pastagens. Trabalhos que avaliem a oferta de fosfato pelo solo sob pastagens são escassos. Embora seja utilizada em rotina, a metodologia de extração pela resina aniônica tem pouco referencial no âmbito de análises de solos sob pastagens. A avaliação da biodisponibilidade do fosfato do solo foi realizada por meio da extração do P pela resina (Pr) e complementada pela determinação do íon fosfato na solução do solo $(\mathrm{Cp})$ e a realização das cinéticas de troca isotópica (CTI) com o radioisótopo ${ }^{32} \mathrm{P}$. Os latossolos de diferentes texturas foram os principais solos estudados. $\mathrm{O}$ estudo seguiu uma abordagem de uma escala regional até a parcela e permitiu destacar os seguintes fatos: i) As extrações pela resina demonstraram a baixa biodisponibilidade do $\mathrm{P}$ do solo sob pastagens cultivadas conforme os níveis atualmente considerados limitantes para o crescimento da forrageira. O Pr também foi limitante sob 
pastagens recém renovadas a um curto período de tempo e consideradas de boa produtividade; ii) Os extratos $\mathrm{Cp}$ apresentaram limitações metodológicas na sua determinação devido às baixas concentrações de fosfato, mas corroboraram com os da resina, sendo considerados limitantes para o crescimento da planta conforme resultados da literatura; iii) A modelagem dos dados experimentais das CTI permitiu caracterizar de melhor a biodisponibilidade de fosfato do solo, pois leva em consideração o fator tempo de oferta de P pelo solo. Demonstrou-se que a biodisponibilidade de P do solo seria limitante para as plantas após de 2 meses utilização e nas renovadas a partir do terceiro ao quarto ano da renovação, se adubações de manutenção não forem realizadas $\mathrm{e}$, iv) A avaliação da distribuição espacial de $\mathrm{P}$ numa pastagem de baixa produtividade mostrou que existe uma dinâmica própria de reciclagem de $\mathrm{P}$ nestes sistemas. Os conteúdos de Pr "sob touceiras" foram superiores aos "entre touceiras" e apresentaram correlação linear com o $\mathrm{P}$ da planta. Isto evidenciou a necessidade de estudos mais ligados a dinâmica do $\mathrm{P}$ do solo nestas situações, levando em consideração a planta. Estes estudos podem auxiliar no entendimento do balanço dos componentes do consórcio de pastagens ao longo do tempo, pois interferem diretamente na dinâmica do $\mathrm{P}$ do solo e sua absorção pelas plantas. Há necessidade de mais estudos de campo para a elaboração de base de dados mais consistente para estas espécies adaptadas a solos de baixa fertilidade química para o estabelecimento dos níveis críticos de P. A CTI poderia ser utilizada como uma ferramenta melhorando as avaliações atualmente realizadas por metodologias convencionais. 


\title{
PHOSPHATE BIOAVAILABILITY IN SOILS UNDER CULTIVATED PASTURES IN THE CERRADO REGION
}

\author{
Author: Edemar Joaquim Corazza
}

Adviser: Prof. Takashi Muraoka

\section{SUMMARY}

The objective of this study was to evaluate soil phosphate (P) bioavailability under pastures cultivated with Brachiaria spp in different management situations and soil types in the Cerrado Region. The Cerrado occupies a little more than $24 \%$ of Brazil (207 million hectares). In this region, cultivated pastures cover 49.5 million hectares, of which $80 \%$ show low productive capacity. The low $\mathrm{P}$ bioavailability in the soils is put forward as one of the causes of productive capacity loss in these cultivated pastures. A survey of the literature emphasizes the lack of adequate studies to evaluate the abundance of phosphate in the soil. Despite its routine use, the methodology of extraction by anionic resin has not been used much in the area of soil analysis under pasture. The evaluation of soil phosphate bioavailability was carried out by extracting $\mathrm{P}$ by resin ( $\mathrm{Pr}$ ) and complemented by determining the phosphate ion in the soil solution (Cp) and isotope exchange analyses (IEK) were undertaken with the radioisotope ${ }^{32} \mathrm{P}$. The latosols of different textures were the main soils studied. The study took from the regional to the plot scales approaches and led to the following facts being emphasized: i) The extractions by resin demonstrated the low $\mathrm{P}$ bioavailability of soil under cultivated pastures according to levels currently considered limiting for forage growth. Under pastures renovated shortly before, considered to be of good productivity, the Pr was also 
limiting; ii) The $\mathrm{Cp}$ extracts showed methodological limitations in their determination due to the low concentrations of phosphate, but corroborated those done by resin, considered limiting for plant growth in the literature; iii) The modeling of experimental data of the IEK analyses allowed the best type of characterization of soil phosphate bioavailability, since it took into consideration the time factor for soil P supply. In one of the studied sites, it was demonstrated that soil P bioavailability was limiting for the plant after two months and in renovated pastures from the third to fourth year of renovation, if regular fertilization was not carried out, and iv) The evaluation of the $\mathrm{P}$ spatial distribution in a pasture of low productivity showed that there is a $\mathrm{P}$ recycling dynamic at work in these systems. The Pr content "under grass tussocks" was higher than that "between grass tussocks" and showed a linear correlation with the plant $\mathrm{P}$. This pointed to the need for studies connected more to the soil P dynamic in these situations, taking the plant into account. These studies can aid the understanding of the balance of components over time in mixed pastures, since the components interfere directly in the soil $\mathrm{P}$ dynamic and its absorption by plants. More field-level studies need to be undertaken, with the aim of building up a database that is more consistent with these species that are adapted to low chemical fertility, to establish critical P levels. The IEK analyses could be used as a tool to improve the methods currently used in conventional methodologies. 


\title{
BIODISPONIBILITÉ DE L'ION PHOSPHATE DE SOLS SOUS PÂTURAGES CULTIVÉS DE LA RÉGION DU CERRADO
}

\author{
Auteur : Edemar Joaquim Corazza \\ Directeur de thèse : Prof. Takashi Muraoka
}

RÉSUMÉ

L'objectif de ce travail était d'évaluer la biodisponibilité du phosphate (P) de sols sous pâturages cultivés avec Brachiaria spp. en diverses situations de gestion et types de sols de la région du Cerrado. Dans le Cerrado, qui occupe un peu plus de $24 \%$ du territoire brésilien avec 207 milhões de hectares, les pâturages cultivés couvrent 49,5 millions d'hectares, dont approximativement $80 \%$ présentent de faibles productivités. La faible biodisponibilité du $\mathrm{P}$ des sols est signalée comme une des causes probables de la perte de capacité productive de ces pâturages. L'analyse bibliographique montre que les travaux analysant l'offre de phosphate du sol sous pâturages sont peu nombreux pour cette région. Ainsi, malgré que la méthode d'extraction par les résines anioniques soit déjà utilisée en routine, elle ne bénéficie pas d'un référenciel suffisant d'aide à l'interprétation pour ces sols sous pâturages. Les évaluation a été conduite avec l'extraction résine ( $\mathrm{Pr})$, complétée par des mesures de la concentration de phosphate dans la solution du sol $(\mathrm{Cp})$ et la réalisation de cinétiques d'échanges isotopiques (CEI) avec le radioisotope ${ }^{32} \mathrm{P}$. Les latosols de diverses textures ont été les principaux sols étudiés. La démarche suivie intègre une approche régionale à des évaluation à l'échelle de la parcelle, et permet de dégager les résultats suivants: i) Les extraction par les résines ont montré la faible biodisponibilité de $\mathrm{P}$ des sols sous ces pâturages cultivés, 
selon des niveaux actuellement considérés limitants pour la croissance des plantes fourragères. Il est apparu que les valeurs de Pr étaient aussi limitantes dans des pâturages récement renouvelés et considérés comme étant de bonne productivité; ii) Les faibles concentrations en ion phosphate des extraits $\mathrm{Cp}$ posent dans ces sols des problèmes méthodologiques. Cependant, ils confirment les observations faites avec le $\mathrm{Pr}$; iii) La modélisation des données isotopiques expérimentales des CEI a permis de mieux caractériser la biodisponibilité du $\mathrm{P}$, car elle prend en considération le facteur temps dans l'offre de $\mathrm{P}$ par le sol. Dans une étude de cas, il a été montré que si des fertilisations d'entretien n'étaient pas faites, l'offre du P du sol deviendrait limitante pour les plantes au bout de deux mois d'utilisation du pâturage, et que dans des parcelles renouvellées à la troisième ou quatrième année l'offre du sol serait déficitaire, et iv) Dans un pâturage de faible productivité, l'analyse de la distribution spaciale du P a montré qu'il éxiste une dynamique propre de recyclage du phosphore dans ces systèmes. Les contenus de $\mathrm{Pr}$ sous les touffes étaient supérieurs à ceux mesurés entre les touffes, et ils présentaient une relation linéraire positive avec le $\mathrm{P}$ de la plante. Cela met en évidence la nécessité de poursuivre des études sur le cycle du $\mathrm{P}$ dans ce type de situation. Cela pourrait aider à la compréhension du bilan dans les différentes composantes des pâturages au coụrs du temps, car cela interfère directement avec la dynamique du $\mathrm{P}$ dans le sol et son absorption par les plantes. On observe qu'il faut plus d'études au champ pour l'élaboration d'une banque de données qui concerne les espèces adaptés aux sols de fertilité chimique limitée. Cela permetterait de mieux définir les niveaux et seuils critiques pour le $\mathrm{P}$ du sol. La CEI pourrait alors être utilisée comme un instrument d'amélioration des évaluations actuellement réalisées avec des méthodes extractives conventionnelles. 


\section{INTRODUÇÃO}

O Cerrado constitui um modelo de transformações recente do meio ambiente. Sua extensa área abrange 1.027 municípios em doze estados. No século XX, no final da década dos anos 30 , a política governamental de integração favoreceu uma ocupação lenta mas constante da região, que culminou com a construção de Brasília em 1960. O auge do interesse pelo Cerrado ocorreu entre as décadas de 60 e 80 com o desenvolvimento de grandes projetos agropecuários. A transformação da vegetação natural para pastagens cultivadas e cultivos anuais representou um grande avanço do potencial de produção da região. A prioridade não é abrir novas áreas para a agropecuária, mas de manter e melhorar o potencial produtivo das áreas em produção. Isto permite limitar ou inverter os processos de degradação do meio ambiente que se observam mais freqüentemente.

A ocupação agropecuária dos solos do Cerrado ocorreu, prioritariamente, sobre latossolos que perfazem $46 \%$ da área total (Adámoli et al., 1986). Estes solos são naturalmente de baixa fertilidade química. Isto é, que apresentam baixa capacidade de troca de cátions, e em conseqüência baixos teores de nutrientes, acidez muitas vezes associada a altos teores de alumínio trocável e teores de P-disponível baixos (Adámoli et al., 1986; Lopes \& Cox, 1977). Entretanto, estas áreas de Cerrado estavam em equilíbrio, uma vez que não ocorria a exportação de nutrientes e as perdas destes eram limitadas, permitindo assim a manutenção da vegetação natural.

O bioma Cerrado abrange uma área de aproximadamente $20710^{6}$ ha, possuindo clima tropical com características climáticas próprias, predominantes na maior parte do seu território, mas que vão mudando gradualmente em virtude das influências das regiões vizinhas. Dois parâmetros definem o regime estacional da região: 
a precipitação média anual, com valores entre 750 e $2.000 \mathrm{~mm}$ e a duração do período seco, que oscila entre 4 a 6 meses (Assad et al., 1993). Em 65\% da Região as precipitações representam entre 1.200 e 1.600 mm (Adámoli et al., 1986).

A área de pastagem cultivada no Brasil apresentou um incremento de $250 \%$ de 1970 a 1995 (Zimmer \& Euclides Filho, 1997), principalmente devido à incorporação do Cerrado ao sistema produtivo agropecuário. Dos $207 \quad 10^{6}$ ha do Cerrado, aproximadamente $7510^{6}$ ha são ocupados por pastagens nativas e $4210^{6}$ ha por pastagens cultivadas (Yokohama et al., 1995). Segundo o Centro de Pesquisa Agropecuária dos Cerrados (Embrapa Cerrados) o potencial de expansão do cultivo das pastagens é de até $6010^{6}$ ha (Macedo, 1995). Levantamentos recentes apontam a existência de uma área de 49,5 $10^{6}$ ha de pastagens cultivadas (Sano et al., 2000). Entretanto, $80 \%$ destas pastagens são consideradas de baixa produtividade ou degradadas (Klutouski et al., 1999). Assim, enquanto ocorre um aumento da área cultivada com pastagens concomitantemente aumenta a percentagem de área de pastagens de baixa produtividade ou degradadas.

A "degradação das pastagens" é definida como o processo evolutivo de perda de vigor, de produtividade, de capacidade de recuperação natural das pastagens para sustentar os níveis de produção e qualidade exigida pelos animais, assim como, o de superar os efeitos nocivos de pragas, doenças e plantas invasoras, culminando com a degradação avançada dos recursos naturais, em razão de manejos inadequados (Macedo \& Zimmer, 1993; Barcellos, 1996). Este processo do declínio da produtividade vegetal é observado nas pastagens cultivadas nos primeiros anos após a implantação da pastagem, entre 3-10 anos de pastejo, dependendo da espécie e fertilidade química do solo entre outros.

O trabalho apresentado integra-se numa estratégia de pesquisa multiorganismos entre a Embrapa, IRD (França) e Universidades, no estudo dos fatores e processos de declínio da produção das pastagens cultivadas desta região. O projeto visou estudar as transformações das características biológicas e físico-químicas de solos sob pastagens nos Cerrados e a recuperação / renovação destas pastagens de Brachiaria spp. através do consórcio com leguminosas e adubação fosfatada. 
As hipóteses a serem consideradas na biodisponibilidade de $\mathrm{P}$ dos solos destas pastagens são: i) nas pastagens degradadas e em processo de degradação, a biodisponibilidade de $\mathrm{P}$ é limitante a produção forrageira; ii) em processos de renovação ou recuperação a fertilização fracionada de manutenção é indispensável (desde que $\mathrm{N} \mathrm{e}$ Ca não sejam limitantes). Esta problemática agronômica pode ser acrescentada pela necessidade de descrever melhor os compartimentos do fosfato do solo a fim de prever sua estabilidade no decorrer do tempo.

$\mathrm{Na}$ Região do Cerrado, o fósforo $(\mathrm{P})$ é reconhecido como um fator limitante à produção forrageira. Isto é devido a sua baixa biodisponibilidade, tanto pelo seu nível de reserva como pela elevada capacidade de retenção do fosfato pelo solo. Deste modo o $\mathrm{P}$ é um dos fatores responsável pela rápida queda da capacidade produtiva das pastagens cultivadas, colocando em cheque a sustentabilidade do sistema. Assim, o conhecimento da biodisponibilidade de $\mathrm{P}$ nos solos de pastagens degradadas e em processo de recuperação, poderia fornecer importantes subsídios para a sua utilização racional em recuperação de pastagens, o que, no mínimo, atenuaria a situação vigente.

A biodisponibilidade de um nutriente ("available" ou "bioavailable nutrient") foi definida por Barber (1984) como o nutriente presente num compartimento de íons do solo que pode se mover para a raiz da planta durante o período de crescimento dela se a raiz estiver suficientemente perto. Esta definição é restrita para formas inorgânicas presentes no solo durante o crescimento da planta e incluem íons liberados da matéria orgânica durante o período de tempo considerado.

A ciclagem do P é influenciada pela sua baixa solubilidade e mobilidade no solo. Então, quantidades totais de $\mathrm{P}$ num ecossistema tendem a ser relativamente constantes através do tempo, mas a quantidade de $\mathrm{P}$ em diferentes compartimentos podem variar de ano para ano. A remoção de $P$ pelas colheitas constitui a maior saída de $\mathrm{P}$ dos sistemas cultivados, ao passo que em situações de pastejo o retorno do $\mathrm{P}$ através dos resíduos das plantas e dejetos dos animais, resulta em um ciclo relativamente fechado. Neste sistema, há três estoques de P: i) $\mathrm{P}$ na biomassa da planta e animal; ii) $\mathrm{P}$ nos resíduos de plantas e dejetos animais, e iii) $\mathrm{P}$ no solo. Entre estes se desenvolve um sistema natural de reciclagem do P (Figura 1), que passa obrigatoriamente por um 
compartimento quantitativamente pouco representado, mas indispensável para o suprimento de P para a planta, que é o compartimento de íons na solução.

A maior parte do P biodisponível provêm da mineralização da fração orgânica do solo no sistema solo-planta-animal, quando não se faz fertilizações de manutenção. Neste caso, a estratégia no manejo da pastagem é manter alta a taxa de transferência de $\mathrm{P}$ dos resíduos e do $\mathrm{P}$ não disponível do solo para a reserva de P-disponível, a fim de suprir um nível adequado e assim manter um crescimento suficiente da forrageira para um bom pastejo.

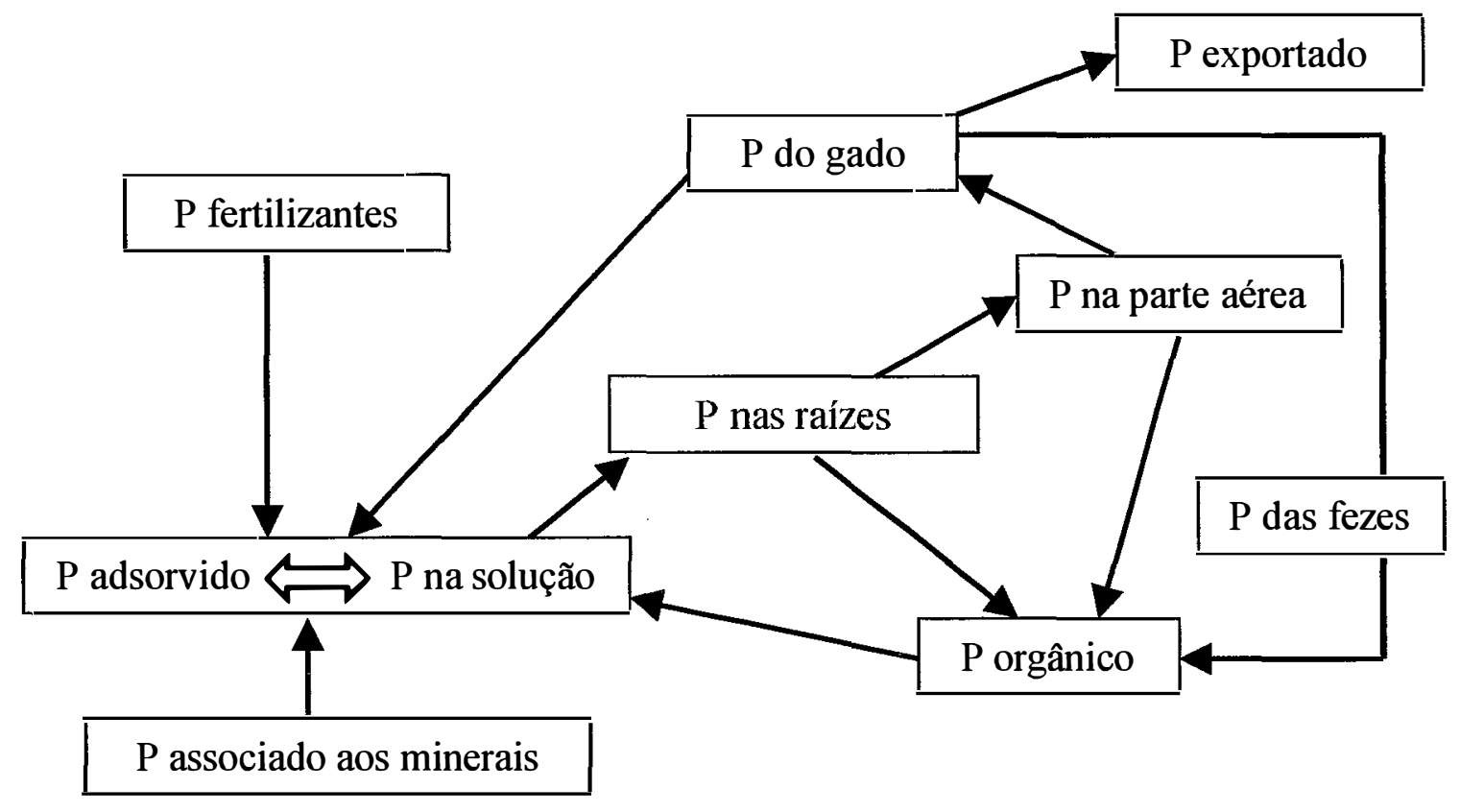

Figura 1 - Ciclo simplificado do fósforo do solo num sistema de pastagem.

$\mathrm{O}$ objetivo desta tese foi de avaliar a biodisponibilidade de $\mathrm{P}$ do solo sob pastagens de Brachiaria spp. em diferentes situações de manejo e tipos de solo. As avaliações foram realizadas por meio de métodos convencionais e isotópicos. $\mathrm{O}$ trabalho foi organizado em quatro artigos que estão sendo enviados para publicação, na forma de capítulos, além de um capítulo da revisão de literatura.

No capítulo 3 , procurou-se caracterizar a biodisponibilidade de íons fosfato utilizando as cinéticas de troca isotópica (CTI). Esta metodologia foi aplicada num 
conjunto de amostras de cinco regiões do Cerrado, numa tentativa de realizar a modelagem dos compartimentos biodisponíveis do íon fosfato do solo em função do tempo (Fardeau, 1993). Com base nesta metodologia, objetivou-se verificar se o fosfato é um fator limitante para o crescimento das plantas, como era comumente aceito no âmbito de produtores e agrônomos.

No capítulo 4, analisou-se a biodisponibilidade do fosfato do solo considerando a realidade de uma unidade de produção de pecuária. Esta análise foi realizada com a metodologia da resina e complementada pelas cinéticas de troca isotópica (CTI). Esta abordagem permite descrever melhor os fatores a serem considerados no decorrer do tempo para manter a biodisponibilidade do $\mathrm{P}$ em níveis compatíveis com a demanda da planta.

No capítulo 5, analisou-se a variabilidade espacial da biodisponibilidade do $\mathrm{P}$ do solo e suas relações com a distribuição de plantas considerando uma unidade de produção pecuária menor que a do capítulo anterior. Esta abordagem de forma mais detalhada permite verificar a variabilidade existente dependendo da maneira da coleta das amostras e da distribuição dos fertilizantes por ocasião da implantação de um experimento de recuperação de pastagem. As determinações da biodisponibilidade do $P$ resina foram complementadas pelas cinéticas de troca isotópica (CTI).

No capítulo 6, o objetivo inicial do trabalho foi estabelecer os fluxos de P para a Brachiaria brizantha cv. Marandu (BB), Stylosanthes guianensis cv. Mineirão (SG) e a consorciação destes utilizando duas fontes de $\mathrm{P}$, o superfosfato triplo (SFT) e o fosfato reativo de gafsa (FRG) com o solo da área experimental do capítulo 5. Em complementação, realizou-se um experimento de incubação com o mesmo solo e fontes de $\mathrm{P} O \mathrm{O}$ experimento foi implantado com sucesso no campo, entretanto tivemos problemas de condução com os animais e de avaliação da oferta do $\mathrm{P}$ do solo pela estratégia de amostragem escolhida. 


\section{REVISÃO DE LITERATURA}

$\mathrm{O}$ enfoque da revisão de literatura foi no compartimento do $\mathrm{P}$ do solo de latossolos de ocorrência no Brasil, de preferência na Região do Cerrado, que estavam sendo cultivados com pastagens. Esta abordagem limitou o número de trabalhos publicados encontrados em revistas indexadas, principalmente de experimentos de campo, o que já tinha sido constatado por Lobato et al. (1986) e mais recentemente por Novais \& Smyth (1999).

\subsection{P-total}

Os conteúdos de P-total $(\mathrm{Pt})$ nas camadas superficiais de solos variam entre 100 a $3000 \mathrm{mg} \mathrm{kg}^{-1}$ (Harrison, 1987). Em solos altamente intemperizados, estes conteúdos são menores devido à exaustão dos materiais primários que continham $\mathrm{P}$ e foram transformados em minerais secundários. Os dados disponíveis na literatura sobre Pt no ecossistema cerrado são escassos e, usualmente somente a camada superficial do solo foi analisada (Chapuis-Lardy et al., 2002).

Assim, constatou-se que conteúdos do Pt de solos da Região do Cerrado apresentaram correlação linear $\left(y=0,3936 X+156,13 ; r^{2}=0,51 ; p<0,05 ; n=35\right)$ com o conteúdo de argila de latossolos, podzólicos, areias quartzosas e um plintossolo (Guerra et al., 1996; Lilienfein et al., 2000; Neufeldt et al., 2000; Chapuis-Lardy et al., 2002). O Pt variou entre 87 a $577 \mathrm{mg} \mathrm{kg}^{-1}$, sendo que os solos arenosos apresentaram conteúdos abaixo de 200 e os solos com mais de $30 \%$ de argila 200 e $577 \mathrm{mg} \mathrm{kg}^{-1} \mathrm{de} \mathrm{Pt}$. Os valores superiores nos solos argilosos demonstram que a alta capacidade de sorção destes solos é responsável por manter o fósforo no sistema. 


\subsection{P-orgânico}

Neste item são apresentados resultados sobre a participação do compartimento do P-orgânico (Po) no Pt de solos no Cerrado. Recentes estudos têm demonstrado a grande participação do compartimento de Po, de até aproximadamente $50 \%$ do Pt do solo (Chapuis-Lardy et al., 2001; Chapuis-Lardy et al., 2002) em solos sob pastagens de baixa produtividade. A proporção de Po é mais elevada principalmente onde não há aplicação de fertilizantes químicos, como ocorre em sistemas naturais ou em pastagens de baixa produtividade (Sharpley, 1985).

Os resultados de Po catalogados na literatura seguiram diferentes procedimentos de determinação, tornando um pouco difícil a comparação dos resultados (Harrison, 1987). Basicamente duas metodologias são utilizadas, a indireta, pelo método da ignição ou por extração. Pelo método da ignição, uma amostra é submetida a alta temperatura $\left(200-550{ }^{\circ} \mathrm{C}\right)$, o que causa a oxidação de compostos orgânicos de Po, para Pi. A concentração de Po é determinada pela diferença entre as concentrações de Pi obtidas por extração ácida, de uma subamostra não calcinada e de uma calcinada (Condron et al., 1990).

Os métodos de extração ou fracionamento seqüencial (Bowman \& Cole, 1978; Hedley et al., 1982; Tiessen \& Moir, 1993) utilizam bases $\left(\mathrm{NaHCO}_{3}, \mathrm{NaOH}\right)$ e ácidos $\left(\mathrm{HCl}, \mathrm{H}_{2} \mathrm{SO}_{4}\right)$ a diferentes concentrações extraindo formas orgânicas e inorgânicas de $\mathrm{P}$, permitindo sua classificação em compartimentos, numa escala decrescente de solubilidade, que é em certos casos associada a uma escala de disponibilidade para as plantas, do disponível ao não disponível. Entretanto, quando se realiza o fracionamento seqüencial do $\mathrm{P}$ em vários compartimentos, às vezes o significado prático das concentrações não é claro.

Em latossolos do Planalto Central do Distrito Federal, em condições naturais e cultivados com pastagens, o Po representou de 26 a 43\% do Pt na camada $0-20 \mathrm{~cm}$ do cerrado, $75 \%$ numa mata de galeria e aproximadamente $30 \%$ nas pastagens. O conteúdo de Po variou de 86 a $194 \mathrm{mg}$ de Po $\mathrm{kg}^{-1}$ de solo, na camada superficial do solo e diminuiu com a profundidade, em média 70 e $47 \mathrm{mg}$ de $\mathrm{Po} \mathrm{kg}^{-1}$ de solo, respectivamente no horizonte BA e Bw (Chapuis-Lardy et al., 2002). 
Em estudo realizado por Guerra et al. (1996) foram analisados 17 solos brasileiros, o conteúdo de Po variou de 7 até $272 \mathrm{mg} \mathrm{kg}^{-1}$ de solo, com valores médios de $50 \mathrm{mg} \mathrm{kg}^{-1}$. Esses valores representaram de 13 a $47 \%$ do Pt (para um solo sob Areia Quartzosa e um Podzólico Vermelho Amarelo, respectivamente), predominando amplamente sobre a fração inorgânica lábil. Nos solos podzólicos e latossolos o Po lábil correlacionou-se positivamente com o P disponível determinado pelo extrator Mehlich I.

Considerando que a fração orgânica lábil encontra-se fracamente ligada à fase sólida do solo e, portanto, mais acessível a mineralização, a relação íntima com o P disponível sugere que o reservatório lábil deve ocupar um papel na fertilidade do solo (biodisponibilidade), maior do que o antes reconhecido, principalmente em solos de baixa fertilidade natural (Guerra et al., 1996).

Um estudo de formas de $\mathrm{P}$ pelo fracionamento seqüencial (Hedley modificado) em latossolos sobre diferentes sistemas de manejo do Brasil Central demonstrou que sobre cerrado mais de $60 \%$ do $\mathrm{P}$ disponível estava na forma orgânica, refletindo a alta contribuição do Po para a nutrição das plantas. Por outro lado, as fertilizações após o cultivo da terra aumentaram somente os compartimentos de Pi disponível (Neufeldt et al., 2000). Resultados semelhantes foram determinados por Lilienfien et al. (2000) em latossolos da mesma região.

Os latossolos sob vegetação de cerrado apresentaram conteúdos superiores de Po daqueles reportados na literatura para outras savanas (Chapuis-Lardy et al., 2001). Estes conteúdos representam um importante compartimento que é utilizado para a nutrição das plantas nestes sistemas, em condições naturais ou em pastagens de baixa produtividade, onde são utilizados pouco ou nenhum insumo e o manejo do solo que leve a mineralização do Po. Isso poderá acarretar quedas acentuadas de produtividade ao longo do tempo pelo aumento da competição do solo e decréscimo de formas disponíveis de P na solução do solo (Tiessen et al., 1992). Por outro lado, o melhor conhecimento dos compartimentos e da ciclagem do $\mathrm{P}$ neste sistema pode viabilizar sistemas mais sustentáveis.

$\mathrm{Na}$ agricultura de alta tecnologia como a adotada atualmente em condições de cerrados, com a aplicação de doses elevadas de fertilizantes fosfatados, a contribuição 
do Po como fonte de P para o crescimento das plantas deve-se tornar irrelevante, justificando assim a pequena importância que se têm dado ao estudo do Po no Brasil (Novais \& Smyth, 1999). Porém, na Região do Cerrado, aproximadamente 12 milhões de ha pratica-se a agricultura de "altos inputs" de $P$, enquanto que 49,5 milhões de ha apresentam-se sob pastagens cultivadas, ou sem "inputs".

\subsection{Critérios agronômicos de disponibilidade de $\mathbf{P}$}

As plantas necessitam de suprimento contínuo de P na solução do solo. Beckett \& White (1964), para caracterizar a disponibilidade de $\mathrm{P}$ do solo, propuseram o uso de três fatores: i) o fator intensidade (I), que é a concentração de íons fosfato $\left(\mathrm{H}_{2} \mathrm{PO}_{4}{ }^{-}\right.$; $\left.\mathrm{H}_{2} \mathrm{PO}_{4}{ }^{2-}\right)$ na solução do solo; ii) o fator quantidade (Q), que é a quantidade de fosfato que pode potencialmente ser absorvida pela planta, e iii) o fator capacidade (FCP), que descreve a habilidade de um solo para manter o fator intensidade (I) constante quando o fator quantidade $(\mathrm{Q})$ varia. $\mathrm{O}$ fator capacidade, definido pela razão de equilíbrio entre a quantidade de $\mathrm{P}(\mathrm{Q})$ e o $\mathrm{P}$ em solução (I) $(\mathrm{FCP}=\mathrm{Q} / \mathrm{I})$, é conhecido também como poder tampão de fosfato, que é uma medida da capacidade do solo em manter um nível determinado de P na solução (White \& Beckett, 1964), levando em conta o fato de as plantas absorverem apenas o $\mathrm{P}$ que se encontra na solução do solo. A complexidade intrínseca à disponibilidade de $\mathrm{P}$ no solo é a razão da diversidade com que o assunto tem sido tratado nos trabalhos de pesquisa.

A concentração de $\mathrm{P}$, para diferentes formas de $\mathrm{P}$ na solução do solo, que define o I tem sido considerada um índice de disponibilidade desse nutriente para as plantas, quando outros fatores (Q e, ou, FCP) são também considerados (Novais \& Smyth, 1999). O I não é considerado isoladamente devido a dificuldade da sua determinação em solos tropicais, que apresentaram valores muito baixos de fosfato na solução do solo e que estão abaixo do nível de deteç̧ão de $\mathrm{P}$, pelos métodos usuais de análise (Fardeau, 1996; Frossard et al., 1998). Por outro lado, como o Q é quantitativamente mais importante fonte de $\mathrm{P}$ para as plantas do que $\mathrm{I}$, compreende-se a maior ênfase que a pesquisa tem dado aos extratores químicos, como medida de Q, do que às medidas de $\mathrm{I}$. 
O fator quantidade ou P-lábil envolve, para fins práticos, a soma da concentração do elemento, teoricamente considerado fator quantidade $(\mathrm{Q})$ mais sua concentração em solução (I). A separação das duas formas, para a obtenção do valor de $\mathrm{Q}$, não se justifica, uma vez que a concentração do $\mathrm{P}$ em solução é, de modo geral, extremamente menor que a de $\mathrm{Q}$, não alterando, para o nível de precisão da determinação, o valor de $\mathrm{Q}$ obtido. Entretanto, a utilização da técnica da diluição isotópica permite a determinação do Q separadamente do I (Frossard et al., 1994; Morel \& Plenchette, 1994; Fardeau, 1996) que serão definidos mais adiante.

$\mathrm{O}$ fator capacidade de $\mathrm{P}$ (FCP) pode ser entendido como a resistência do solo a mudanças no fator intensidade (I) quando se adiciona ou se retira $\mathrm{P}$ do solo (Q). Em latossolos da região do cerrados são freqüentes valores de CMAP (capacidade máxima de adsorção de P) superiores a $1 \mathrm{mg} \mathrm{g}^{-1}$ de P no solo (Bahia Filho \& Braga, 1975; Ker, 1995), enquanto o valor de intensidade fica em torno de $0,05 \mathrm{mg} \mathrm{L}^{-1}$ de $\mathrm{P}$ (Yost et al., 1979). Essa relação entre os valores máximos de Q (igual a CMAP) e de $I$, neste exemplo (1.000 mg kg $\mathrm{kg}^{-1} \mathrm{P}$ 0,05 $\mathrm{mg} \mathrm{L}^{-1} \mathrm{P}$ ), é de 20.000. Para um solo arenoso, comparado a um argiloso, ambos pertencentes a um mesmo grande grupo, a relação entre os valores diminui consideravelmente, não só pelo menor tamanho de $\mathrm{Q}$, também, pelo aumento de I. Para o mesmo valor de Q, deve-se encontrar valores de I bem maiores nos solos arenosos.

\subsection{Métodos de extração de P-disponível}

A determinação da disponibilidade de $\mathrm{P}$ do solo por meio de metodologias convencionais químicas extrativas apresentam limitações conceituais e metodológicas em razão da natureza das amostras. Esta determinação envolve a necessidade de correlação entre o que o método "extrai" ou P-extraível do solo e o crescimento da planta. Dessa maneira, fica evidente a necessidade de levar em consideração o fator tempo na avaliação da biodisponibilidade, considerando a planta e suas exigências.

A avaliação do "P-disponível" de um solo tem sido feita com o uso de soluções extratoras com características constitutivas diversas, quanto a acidez, diluição, tamponamento, presença de compostos complexantes, fósforo marcado, etc. e, um pouco 
mais recentemente no Brasil, com a resina de troca aniônica. As extrações de "Pdisponível" fornecem valores que variam entre intensidade (I) e quantidade $(\mathrm{Q})$, às vezes, até mesmo parte do $\mathrm{P}$ não-lábil (NQ), dependendo das propriedades do extrator e das condições de extração, sem informar sobre o fator capacidade $(\mathrm{Q} / \mathrm{I})$ (Novais \& Smyth, 1999).

Em revisão recente sobre o tema, Silva \& Raij (1999) chegaram as seguintes conclusões: na avaliação agronômica de métodos de extração de $\mathrm{P}$ dos solos, o método das resinas trocadoras de íons supera os demais métodos existentes, na determinação do "P-disponível" no solo, pelas seguintes razões: i) apresenta valores de coeficientes de determinação, para a correlação entre $\mathrm{P}$ absorvido por plantas e $\mathrm{P}$ do solo, superior aos demais métodos, na maior parte dos trabalhos revisados; ii) pode ser usado tanto em solos ácidos como em solos alcalinos, o que não é o caso dos outros extratores importantes; iii) é o único método que revela adequadamente o efeito da calagem em aumentar a disponibilidade de P para as plantas; iv) não superestima, como os extratores ácidos, a disponibilidade de $\mathrm{P}$ em solos tratados com fosfatos naturais; v) é o método que apresenta o melhor embasamento teórico para a determinação do chamado "fator quantidade" de $\mathrm{P}$ nos solos, que é o mais importante índice da disponibilidade do nutriente.

Da mesma forma, existem resultados contraditórios. Por exemplo: Corrêa \& Haag (1993a) trabalhando em casa de vegetação com um Latossolo Vermelho Amarelo (LV) com $30,7 \%$ de argila, encontraram um nível crítico no solo para o P extraído pelo Mehlich I de 8 no primeiro corte e 14 ppm no segundo do Panicum maximum. Por outro lado, Fonseca et al. (1997a), trabalhando com um LV com 57\% argila, com a mesma planta, nas mesmas condições, relatam $41 \mathrm{mg} \mathrm{dm}^{-3} \mathrm{de}$ P. Estes dois experimentos foram também conduzidos a campo, e os níveis críticos para Corrêa \& Haag, (1993b) ficaram entre 3,5 e 8,0 ppm de $\mathrm{P}$ e para Fonseca et al. (1997b) foram, em média $64,1 \mathrm{mg} \mathrm{dm}^{-3} \mathrm{de}$ $\mathrm{P}$, corroborando com os comentários a seguir.

Novais \& Smyth $(1999$, p. 211) comentando sobre a determinação do "Pdisponível" concluem que "quanto mais se lê sobre "P-disponível" mais se convence do empirismo envolvido em sua solução. Nessas leituras, percebe-se a enorme discrepância 
entre trabalhos, correlações e ajustamentos relativamente pobres, apesar da significância estatística, a forte tendência de agrupar resultados sem levar em consideração diferenças entre solos, plantas, ambiente. Solos ... ... Há muito por fazer, ainda, no estudo dos extratores do "P-disponível". Faltam idéias mais criativas, com melhor embasamento teórico, talvez até mesmo alguma mudança de rumo naquilo que se faz, com relativamente poucas mudanças, desde $\operatorname{Dyer}^{1}$ (1894)."

Por esse ponto de vista, a utilização do método da cinética de troca de isotópica para avaliar o fosfato trocável em função unicamente do fator tempo, que será apresentada a seguir, pode ser considerado uma idéia inovadora. No Brasil, a utilização de fosfato radioativo $\left({ }^{32} \mathrm{P}\right)$ em trabalhos de pesquisa ocorreu nos primórdios do desenvolvimento do método (Malavolta \& Pellegrino, 1954; Catani \& Pellegrino, 1957). Entretanto, dificuldades inerentes do método por utilizar material radioativo e outras, poucos trabalhos tem sido publicados.

Métodos isotópicos têm sido usados desde 1948 para acessar a disponibilidade de $\mathrm{P}$ do solo (McAuliffe et al., 1948). Estes procedimentos permitiram, nas suas aplicações clássicas, medir a quantidade do $\mathrm{P}$ isotopicamente trocável do solo com íons ${ }^{32} \mathrm{PO}_{4}$ introduzidos na solução do solo após um dado tempo de troca (por ex. 24 horas). Esta técnica teve um considerável interesse para a determinação da disponibilidade de nutrientes do solo para a planta desde a identidade entre $\mathrm{P}$ isotopicamente trocável e o $\mathrm{P}$ disponível para a planta (Frossard et al., 1994; Morel \& Plenchette, 1994). Fardeau et al., $(1977$; 1985) propuseram caracterizar os parâmetros da cinética de troca considerando somente um ponto no tempo. Entretanto, eles demonstraram que o fosfato e o $\mathrm{K}$ inorgânico do solo foram distribuídos numa infinidade de compartimentos em trocas mais ou menos rápidas com íons localizados na solução (Fardeau et al., 1991; Fardeau, 1993).

Para a obtenção de dados que são relevantes do ponto de vista agronômico, os seguintes compartimentos podem ser considerados (Figura 2).

\footnotetext{
${ }^{1}$ DYER, B. On the analytical determination of probable available mineral plant food in soils. Trans.
} Chem. Soc., v.65, p. 115-117, 1894. 
O compartimento dos íons fosfato na solução do solo (Cp) - íons fosfato presentes na solução do solo, geralmente determinado por métodos colorimétricos.

O compartimento de íons fosfato livres (1 $\mathrm{min})$ - Este contem íons fosfato localizados na solução do solo e íons localizados na fase sólida do solo que são instantaneamente trocáveis com aqueles presentes na solução. Íons fosfato localizados neste compartimento são completamente e imediatamente disponíveis para a planta. Estes íons podem ser diretamente trocados com íons localizados nos outros quatro compartimentos. Nos solos tropicais, o conteúdo de $\mathrm{P}$ deste compartimento é praticamente igual a quantidade do $\mathrm{P}$ isotopicamente trocável num minuto (compartimento $\mathrm{Ep}_{\mathrm{Imin}}$ ).

Compartimento de

íons livres (1 min)

Íons trocáveis

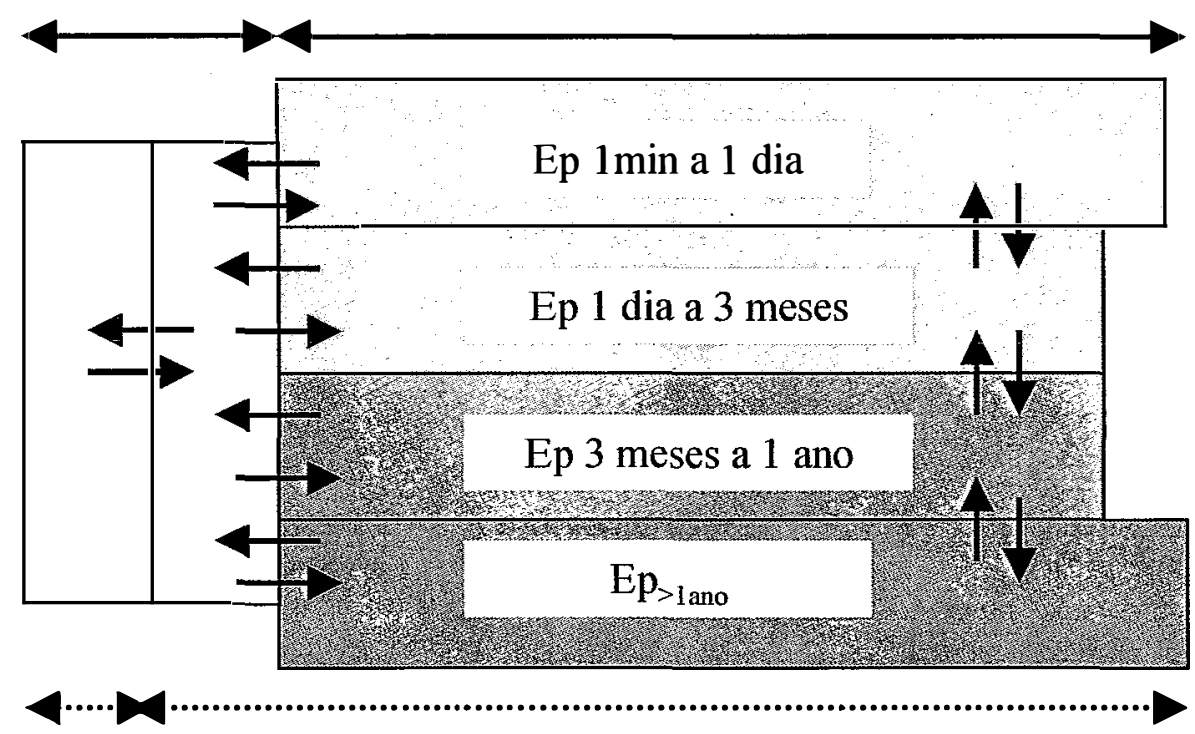

Solução

Fase sólida

do solo

Figura 2 - Representação esquemática do modelo multi-compartimental do fósforo trocável do solo (adaptado de Fardeau, 1993) (Ep = fósforo isotopicamente trocável). 
$\mathrm{O}$ compartimento de $\mathrm{P}$ trocável entre 1 minuto e 1 dia $\left(E p_{1 \min -1 \mathrm{~d}}\right)-$ Este corresponde a quantidade de fosfato que pode ser trocada durante um período equivalente ao tempo da absorção ativa do $\mathrm{P}$ por uma única raiz ou pelo radicular.

$\mathrm{O}$ compartimento de $\mathrm{P}$ trocável entre 1 dia e 3 meses $\left(\mathrm{Ep}_{\mathrm{ld}-3 \mathrm{~m}}\right)$ - Este corresponde a quantidade de íons fosfato que pode ser trocada durante um período equivalente ao tempo de absorção ativa do $\mathrm{P}$ por todo o sistema radicular de um cultivo anual.

O compartimento de $\mathrm{P}$ trocável entre 3 meses e 1 ano $\left(\mathrm{Ep}_{3 \mathrm{~m}-\mathrm{la}}\right)$ - Este período de tempo serve para completar ciclo completo das plantas.

E o compartimento de $\mathrm{P}$ que não é trocável no ano $\left(E p_{>1 a}\right)$ - Este corresponde a quantidade de $\mathrm{P}$ trocável após o período de 1 ano.

Esta distribuição do $\mathrm{P}$ trocável obtida por este modelo é relacionada com a absorção da planta e com a especiação físico-química do $P$ (Frossard et al., 1994). Os compartimentos calculados nos capítulos 3, 4 e 5 foram diferentes dos citados acima, pois se considerou a forrageira, uma cultura perene e que apresenta duas estações bem definidas de crescimento relacionadas à estação seca e chuvosa.

A equivalência dos critérios agronômicos de disponibilidade definidos por Beckett \& White (1964) com os compartimentos do modelo de Fardeau (1993) apresentado acima, são os seguintes: i) a Cp equivale ao fator I, ii) o Ep $p_{\text {min }}$ equivale ao fator $\mathrm{Q}$ e, iii) o $\mathrm{Ep}_{\mathrm{lmin}} / \mathrm{Cp}$ equivale ao fator capacidade (FCP). Entretanto, nos capítulos a seguir se utilizará o termo biodisponibilidade conforme definido no capítulo 1 , termo que se adequa melhor ao modelo de cinéticas de troca isotópicas.

Do ponto de vista agronômico, o $\mathrm{P}$ é considerado o nutriente mais estudado no Brasil. Entretanto, foram encontrados apenas 8 trabalhos publicados na Revista Brasileira de Ciência do Solo relacionando P do solo e pastagem de 101 artigos onde a pesquisa principal era sobre P do solo, no período de 1978 a 2000 (Apêndice 1). Na Revista Pesquisa Agropecuária Brasileira encontrou-se aproximadamente o mesmo número. Estas duas revistas, as mais representativas na área e de ampla circulação nacional e até internacional demonstram a pequena produção científica neste tema de tamanha relevância. Já sobre P em culturas anuais a disponibilidade de trabalhos é bem 
superior. Porém, considerando-se a relação de área entre pastagens cultivadas e culturas anuais, que é de aproximadamente 5:1 na Região do Cerrado, constata-se que ainda há muito por fazer.

No início do desenvolvimento do trabalho e planejamento sabíamos que a literatura era limitada sobre o assunto, principalmente de resultados de campo. De certa forma isto nos incentivou a desenvolver uma avaliação da biodisponibilidade do $\mathrm{P}$ em diferentes escalas de estudo. 


\section{BIODISPONIBILIDADE POTENCIAL DE FOSFATO EM SOLOS SOB PASTAGENS CULTIVADAS TROPICAIS: UMA ABORDAGEM REGIONAL ${ }^{1}$}

\section{Resumo}

As pastagens cultivadas na região dos Cerrados recobrem uma extensa área, das quais aproximadamente $80 \%$ são classificadas como pastagens de baixa produtividade. $\mathrm{O}$ fósforo $(\mathrm{P})$ é um dos mais limitantes fatores da produção forrageira nestas pastagens. O objetivo deste trabalho foi avaliar a biodisponibilidade de íons fosfato de solos sob pastagens cultivadas utilizando as cinéticas de troca isotópica (CTI). Amostras de solo oriundas de seis áreas representativas da diversidade dos solos da região do Cerrado foram selecionadas, para análise de íons fosfato na solução (Cp), capacidade tampão do solo $\left(\mathrm{R} / \mathrm{r}_{1}\right)$. Os seguintes compartimentos de fosfato isotopicamente trocável foram determinados: $\mathrm{Ep}_{1 \mathrm{~min}}, \mathrm{Ep}_{\mathrm{lmin}-\mathrm{lh}}, \mathrm{Ep}_{\mathrm{lh}-\mathrm{ld}}, \mathrm{Ep}_{\mathrm{ld}-2 \mathrm{~m},} \mathrm{Ep}_{2 \mathrm{~m}-\mathrm{6m}}$, $\mathrm{Ep}_{6 \mathrm{~m}-\mathrm{l}}, \mathrm{Ep} \mathrm{p}_{\mathrm{l}_{\mathrm{a}}}$ segundo o modelo multi-compartimental de Fardeau. Realizou-se análise em componentes principais (ACP) para definir diferentes grupos de tratamentos e o teste de Tukey para testar efeitos de diferentes sistemas. A biodisponibilidade de fosfato é limitante a produção das pastagens, principalmente naquelas onde não é realizada adubações de manutenção. $\mathrm{O} E \mathrm{E}_{\operatorname{lmin}}$ forneceu a melhor aproximação do fosfato prontamente disponível para as plantas. A avaliação da $\mathrm{Cp}$ nesses solos apresentou uma série de limitações metodológicas na determinação, devido as baixíssimas concentrações de fosfato na solução aquosa do solo.

\footnotetext{
${ }^{1}$ A ser submetido a Revista Agronomie em março de 2002.
} 
Palavras chaves: latossolo, Cerrado, Brasil, cinética de troca isotópica, ${ }^{32} \mathrm{P}$, Brachiaria spp.

\section{POTENTIAL PHOSPHATE BIOAVAILABILITY IN SOILS UNDER TROPICAL CULTIVATED PASTURE: A REGIONAL APPROACH (CERRADO, BRASIL)}

\section{Summary}

The cultivated pasture in the cerrado region (brazilian savannah) cover an extensive area, from which $80 \%$ are classified as low productive pastures. The phosphorus $(\mathrm{P})$ is one of most limiting factors of forage production in these pastures. The objective of this work is to evaluate the phosphate ions bioavailability of soils under cultivated pastures using isotopic exchange kinetic (IEK). Soil samples from six representative areas of diversity of cerrado regions soils were selected for the analysis of solution phosphate ions $(\mathrm{Cp})$, soil buffering capacity $\left(\mathrm{R} / \mathrm{r}_{1}\right)$. The following isotopic exchangeable P compartments (Fardeau multicompartmental model) were determined: $E p_{1 \text { min }}, E p_{1 \text { min-lh }}, E p_{1 h-1 d}, E p_{1 d-2 m}, E p_{2 m-6 m}, E p_{6 m-1 a}, E p_{>l a}$. The statistical analysis were performed in principal components analysis (PCA) to define different groups of treatments and Tukey test to test the effects of different systems. The bioavailability of $P$ is limiting to pasture productions, mainly in those the maintenance fertilizer were not applied. The $\mathrm{Ep}_{1 \min }$ gave the best approach of plant readily bioavailable phosphorus. The $\mathrm{Cp}$ evaluation in these soils gave a serie of methodological limitation in $\mathrm{P}$ determination, due to the extremely low P concentration in the soil solution.

Key words: ferralsol, Cerrado, Brazilian savannah, isotopic exchange kinetic, ${ }^{32} \mathrm{P}$, Brachiaria spp., grassland 


\subsection{Introdução}

A região do Cerrado no Brasil está situada entre $2^{\circ}$ e $23^{\circ}$ Sul e $45^{\circ}$ e $63^{\circ}$ Oeste. O bioma Cerrado é essencialmente constituído de ecossistemas do tipo savanas tropicais associados à formações vegetais diversas. Ele abrange uma área de aproximadamente $20710^{6}$ ha. Nesta região a agricultura tem sido intensamente desenvolvida desde a década de 1960 (Garcia, 1995; Rocha \& Madeira Neto, 1998). As áreas dedicadas à agropecuária são estimadas em 49,5 $10^{6}$ ha de pastagens cultivadas (Sano et al., 2000), $13,410^{6}$ ha de cultivos anuais (soja, milho, feijão, arroz, algodão entre os principais), 2 $10^{6}$ ha de cultivos perenes (cana-de-açúcar, café e citrus) e 4,6 $10^{6}$ ha são declaradas como reservas (Embrapa - dados não publicados). Pode-se considerar que os limites de áreas disponíveis para a agricultura já foram atingidos. Atualmente, a questão não deve ser colocada em termos de abertura de novas áreas, mas de manter, ou melhorar, o potencial das áreas já abertas. Os Ferralsols (Deckers et al., 1998; Klamt \& Van Reeuwijk, 2000), latossolos da classificação brasileira (Bennema et al., 1959; Camargo et al., 1987), são os solos mais comumente cultivados, dado sua posição na paisagem (Adámoli et al., 1986). Por outra lado, o desenvolvimento advindo do cultivo desses solos foi sustentado por um simples axioma: considerou-se que os latosolos não apresentavam impedimentos físicos mas sim um conjunto de limitações químicas essencialmente ligadas a natureza e propriedades da fase mineral (Van Wambeke, 1992). A abordagem agroquímica clássica podia então assumir o manejo do cultivo desses solos.

A distribuição das precipitações e as limitações químicas naturais dos solos comprometem a produção de forragem natural, tanto em sua qualidade quanto em sua quantidade. A mudança da vegetação natural para pastagens cultivadas representou uma alternativa para aumentar a produção de carne da região com a introdução de plantas forrageiras de origem africana de grande capacidade de adaptação aos solos e climas. São elas três gêneros : Brachiaria (aproximadamente $80 \%$ das pastagens cultivadas), Panicum e Andropogon (Savidan et al., 1985). Em relação à carga animal existente em pastagens nativas as cultivadas permitiram um fator multiplicativo de 5 a 10 (Zimmer \& 
Correa, 1993). A pecuária bovina do Cerrado constitue $40 \%$ do gado brasileiro (Barcellos, 1996), e contribui com 33 \% da produção de carne do país (Carvalho et al., 1990; Macedo, 1995). Embora seja grande o desenvolvimento agropecuário, foi registrada uma queda gradativa da produtividade das pastagens cultivadas nos últimos dez anos, atingindo atualmente $80 \%$ das áreas pastejadas (Kluthcouski et al., 1999). O sobrepastejo é uma das causas do declínio das pastagens, e embora estando institucionalmente bem avaliado ainda é mal percebido pelos produtores (Costa \& Rehman, 1999). No total, nos sistemas atuais, a oferta de nutrientes do solo à planta é seguramente limitante na medida em que a fertilização de manutenção não é realizada, e o sistema pecuário deve ser considerado estrativista (Barcellos et al., 2001). O fósforo (P) é um dos principais fatores limitantes dos sistemas cultivados desta região (Lopes \& Cox, 1977; Goedert, 1983; Adámoli et al., 1986).

As extrações químicas convencionais são utilizadas para determinar a quantidade de $\mathrm{P}$ disponível para a planta (fator quantidade). Na Região do Cerrado, o "Mehlich I" (Mehlich, 1953; Embrapa, 1997) é o método recomendado para a extração de P. Entretanto, este não se correlaciona tão bem quanto ao método da resina com o crescimento ou com o P absorvido e acumulado pela planta (Silva \& Raij, 1999). A utilização de cinéticas de troca isotópica (CTI) (Fardeau \& Jappé, 1976) permite a identificação de todo o P na fase sólida trocável com o P da solução do solo. Diversos trabalhos indicam que o $\mathrm{P}$ absorvido pelas plantas é derivado do $\mathrm{P}$ isotopicamente trocável (Ep) do solo (Fardeau \& Jappé, 1976; Frossard et al., 1994; Morel \& Plenchette, 1994). Uma das mais importantes informações do modelo funcional dada pelos parâmetros cinéticos é a descrição da habilidade dos íons biodisponíveis de $\mathrm{P}$ do solo sair da fase sólida do solo para a solução do solo (Fardeau, 1996).

O objetivo do presente trabalho foi avaliar a biodisponibilidade de íons fosfato de solos sob pastagens utilizando as CTI. Para este trabalho foram selecionadas amostras de solo oriundas de seis áreas do Cerrado, representativas da diversidade dos solos. As parcelas de pastagens selecionadas encontram-se em propriedades, algumas delas no âmbito de experimentos com produtores ou em estação experimental. 


\subsection{Material e Métodos}

\subsection{1 Áreas de amostragem}

As Características dos locais de amostragens estão na Tabela 1.

1/ Uma área localizada no município de Brasilândia, no estado do Mato Grosso do Sul. As áreas escolhidas foram as seguintes: uma sob vegetação natural, duas pastagens manejadas de forma tradicional e duas áreas com tratamentos de renovação de pastagens pela implantação da Brachiaria brizantha cv. Marandu (BB) associada ao milho (Balbino et al., 2002; cap. 4).

2/ Dois grupos de amostras de solo, um grupo referente a um solo argiloso e o outro a um solo arenoso, foram coletados em março de 1997 e maio de 1998 na Região de Uberlândia, no Estado de Minas Gerais, em experimentos de melhoramento de sistemas agropastoris com o uso de leguminosas (Ayarza et al., 1999).

Tabela 1. Características das áreas selecionadas.

\begin{tabular}{|c|c|c|c|c|c|c|}
\hline Sítio & $\begin{array}{c}\text { Classe } \\
\text { de solo }\end{array}$ & $\begin{array}{l}\text { Argila } \\
\text { g } 100 \mathrm{~g}^{-1}\end{array}$ & $\begin{array}{c}\mathrm{pH} \\
\mathrm{H}_{2} \mathrm{O}\end{array}$ & Plantas & $\begin{array}{c}\text { Idade das } \\
\text { pastagens } \\
\text { (anos) }\end{array}$ & $\begin{array}{c}\text { Identificação das } \\
\text { amostras }\end{array}$ \\
\hline 1 & $\mathrm{LV}$ & $20-35$ & 4,0 a 5,9 & $\mathrm{BB}, \mathrm{BH}, \mathrm{CE}$ & $3,23,30$ & $100,104,113,154$ e 181 \\
\hline 2.1 & LVA & 60 & - & BD & 5,18 & $119,125,128,135,142$ e 143 \\
\hline 2.2 & LVA & 11 a 14 & - & $\mathrm{BR}, \mathrm{SR}, \mathrm{PA}$ & 6,19 & $202,205,208$ e 211 \\
\hline 3.1 & CAM & 24 & 5,7 & BD & 22 & 753 \\
\hline 3.2 & LV & 48 & 6,2 & BB & 16 & 757 \\
\hline 3.3 & LV & 52 & 6,0 & BB & 1 & 761 \\
\hline 3.4 & LVA & 41 & 6,1 & BB & 6 & 769 \\
\hline 3.5 & CAM & 16 & 7,6 & BD & 5 & 770 \\
\hline 3.6 & CAM & 19 & 6,8 & BB & 4 & 771 \\
\hline 3.7 & LVA & 24 & 4,8 & SG & 4 & 776 \\
\hline 3.8 & LVA & 28 & 5,2 & B spp. & 6 & 777 \\
\hline 3.9 & nc & 34 & 5,9 & $\mathrm{BD}$ & - & 778 \\
\hline 4 & LV & 60 & 5,8 & BB & 9 & 2168 a 2175 \\
\hline 5 & LV & 70 & - & $\mathrm{AG}, \mathrm{PA}$ & 9 & 3017 a 3024 \\
\hline \multicolumn{7}{|c|}{$\begin{array}{l}\text { } \mathrm{LV}=\text { latossolo vermelho, LVA = latossolo vermelho-amarelo; CAM = cambissolo; nc = não } \\
\text { classificado. }{ }^{2} \text { Pastagem de: } \mathrm{BB}=\text { Brachiaria brizantha cv. Marandu; } \mathrm{BH}=\text { Brachiaria } \\
\text { humidicola; } \mathrm{BD}=\text { Brachiaria decumbens; } \mathrm{BR}=\text { Brachiaria ruziziensis; } \mathrm{SG}=\text { Stylosanthes } \\
\text { guianensis cv. Mineirão; } \mathrm{AG}=\text { Andropogon gayanus; } \mathrm{PA}=\text { Panicum maximum; B spp. } \\
\text { mistura de BD, BB e BR; CE = vegetação natural - cerrado. }\end{array}$} \\
\hline
\end{tabular}


3/ Amostras coletadas em janeiro de 1998, no município de Silvânia, no Estado de Goiás, de diferentes tipos de solos sob pastagens (Figuié, 2001).

4/ Amostras coletadas durante o ano de 1998 de um experimento na Fazenda Rio de Janeiro, no município de Planaltina, no Estado de Goiás, com Brachiaria brizantha cv. Marandu (BB) (Balbino et al., 2001; cap. 5)

5/ Amostras coletadas em 2000, oriundas de um experimento conduzido em parceria entre o CIAT e a EMBRAPA, que foi implantado em 1991, no campo experimental da Embrapa Cerrados, em Planaltina, no Distrito Federal (Araújo et al., 1996; Vilela et al., 2001).

\subsubsection{Amostragens do solo}

As amostras de solo foram compostas por 30 subamostras aleatórias coletadas com trado em três profundidades $(0-10,10-20$ e $20-30 \mathrm{~cm})$. As amostras foram secas ao ar, tamisadas a $2 \mathrm{~mm}$ para posterior análises químicas. Para as análises de $\mathrm{P}$ total $(\mathrm{Pt}) \mathrm{e}$ orgânico (Po) uma alíquota da amostra foi finamente moída.

\subsubsection{Análises}

A extração pela resina de $\mathrm{P}(\mathrm{Pr})$ seguiu a metodologia da resina aniônica e catiônica (Raij et al., 1986). O Pr foi determinado por colorimetria em espectrofotômetro no comprimento de onda $882 \mathrm{~nm}$ (John, 1970), Ca e Mg por espectrofotometria de absorção atômica e o K por fotometria de chama.

$\mathrm{O}$ Pt foi determinado pela digestão de $0,5 \mathrm{~g}$ de amostra com uma mistura triácida (5 mL de ácido fluorídrico, $5 \mathrm{~mL}$ de ácido nítrico e $2 \mathrm{~mL}$ de ácido perclórico) e posterior diluição com $50 \mathrm{~mL}$ de $\mathrm{HCl} 0,1 \mathrm{M}$. O Po foi determinado com duas alíquotas de $2 \mathrm{~g}$ de solo da mesma amostra, sendo uma delas calcinada em uma mufla por 2 horas a $550{ }^{\circ} \mathrm{C}$. Adicionou-se $50 \mathrm{~mL}$ de $\mathrm{H}_{2} \mathrm{SO}_{4} 1 \mathrm{M}$ nas 2 alíquotas, agitou-se por 16 horas num agitador horizontal (Anderson, 1960), determinando-se o fósforo por colorimetria em espectrofotômetro (John, 1970). Obteve-se o Po pela diferença entre a amostra calcinada e não calcinada. 


\subsubsection{Determinação do fosfato isotopicamente trocável}

As análises de cinética de troca isotópica (CTI) foram conduzidas no sistema solo-solução (SSS) após as amostras atingirem o equilíbrio de concentração de fosfato na solução numa relação solo-solução 1:10 (Salcedo et al., 1990; Fardeau et al., 1991; Frossard et al., 1994). Para compor o sistema foram utilizados $10 \mathrm{~g}$ de solo, tamisados a $2 \mathrm{~mm}$ e $99 \mathrm{~mL}$ de água desionizada em um recipiente de plástico com capacidade de 250 $\mathrm{mL}$. As amostras foram agitadas durante 16 horas. A seguir, as amostras foram postas a agitar suavemente em um agitador magnético e, adicionou-se ao tempo zero $(\mathrm{t}=0), 1 \mathrm{~mL}$ de solução contendo o radioisótopo ${ }^{32} \mathrm{P}$ livre de carregador. As atividades utilizadas foram de aproximadamente $1 \mathrm{MBq} \mathrm{mL}{ }^{-1}$. Após $t_{1}=1, t_{2}=3, t_{3}=10$ e $t_{4}=15 \mathrm{~min}$, tomou-se uma alíquota de $\pm 8 \mathrm{~mL}$ da suspensão com uma seringa de plástico, que foi imediatamente acoplada a uma unidade de porta filtro de pressão com um filtro de membrana de $0,05 \mu \mathrm{m}$. A suspensão foi filtrada em \pm 10 segundos e desta foi utilizada uma alíquota de $0,25 \mu \mathrm{L}$, retirada com uma micropipeta, completando-se o volume a 20 $\mathrm{mL}$ para posterior determinação das contagens do ${ }^{32} \mathrm{P}$ pelo efeito Cerenkov no contador de cintilação líquida Wallac 1409. Ao final, foram utilizadas seringas de $60 \mathrm{ml}$ para obter maior quantidade de solução para determinação da concentração de fosfato $(\mathrm{Cp})$ presente na solução do solo por colorimetria pelo método do verde malaquita (Rao et al., 1997). A concentração dos íons fosfato da solução filtrada, foi realizada com peças de 3 x $2 \mathrm{~cm}$ de resina aniônica tipo membrana, marca BDH15 1TD (Salcedo et al., 1990). Os valores obtidos da concentração de fosfato na solução do solo de uma amostra padrão apresentaram coeficiente de variação de $1,23 \%$ com 3 repetições.

3.2.5 Fórmulas básicas para o cálculo da quantidade de $P$ isotopicamente trocável (Pit) de um sistema solo-solução e da quantidade de Pit a qualquer tempo t (Fardeau, 1993; INTERNATIONAL ATOMIC ENERGY AGENCY (IAEA), 2001b)

As medidas de Pit no SSS devem ser conduzidas num equilíbrio (steady state), que é um requerimento básico para interpretação dos resultados experimentais e a seguir são definidos alguns parâmetros: 
- R é a quantidade de radioatividade aplicada no SSS como íons $\mathrm{PO}_{4}{ }^{3-}$;

- $r_{(t)}$ é a quantidade de radioatividade presente na solução do solo após um tempo $t$ de troca isotópica;

- $E_{(t)}$ é a quantidade de Pit após um tempo $t$ de troca isotópica e,

- $\mathrm{q}_{\mathrm{s}}$ é a quantidade de $\mathrm{P}$ como íons $\mathrm{PO}_{4}{ }^{3-}$ solúvel no SSS num estado de equilíbrio.

A quantidade $\mathrm{Ep}_{(\mathrm{t})}$ é calculada assumindo que a composição isotópica, a atividade específica, por exemplo a relação entre a quantidade de radioatividade e a quantidade de $\mathrm{P}$ como íons $\mathrm{PO}_{4}{ }^{3-}$ (ambas as expressões podem ser utilizadas), é a mesma para íons $\mathrm{PO}_{4}{ }^{3-}$ de uma solução e todos os Pit no sistema. Então,

$$
\mathrm{R} / \mathrm{Ep}_{(\mathrm{t})}=\mathrm{r}_{(\mathrm{t})} / \mathrm{q}_{\mathrm{s}}
$$

E por isso:

$$
E p_{(t)}=q_{s} R / r_{(t)}
$$

Como a quantidade de Pit na solução, $\mathrm{Ep}_{(\mathrm{t})}$, aumenta quando o tempo $\mathrm{t}$ aumenta, a radioatividade $r_{(t)}$ na solução diminui com o aumento do tempo de troca, conforme mostrado na relação entre $r_{(t)}$ e $t$, expressa em minutos, o que pode ser descrita pela seguinte equação:

$$
r_{(t)} / R=r_{1} / R\left[t+\left(r_{1} / R\right)^{1 / n}\right]^{-n}+r_{e q} / R
$$

Na eq. (3), $r_{\text {eq }}$ é a radioatividade do SSS no equilíbrio e, sendo :

$$
\mathrm{r}_{\mathrm{eq}} / \mathrm{R}=\mathrm{q}_{\mathrm{s}} / \mathrm{Pt}
$$

Onde Pté o $P$ total do solo. Substituindo $\mathrm{r}_{\mathrm{eq}} / \mathrm{R}$, pode-se considerar:

$$
r_{(t)} / R=r_{1} / R\left[t+\left(r_{1} / R\right)^{1 / n}\right]^{-n}+q_{s} / P t
$$

Como:

$$
E p_{(t)}=q_{s} R / r_{(t)}
$$

E pela eq. (4) que mostra, que para o cálculo do Pit, $\mathrm{Ep}_{(\mathrm{t})}$ a qualquer tempot da troca isotópica, os seguintes parâmetros são necessários: $\mathrm{q}_{\mathrm{s}}, \mathrm{Pt}, \mathrm{r}_{1} / \mathrm{R}$ (é a relação da radioatividade encontrada no SSS após 1 minuto de troca isotópica para o total de radioatividade aplicada) e, $\mathrm{n}$ (expoente da declividade da função logarítmica, descrevendo a taxa de troca de radioatividade na solução com tempo t). Para um tempo $\leq 10$ minutos, o valor de $\left(\mathrm{r}_{1} / \mathrm{R}\right)^{1 / n}$ é geralmente menor do que 0,02 para qualquer valor de 
n e $r_{1} / R$ e pode ser então negligenciado. Deste modo, a eq. (5) pode ser simplificada como:

$$
\mathrm{r}_{(\mathrm{t})} / \mathrm{R}=\mathrm{r}_{1} / \mathrm{R}[\mathrm{t}]^{-\mathrm{n}}+\mathrm{q}_{\mathrm{s}} / \mathrm{Pt}
$$

Geralmente para qualquer tempo $\mathrm{t} \leq 10 \mathrm{~min}$, a relação $\mathrm{q}_{\mathrm{s}} / \mathrm{Pt}$, que reflete o valor de equilíbrio para a radioatividade remanescente na solução para um tempo infinito é negligenciavel comparado com o valor $r_{1} / R[t]^{-n}$. Por isso, a equação geral (5) pode ser ainda mais simplificada, como:

$$
r_{(t)} / R=r_{1} / R[t]^{-n}
$$

Esta eq. (7) pode também ser escrita como:

$$
\log \left[\mathrm{r}_{(t)} / \mathrm{R}\right]=\log \left[\mathrm{r}_{1} / \mathrm{R}\right]-\mathrm{n} \log \mathrm{t}
$$

O n e $\log \left[r_{1} / R\right]$ podem ser considerados como os "mais prováveis valores" da declividade e o respectivo intercepto da linha da regressão linear entre $\log \left[\mathrm{r}_{(\mathrm{t})} / \mathrm{R}\right]$ e $\log \mathrm{t}$ para os valores de $r_{(t)} / R$ obtidos para cada amostragem num tempo $t$, para qualquer tempo t entre 1 min e 10 min.

Entretanto, no mínimo duas determinações da mistura marcada com ${ }^{32} \mathrm{P}$ tem que ser realizadas para determinar o $\mathrm{n}$ e o $\log \left[\mathrm{r}_{1} / \mathrm{R}\right]$. De fato bons resultados podem ser obtidos com 4 determinações a 1, 3, 7 e 10 min. Para muitos solos outros intervalos de tempo podem ser utilizados, por exemplo 1, 4, 10 e $20 \mathrm{~min}$. A escolha do intervalo de tempo depende da prática e da experiência do analista. Neste trabalho foram utilizados 1 , 3,10 e $15 \mathrm{~min}$.

3.2.6 Cálculo do tamanho dos compartimentos de fosfato do solo (Ep) do modelo multi-compartimental (Fardeau, 1993; Frossard et al., 1995; IAEA, 2001b)

Sete compartimentos foram determinados por meio da eq. 09 onde o tempo (t) de todos os cálculos é expresso em minutos.

$$
E p=\frac{C p \times 10}{\left(r_{1} / R\right) \times\left[t+\left(r_{1} / R\right)^{1 / n}\right]^{-n}+q_{s} /(P t-P o)}
$$

3.2.6.1 Compartimento $E p_{\text {Imin }}$ Este é isotopicamente trocável durante o primeiro minuto de troca e reflete o Pit instantaneamente. Representa a quantidade de P, como íons 
fosfato, que podem se mover do solo para a solução quase instantaneamente, podendo ser considerado como o compartimento de íons fosfato diretamente disponível para as plantas sem transformação química.

3.2.6.2 Compartimento E $p_{\text {Imin-Ih }}$. Corresponde a quantidade de Pit no período de 1 minuto e 1 hora.

3.2.6.3 Compartimento E $p_{\text {Ih-ld. }}$. Corresponde a quantidade fosfato que pode ser tomado por uma zona de raiz dada, que pode ativamente absorver $\mathrm{P}$ dentro de um tempo, limitado entre 1 e 2 dias. 1 dia foi escolhido para os cálculos.

3.2.6.4 Compartimento Ep $p_{I d-2 m}$. É explorado durante o tempo de funcionamento das raízes para um período de ocupação e descanso da pastagem, conforme o manejo dos animais.

3.2.6.5 Compartimento $E p_{2 m-6 m}$. Corresponde para a quantidade de íons fosfato que pode ser liberada do solo para a solução entre 2 e 6 meses.

3.2.6.6 Compartimento Ep $p_{6 m-1 a}$ Corresponde ao $\mathrm{P}$ lentamente trocável que pode ser liberado na solução do solo entre 6 meses a um ano. Seria o período de uma estação, a seca ou chuvosa.


liberado na solução do solo ao longo dos anos sob a condição da não utilização de fertilizantes fosfatados. Reflete a habilidade do solo para liberar íons fosfato para as plantas em muitos países tropicais em desenvolvimento, onde não se adiciona P para produção das culturas.

\subsubsection{Análise estatística}

A análise em componentes principais (ACP) é um método estatístico essencialmente descritivo: seu objetivo é de apresentar, sob a forma gráfica, o máximo de informação contida numa tabela de dados. Utilizou-se o programa (SPAD, 1998). Os efeitos dos diferentes sistemas de renovação de pastagens foram testados através do teste de Tukey com o teste da diferença mínima significativa ao nível de $5 \%(p<0,05)$, com o programa sistema de análise estatística (SAS, 1989). 


\subsection{Resultados e Discussão}

\subsubsection{Análise em componentes principais (ACP)}

A ACP foi utilizada na primeira etapa da investigação para verificar as possíveis associações entre as variáveis da CTI de todos os solos estudados. A variância dos indivíduos representada pela soma dos autovalores nos três primeiros eixos foi de $80 \%$. O eixo 1 explicou $45 \%$ da variação inicial, o 2 explicou $22 \%$, e o 3 explicou $13 \%$. As variáveis que mais contribuíram para a explicação da variação em cada eixo foram: i) no eixo 1: o $E p_{1 m i n}$ e o $R / r_{1}$ no sentido oposto a $E p_{1 d-2 m}, E p_{2 m-6 m}$, Ep 6 m-1a; ii) no eixo 2 o $\mathrm{Ep}_{1 \mathrm{~min}-1 \mathrm{~h}}$ e Ep $\mathrm{p}_{1 \mathrm{~h}-1 \mathrm{~d}}($ Figura 3); iii) no eixo 3: a Cp. Esta informação foi gerada pelo coeficiente de correlação entre a variável e o eixo. O P-resina (Pr) não acrescentou nos resultados obtidos com ACP.

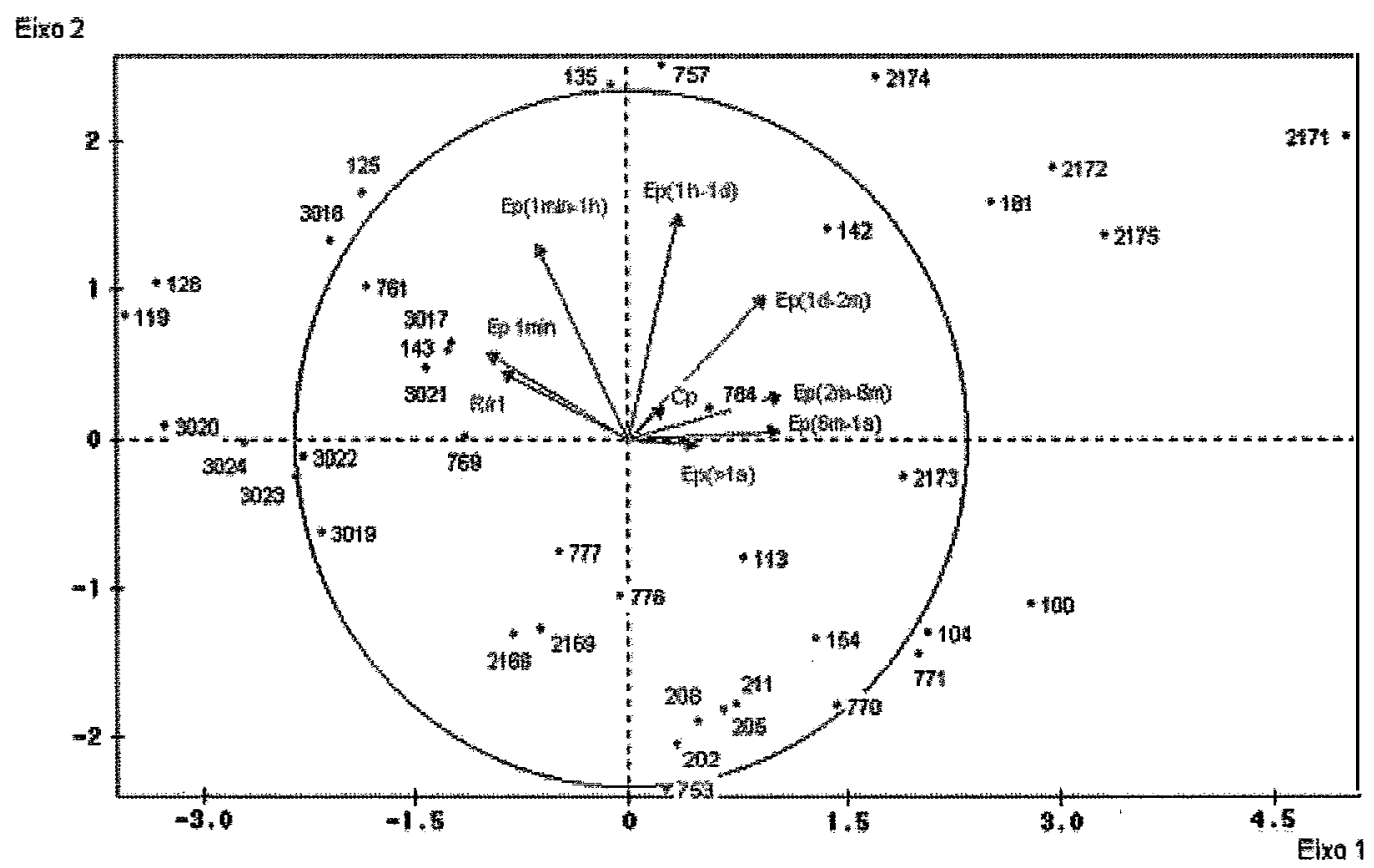

Figura 3 - Análise em componentes principais das cinéticas de troca isotópica. 
Na Figura 3, as amostras são apresentadas em gráfico bidimensional, eixos 1-2. As informações do eixo 1 foram representadas em $27 \%$ pelas amostras sob pastagem da Fazenda RJ (2171, 2175, 2172, 2174 e 2173) e o cerrado de Brasilândia (181), formando um grupo no quadrante 1, enquanto que as amostras sob pastagens de Brasilândia (100 e 104) representaram $7,5 \%$ da variação, formando um grupo no quadrante 2 juntamente com as amostras 113 e 154 ( 3 \% da variação). As características do grupo no quadrante 1 foram: pastagens não adubadas de baixa produtividade sob solo argiloso com exceção da $181, \mathrm{Ep}_{\text {Imin }}$ não limitante - 5-16 $\mathrm{mg} \mathrm{kg}^{-1}$ de P (tabela 3), solo altamente fixador $\left(\mathrm{R} / \mathrm{r}_{1}\right.$ tabela 2). As pastagens do grupo do quadrante 2, são de baixa e boa produtividade sob solo areno-argiloso, $\mathrm{Ep}_{1 \min }$ limitante - 0,2 a $0,7 \mathrm{mg} \mathrm{kg}^{-1}$ de $\mathrm{P}$ (tabela 3), solo altamente fixador, porém com $\mathrm{R} / \mathrm{r}_{1}$ inferiores do grupo no quadrante 1 (tabela 2). Estas amostras relacionaram-se mais com as variáveis $\mathrm{Ep}_{1 \mathrm{~d}-2 \mathrm{~m},} \mathrm{Ep}_{2 \mathrm{~m}-6 \mathrm{~m},} \mathrm{Ep}_{6 \mathrm{~m}-\mathrm{la}}$. A ACP para estes dois grupos discriminou as amostras sob cerrado (2168 e 2169 - quadrante 3; 181 quadrante 1) das amostras sob pastagens pelas suas diferentes características.

No lado oposto do eixo 1, as amostras sob pastagem da Embrapa (série 3000), de Uberlândia $(119,128,125,143)$ e de Silvânia (761 e 769) representaram 27,1, 15,4 e $3,8 \%$ da informação do eixo, respectivamente. Estas formaram um grupo mais relacionado com as variáveis $\mathrm{Ep}_{\mathrm{Imin}} \mathrm{e} \mathrm{R} / \mathrm{r}_{1}$. Dessa forma, formou-se um grupo de solos argilosos e muito argilosos, sob pastagens adubadas e não adubadas, Ep ${ }_{\text {lmin }}$ não limitante (tabela 3) e solos altamente fixadores $\left(\mathrm{R} / \mathrm{r}_{1}-\right.$ tabela 2$)$ muito superiores aos grupos formados anteriormente.

No eixo 2, as amostras de Uberlândia (202, 205, 208 e 211) e as de Silvânia (753, 770 e 771) representaram 16,2 e $12 \%$ da informação do eixo, respectivamente, formando um grupo oposto as variáveis estudadas. Este grupo apresentou solos sob pastagens de baixa produtividade, adubadas e consorciadas, arenosos, $\mathrm{Ep}_{1 \mathrm{~min}}$ limitantes (Tabela 3) e fixadores $\left(\mathrm{R} / \mathrm{r}_{1}\right.$ - tabela 2$)$ e que estão relacionadas com a variável Cp que mais contribuiu na determinação do eixo 3 . Por outro lado, as amostras 757, 2174, 135, 2171 e 2172 representaram $23,9 \%$ da variação do eixo, formando um grupo que se relacionou com as variáveis $\mathrm{Ep}_{\text {lmin-lh }}$ e $\mathrm{Ep}_{\text {lh-ld. }}$. Assim, a CTI pode ser utilizada para 
caracterizar e diferenciar os solos analisados e demonstrar alguns indicativos do nível de fosfato destes solos sob pastagem.

Tabela 2. Capacidade tampão do solo $\left(\mathrm{R} / \mathrm{r}_{1}\right)$, fosfato na solução do solo (Cp), declividade da reta (n), P-total (Pt) e P-orgânico (Po) em diferentes solos e pastagens na Região do Cerrado.

\begin{tabular}{|c|c|c|c|c|c|c|}
\hline Amostra & $\mathrm{R} / \mathrm{r}_{1}$ & $r_{1} / R$ & $\mathrm{Cp}$ & $\mathrm{n}$ & $\mathrm{Pt}$ & Po \\
\hline & & \multicolumn{3}{|c|}{$\left(\mathrm{mg} \mathrm{L}^{-1}\right)$} & \multicolumn{2}{|c|}{-...- $\left(\mathrm{mg} \mathrm{kg}^{-1}\right)$} \\
\hline \multicolumn{7}{|c|}{ Brasilândia (MS) } \\
\hline 100 & $34 b^{1}$ & 0,031 a & 0,0006 a & $0,55 \mathrm{a}$ & 240 & 89 \\
\hline 104 & $66 \mathrm{~b}$ & $0,015 \mathrm{~b}$ & $0,0004 \mathrm{a}$ & $0,51 \mathrm{a}$ & 198 & 71 \\
\hline 113 & $148 \mathrm{~b}$ & $0,007 \mathrm{bc}$ & $0,0005 \mathrm{a}$ & $0,62 \mathrm{a}$ & 187 & 77 \\
\hline 154 & $55 \mathrm{~b}$ & $0,018 \mathrm{~b}$ & 0,0009 a & 0,51 a & 208 & 115 \\
\hline 181 & $655 \mathrm{a}$ & $0,0016 \mathrm{c}$ & $0,0011 \mathrm{a}$ & 0,48 a & 210 & 88 \\
\hline$d m s$ & 228 & 0,0115 & 0,0007 & 0,15 & & \\
\hline$c v$ & 44 & 29 & 38 & 10 & & \\
\hline \multicolumn{7}{|c|}{ Solo arenoso - Uberlândia (MG) } \\
\hline 202 & $7,0 \mathrm{c}$ & $0,1419 \mathrm{~b}$ & $0,0017 \mathrm{a}$ & 0,38 a & 180 & 64 \\
\hline 205 & $8,9 \mathrm{~b}$ & $0,1128 \mathrm{~b}$ & 0,0039 a & 0,34 a & 184 & 84 \\
\hline 208 & $4,8 \mathrm{~d}$ & 0,2084 a & 0,0043 a & $0,34 \mathrm{a}$ & 194 & 85 \\
\hline 211 & 12,8 a & $0,0779 \mathrm{c}$ & 0,0039 a & 0,32 a & 189 & 87 \\
\hline$d m s$ & 1,3 & 0,027 & 0,0038 & & & \\
\hline$c v$ & 6 & 8 & 42 & & & \\
\hline \multicolumn{7}{|c|}{ Solo argiloso - Uberlândia (MG) } \\
\hline 119 & $66367 \mathrm{a}$ & 0,000015 & $0,00082 \mathrm{a}$ & 0,36 a & 398 & 123 \\
\hline 125 & $24596 \mathrm{~b}$ & 0,00004 & $0,00092 \mathrm{a}$ & 0,39 a & 468 & 146 \\
\hline 128 & 52205 a & 0,00002 & $0,00076 \mathrm{a}$ & 0,43 a & 439 & 143 \\
\hline 135 & $12280 \mathrm{bc}$ & 0,00008 & $0,00062 \mathrm{a}$ & $0,38 \mathrm{a}$ & 533 & 195 \\
\hline 142 & $1901 \mathrm{c}$ & 0,00054 & $0,00093 \mathrm{a}$ & 0,44 a & 454 & 197 \\
\hline 143 & $10286 \mathrm{bc}$ & 0,00010 & $0,00091 \mathrm{a}$ & 0,48 a & 421 & 200 \\
\hline$d m s$ & 21017 & 0,0001 & 0,0009 & 0,0009 & & \\
\hline$c v$ & 27 & 36 & 42 & 42 & & \\
\hline
\end{tabular}


Tabela 2. Capacidade tampão do solo $\left(\mathrm{R} / \mathrm{r}_{1}\right)$, fosfato na solução do solo $(\mathrm{Cp})$, declividade da reta (n), P-total (Pt) e P-orgânico (Po) em diferentes solos e pastagens na Região do Cerrado.

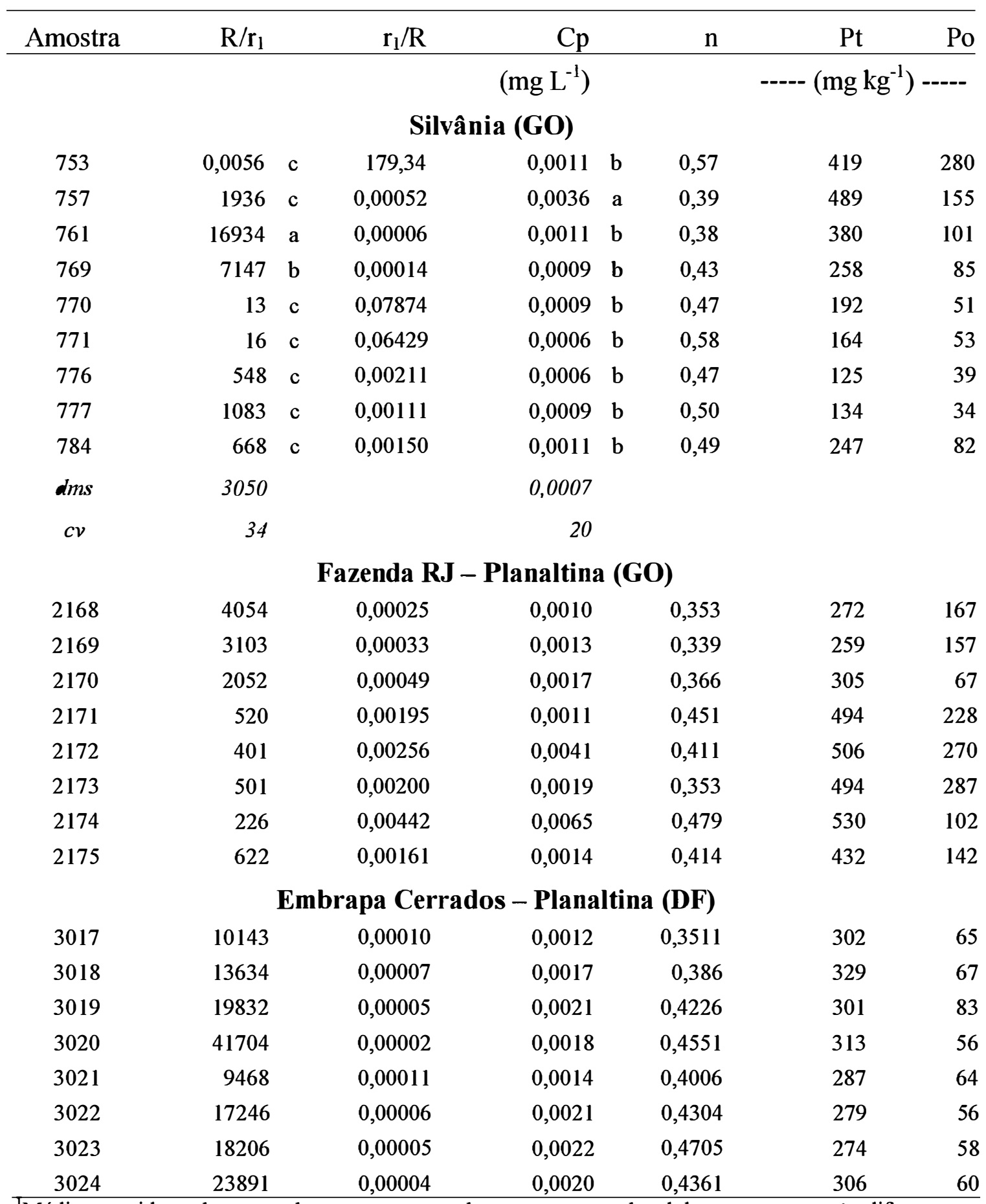

${ }^{\mathrm{T}}$ Médias seguidas pela mesma letra, na mesma coluna e no mesmo local de amostragem, não diferem entre si pelo teste de Tukey a $5 \%$. 


\subsubsection{Dados experimentais das cinéticas de troca isotópica (CTI)}

A relação $R / r_{1}$ é a medida da capacidade tampão do $\mathrm{P}$ dos solos a um determinado tempo (Tran et al., 1988; Salcedo et al., 1990; Frossard et al., 1992). A capacidade tampão é considerada muito alta quando $\mathrm{R} / \mathrm{r}_{1}$ é maior que 10 ; alta quando varia entre 5 a 10; média quando varia entre 2,5 a 5 e baixa quando é menor que 2,5 (Frossard et al., 1995). Os resultados obtidos para os solos arenosos de Uberlândia foram entre 4,8 a 12,8, enquanto que para os solos areno-argilosos de Brasilândia ficaram entre 34 a 55 (Tabela 2). No solo argiloso de Uberlândia sobre diferentes situações de manejo (uso), os valores foram superiores ficando entre 1.901 a 66.367 , demonstrando a alta capacidade tampão destes solos. O solo argiloso da área experimental da Embrapa Cerrados (série 3000) apresentou resultados semelhantes, entre 8.069 a 41.704. Para o solo argiloso da Fazenda Rio de Janeiro, em diferentes situações de manejo, a variação foi de 226 a 4.564. Para os solos de Silvânia, ocorreu uma maior amplitude nos resultados (0,0056 a 16.934), devido aos diferentes tipos de solo analisados (Almeida Neto \& Brasil Sobrinho, 1977; Lopes \& Cox, 1979; Le Mare, 1982; Ker, 1995; Reis et al., 1995; Fontes \& Weed, 1996).

A disponibilidade do fósforo $(\mathrm{P})$ do solo deve ser interpretada levando em conta três fatores. $\mathrm{O}$ fator intensidade (Cp) que é a concentração de $\mathrm{P}$ na solução do solo presente como íons fosfato, o fator quantidade (Q) que pode ser estimado pelo fator $\mathrm{Ep}_{1 \min }$ e o fator capacidade $\left(\mathrm{Ep}_{\mathrm{lmin}_{\mathrm{m}}} / \mathrm{Cp}\right)$ que descreve a habilidade do solo para manter o Ep$_{\text {lmin }}$ constante quando o $\mathrm{P}$ é adicionado ou removido do solo pela aplicação ou absorção pelas raízes das plantas (White \& Beckett, 1964). Cada um deles pode ser limitante para a produção da cultura, mesmo, se os outros dois fatores não forem limitantes.

$\mathrm{O}$ Cp é o mais sensível parâmetro para avaliar a fertilidade do $\mathrm{P}$ do solo podendo variar de aproximadamente 0,002 a $4 \mathrm{mg} \mathrm{L}^{-1}$ de $\mathrm{P}$ (Fardeau, 1996). $\mathrm{O} \mathrm{C}_{\mathrm{p}}$ foi definido pela primeira vez por Beckwith (1965) pela expressão "concentração de equilíbrio", que foi posteriormente denominada P na "solução sobrenadante" ou P na "solução do solo" (Fox \& Kamprath, 1970), com o mesmo significado. Beckwith (1965) 
estabeleceu o nível de $0,2 \mathrm{mg} \mathrm{L}^{-1}$ de $\mathrm{P}$ como a concentração de equilíbrio para o máximo crescimento das plantas. Resultados semelhantes foram obtidos por Fox \& Kamprath (1970). Esse critério de avaliação e de correção do nível de P disponível do solo tem como base a quantidade desse elemento a ser adicionada ao solo para obter uma concentração de P na solução de equilíbrio que se correlacione com o crescimento da planta (Fox \& Kamprath, 1970; Rajan, 1973). Obtêm-se a quantidade de P a ser adicionada a partir de isotermas ajustadas aos dados de concentração de $\mathrm{P}$ em equilíbrio, como variável da quantidade de $\mathrm{P}$ adicionada a esse solo. Entretanto, a quantidade de $\mathrm{P}$ necessária para elevar a $\mathrm{Cp}$ a $0,2 \mathrm{mg} \mathrm{L}^{-1}$ são altas e fora da realidade econômica para ser implementada pelos produtores. Por exemplo, Lopes (1977) calculou a necessidade de $\mathrm{P}$ para três solos entre 162,9, 318,3 e 322,6 $\mathrm{mg} \mathrm{dm}^{-3}$ de $\mathrm{P}$ com teor de argila de 30,2, 33,5 e $34,3 \%$, respectivamente. No experimento de Brasilândia, em solo com aproximadamente $30 \%$ argila, obteve-se produtividade de forragem considerada elevada (cap. 4) com a adição de $60 \mathrm{~kg} \mathrm{ha}^{-1}$ de $\mathrm{P} \mathrm{e}$ a Cp determinada foi muito baixa, variando entre 0,0004 a $0,0006 \mathrm{mg} \mathrm{L}^{-1}$ de P (Tabela 2). Se fosse considerada uma Cp de 0,05 mg $\mathrm{L}^{-1}$ de $\mathrm{P}$ para os mesmos solos, a necessidade de $\mathrm{P}$ seria $112,6,217,2$ e $226,8 \mathrm{mg} \mathrm{dm}^{-3} \mathrm{de}$ $\mathrm{P}$ (Lopes, 1977), ainda assim, muito superiores aos $60 \mathrm{~kg} \mathrm{ha}^{-1}$ de $\mathrm{P}$ adicionados no experimento de campo (cap. 4). Yost et al. (1979) e Smyth \& Sanchez (1980) encontraram valores inferiores a $0,05 \mathrm{mg} \mathrm{L}^{-1} \mathrm{de} \mathrm{P}$ em experimentos com milho e arroz para o crescimento ótimo destas culturas em latossolos do Cerrado. Soares et al. (1999), observaram num experimento sob latossolo argiloso com Brachiaria decumbens no campo durante 5,5 anos que a dose de $140 \mathrm{~kg} \mathrm{ha}^{-1}$ de $\mathrm{P}$ foi suficiente para obter mais de $80 \%$ da produção máxima de matéria seca no período. Essas informações, contrárias ao nível crítico de $0,2 \mathrm{mg} \mathrm{L}^{-1}$, revelam a necessidade de se conhecer melhor o fator $\mathrm{Cp}$ e Ep $_{1 \text { min }}$ dos solos tropicais. Assim, o nível de $0,2 \mathrm{mg} \mathrm{L}^{-1}$ de $\mathrm{P}$, tido como crítico para solos com baixo fator capacidade (FCP), como os solos arenosos, mesmo em condições de maior intemperismo, podem ser reduzidos a valores inferiores a $0,05 \mathrm{mg} \mathrm{L}^{-1} \mathrm{em}$ solos com grande FCP. Nesse caso, apesar do baixo $\mathrm{Cp}$, sua reposição pelo Q (Ep lmin $_{\text {min }}$ é bastante intensa após a absorção de P pela planta (Novais \& Smyth, 1999). 


\subsubsection{Fosfato isotopicamente trocável (Pit)}

Quando $1 \mathrm{~g}$ de matéria seca é produzida, a planta evapora, em média, $300 \mathrm{~mL}$ de água de uma solução que contém, em média $0,2 \mathrm{mg} \mathrm{L}^{-1} \mathrm{de} \mathrm{P}$, nos solos europeus do oeste (Fardeau, 1996). Deste modo, quando $300 \mathrm{~mL}$ de solução do solo são absorvidos pelas raízes da planta e são evaporados, $0,2 \times 0,3=0,06 \mathrm{mg} P$ são absorvidos por fluxo de massa. O conteúdo médio de $\mathrm{P}$ na massa seca é aproximadamente de $3 \mathrm{mg} \mathrm{g}^{-1}$ de $\mathrm{P}$, mesmo que grandes variações dos conteúdos de $\mathrm{P}$ podem ser observados na matéria seca da planta (Walworth \& Sumner, 1987). Estes fatos também mostram que o fluxo de massa explica, em média, somente $100 *(0,06 / 3)=2 \%$ do total de $\mathrm{P}$ absorvido pela cultura. Este fato indica que em média $98 \%$ do $\mathrm{P}$ absorvido pela planta é liberado das partículas do solo durante o período de crescimento. Conseqüentemente, a maior parte do P biodisponível do solo pode ser encontrada na fase sólida do solo (Fardeau, 1996).

$\mathrm{O}$ fator quantidade $(\mathrm{Q})$ representa o compartimento dos íons fosfato que estão fracamente adsorvidos nas partículas do solo e podendo ser trocados instantaneamente com íons fosfato na solução do solo. O P isotopicamente trocável num minuto $\left(\mathrm{Ep}_{1 \mathrm{~min}}\right)$ é uma boa medida para o Q. Este parâmetro pode variar de 0,1 a $50 \mathrm{mg}$ de $\mathrm{P} \mathrm{kg}^{-1}$ de solo. Valores de $\mathrm{Ep}_{\text {lmin }}$ menores do que 5 (Tran et al., 1988) ou $3-4 \mathrm{mg} \mathrm{kg}{ }^{-1}$ (INTERNATIONAL ATOMIC ENERGY AGENCY (IAEA), 2001a) de P indica que a disponibilidade de $\mathrm{P}$ pode ser um fator limitante para a produção das culturas. $\mathrm{Ep}_{\text {Imin }}$ maiores do que $10 \mathrm{mg} \mathrm{kg}^{-1}$ de $\mathrm{P}$ indica a priori solos com fertilidade suficiente para o $\mathrm{Cp}$ exceder $0,02 \mathrm{mg} \mathrm{L}^{-1} \mathrm{de} P$.

As amostras compostas dos solos arenosos de Uberlândia e dos areno-argilosos de Brasilândia apresentaram valores abaixo dos níveis considerados limitantes (Tabela 3). Portanto, estes solos não têm a capacidade de suprir íons fosfato a solução do solo para manter a $\mathrm{Cp}$ a níveis adequados para o desenvolvimento das plantas. $\mathrm{O}$ que era esperado com os baixos resultados de $\mathrm{Cp}$ obtidos. Entretanto, neste conjunto de amostras, algumas pastagens apresentaram boas produtividades (renovadas) e outros não (não renovadas) (Ayarza et al., 1999; cap. 4). Todavia, os valores de Ep$_{\text {lmin }}$ não apresentaram sensibilidade para diferenciá-los. Entretanto, considerando que as plantas forrageiras são adaptadas e melhoradas para estes solos (Rao et al. 1997; 1999b) com 
baixos conteúdos de $\mathrm{P}$, os níveis sugeridos por Tran et al. (1988) e IAEA (2001a) talvez não sejam adequados para estes solos tropicais.

Tabela 3. Conteúdos de $\mathrm{P}$ calculados nos vários compartimentos trocáveis de acordo com o modelo multi-compartamental de Fardeau (1993).

\begin{tabular}{|c|c|c|c|c|c|c|c|c|}
\hline Amostra & $E p_{1 \min }$ & $E p_{1 \min -1 \mathrm{~h}}$ & $E p_{\text {lh-ld }}$ & $E p_{1 d-2 m}$ & $E p_{2 n-6 m}$ & $\mathrm{Ep}_{6 \mathrm{~m}-\mathrm{la}}$ & $E p_{>1 a}$ & $E p_{\Sigma<1 a}$ \\
\hline \multicolumn{9}{|c|}{ Brasilândia (MS) } \\
\hline 100 & $0,22 b$ & $1,7 \mathrm{~b}$ & $8,6 b$ & $52,2 \mathrm{~b}$ & $21,6 \mathrm{a}$ & $13,1 \mathrm{a}$ & $142 \mathrm{a}$ & $98 \mathrm{~b}$ \\
\hline 104 & $0,28 b$ & $2,0 \mathrm{~b}$ & $8,5 b$ & $43,4 b$ & $17,2 \mathrm{ab}$ & $10,6 \mathrm{ab}$ & $116 \mathrm{ab}$ & $82 b$ \\
\hline 113 & $0,70 \mathrm{~b}$ & $8,1 \mathrm{~b}$ & $31,5 b$ & $51,8 b$ & $7,4 \mathrm{c}$ & $3,2 \mathrm{~d}$ & $84 c$ & $103 b$ \\
\hline 154 & $0,48 b$ & $3,2 \mathrm{~b}$ & $11,8 \mathrm{~b}$ & $40,3 b$ & $11,2 \mathrm{bc}$ & $6,0 \mathrm{~cd}$ & $135 \mathrm{a}$ & $73 b$ \\
\hline 181 & $6,91 \mathrm{a}$ & $34,4 \mathrm{a}$ & $80,9 a$ & $113,6 \mathrm{a}$ & $16,0 \mathrm{ab}$ & $7,4 \mathrm{bc}$ & $104 \mathrm{bc}$ & $259 a$ \\
\hline$d m s$ & 3,4 & 12,0 & 24,0 & 29,0 & 8,0 & 3,9 & 31,0 & 31,0 \\
\hline$c v$ & 75 & 44 & 32 & 18 & 20 & 18 & 10 & 9 \\
\hline \multicolumn{9}{|c|}{ Solo arenosos de Uberlândia (MG) } \\
\hline 202 & $0,12 b$ & $0,47 \mathrm{a}$ & $1,44 \mathrm{a}$ & $7,32 \mathrm{a}$ & $4,23 \mathrm{a}$ & $3,44 \mathrm{a}$ & $163 a$ & $17 \mathrm{a}$ \\
\hline 205 & $0,33 \mathrm{ab}$ & $1,05 \mathrm{a}$ & $2,68 \mathrm{a}$ & $10,48 \mathrm{a}$ & $5,06 \mathrm{a}$ & $3,81 \mathrm{a}$ & $161 \mathrm{a}$ & $23 a$ \\
\hline 208 & $0,21 \mathrm{~b}$ & $0,60 \mathrm{a}$ & $1,51 \mathrm{a}$ & $6,40 \mathrm{a}$ & $3,50 \mathrm{a}$ & $2,85 \mathrm{a}$ & $179 \mathrm{a}$ & $15 \mathrm{a}$ \\
\hline 211 & $0,50 \mathrm{a}$ & $1,36 \mathrm{a}$ & $3,16 \mathrm{a}$ & $11,58 \mathrm{a}$ & $5,54 \mathrm{a}$ & $4,21 \mathrm{a}$ & $163 a$ & $26 \mathrm{a}$ \\
\hline$d m s$ & 0,28 & 1,05 & 2,78 & 13,00 & 6,40 & 4,90 & 28 & 28 \\
\hline$c v$ & 37 & 47 & 50 & 55 & 54 & 52 & 7 & 53 \\
\hline \multicolumn{9}{|c|}{ Solo argiloso de Uberlândia (MG) } \\
\hline 119 & $173 \mathrm{a}$ & $67 \mathrm{~b}$ & $22 \mathrm{c}$ & $9 c$ & $0,91 \mathrm{c}$ & $0,42 b$ & $124 \mathrm{c}$ & $274 \mathrm{c}$ \\
\hline 125 & $122 \mathrm{ab}$ & $112 \mathrm{a}$ & $54 \mathrm{bc}$ & $26 \mathrm{bc}$ & $2,65 b c$ & $1,23 b$ & $150 \mathrm{~b}$ & $318 \mathrm{a}$ \\
\hline 128 & $167 a$ & $94 \mathrm{ab}$ & $25 \mathrm{c}$ & $8 c$ & $0,66 \mathrm{c}$ & $0,29 b$ & $144 b$ & $295 b$ \\
\hline 135 & $62 \mathrm{bc}$ & $112 \mathrm{a}$ & $88 a$ & $55 \mathrm{ab}$ & $6,49 \mathrm{ab}$ & $3,08 \mathrm{ab}$ & $206 a$ & $327 \mathrm{a}$ \\
\hline 142 & $17 \mathrm{c}$ & $57 \mathrm{~b}$ & $82 \mathrm{ab}$ & $75 \mathrm{a}$ & $9,35 \mathrm{a}$ & $4,31 \mathrm{a}$ & $210 \mathrm{a}$ & $244 d$ \\
\hline 143 & $65 \mathrm{bc}$ & $98 \mathrm{ab}$ & $41 \mathrm{c}$ & $14 \mathrm{c}$ & $1,03 b c$ & $0,43 b$ & $201 \mathrm{a}$ & $220 \mathrm{e}$ \\
\hline$d m s$ & 81 & 44 & 33 & 32 & 5,6 & 2,8 & 10 & 10 \\
\hline$c v$ & 29 & 18 & 23 & 38 & 58,0 & 63,0 & 2 & 1 \\
\hline
\end{tabular}


Tabela 3. Conteúdos de $\mathrm{P}$ calculados nos vários compartimentos trocáveis de acordo com o modelo multi-compartamental de Fardeau (1993).

\begin{tabular}{|c|c|c|c|c|c|c|c|c|}
\hline Amostra & $E p_{\text {Imin }}$ & $E p_{\text {Imin-Ih }}$ & $E p_{1 h-l d}$ & $E p_{I d-2 m}$ & $\mathrm{Ep}_{2 \mathrm{~m}-6 \mathrm{~m}}$ & $\mathrm{Ep}_{6 \mathrm{~m}-\mathrm{la}}$ & $\mathrm{Ep}_{>1 \mathrm{a}}$ & $E p_{\Sigma<1 a}$ \\
\hline \multicolumn{9}{|c|}{ Silvânia (GO) } \\
\hline 753 & $0,0114 \mathrm{c}$ & $0,00005 d$ & $0,0010 \mathrm{e}$ & $0,032 \mathrm{e}$ & $0,036 \mathrm{e}$ & $0,040 \mathrm{~d}$ & $419 a$ & $0,12 \mathrm{i}$ \\
\hline 757 & $57,93 b$ & $112,95 \mathrm{a}$ & $91,02 a$ & $54,47 \mathrm{a}$ & $5,9 c$ & $2,74 b$ & $164 b$ & $325 a$ \\
\hline 761 & $111,52 \mathrm{a}$ & $99,77 \mathrm{a}$ & $43,04 c$ & $18,75 \mathrm{~d}$ & $1,9 \mathrm{de}$ & $0,89 \mathrm{bcd}$ & $104 d$ & $276 b$ \\
\hline 769 & $47,08 b$ & $70,44 b$ & $36,76 \mathrm{~cd}$ & $15,20 \mathrm{de}$ & $1,3 \mathrm{de}$ & $0,57_{\mathrm{cd}}$ & $87 \mathrm{e}$ & $171 \mathrm{c}$ \\
\hline 770 & $0,12 \mathrm{c}$ & $0,72 d$ & $2,89 \mathrm{e}$ & $18,72 d$ & $11,6 \mathrm{~b}$ & $9,27 \mathrm{a}$ & $149 c$ & $43 h$ \\
\hline 771 & $0,10 \mathrm{c}$ & $0,94 \mathrm{~d}$ & $5,19 \mathrm{e}$ & $36,97 \mathrm{bc}$ & $17,5 \mathrm{a}$ & $10,96 \mathrm{a}$ & $92 \mathrm{e}$ & $72 \mathrm{~g}$ \\
\hline 776 & $3,38 \mathrm{c}$ & $14,99 \mathrm{~cd}$ & $28,15 \mathrm{~d}$ & $29,98 \mathrm{~cd}$ & $3,6 \mathrm{~cd}$ & $1,60 \mathrm{bcd}$ & $43 \mathrm{f}$ & $82 \mathrm{f}$ \\
\hline 777 & $8,46 \mathrm{c}$ & $32,14 \mathrm{c}$ & $34,30 \mathrm{~cd}$ & $20,36 d$ & $1,9 \mathrm{de}$ & $0,80 \mathrm{bcd}$ & $36 \mathrm{f}$ & $98 \mathrm{e}$ \\
\hline 784 & $7,10 \mathrm{c}$ & $33,04 \mathrm{c}$ & $58,52 b$ & $52,43 \mathrm{ab}$ & $5,5 \mathrm{c}$ & $2,37 \mathrm{bc}$ & $88 \mathrm{e}$ & $159 d$ \\
\hline$d m s$ & 24,6 & 24,0 & 11,0 & 16,0 & 3,3 & 2,0 & 10 & 10 \\
\hline$c v$ & 33 & 20 & 12 & 20 & 21 & 22 & 3 & 3 \\
\hline \multicolumn{9}{|c|}{ Fazenda RJ - Planaltina (GO) } \\
\hline 2168 & 29,5 & 36 & 20 & 10 & 1,0 & 0,5 & 175 & 97 \\
\hline 2169 & 29,4 & 30 & 21 & 14 & 2,0 & 1,0 & 161 & 98 \\
\hline 2170 & 30,1 & 63 & 67 & 54 & 7,2 & 3,5 & 80 & 225 \\
\hline 2171 & 5,5 & 26 & 64 & 111 & 19,7 & 9,6 & 258 & 236 \\
\hline 2172 & 16,3 & 45 & 64 & 74 & 11,6 & 5,7 & 289 & 217 \\
\hline 2173 & 9,1 & 25 & 44 & 69 & 14,5 & 7,9 & 324 & 170 \\
\hline 2174 & 14,3 & 70 & 142 & 154 & 18,1 & 8,0 & 123 & 407 \\
\hline 2175 & 8,2 & 31 & 68 & 114 & 21,0 & 10,6 & 179 & 253 \\
\hline \multicolumn{9}{|c|}{ Embrapa Cerrados - Planaltina (DF) } \\
\hline 3017 & 78 & 82 & 45 & 24 & 2,8 & 1,3 & 70 & 232 \\
\hline 3018 & 123 & 89 & 33 & 13 & 1,2 & 0,6 & 69 & 260 \\
\hline 3019 & 143 & 57 & 13 & 4 & 0,3 & 0,2 & 83 & 218 \\
\hline 3020 & 191 & 53 & 10 & 3 & 0,2 & 0,1 & 56 & 257 \\
\hline 3021 & 82 & 81 & 38 & 17 & 1,6 & 0,7 & 66 & 221 \\
\hline 3022 & 137 & 64 & 16 & 5 & 0,4 & 0,2 & 56 & 223 \\
\hline 3023 & 140 & 60 & 12 & 3 & 0,2 & 0,1 & 58 & 216 \\
\hline 3024 & 162 & 64 & 15 & 4 & 0,3 & 0,1 & 60 & 246 \\
\hline
\end{tabular}

${ }^{1}$ Médias seguidas pela mesma letra, na mesma coluna e no mesmo local de amostragem, não diferem entre si pelo teste de Tukey a $5 \%$. 
Os solos de Silvânia apresentaram maior variabilidade, ocorrendo solos

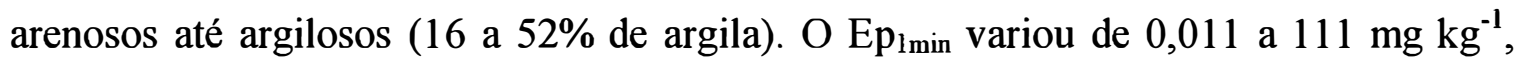
demonstrando variabilidade na biodisponibilidade do $\mathrm{P}, 82 \%$ explicada pelo teor de argila $\left(y=2,729 x-60,60 ; r^{2}=0,82 ;\right.$ onde $x=\%$ argila e $\left.y=E p_{1 \text { min }}\right)$. Está variação está diretamente ligada a capacidade de "fixação" de P destes solos. Para os solos com alta capacidade de "fixação" de P este parâmetro superestimou a disponibilidade de P (Amer et al., 1969; Wolf et al., 1986; Tran et al., 1988). Por outro lado, apresentou vantagens em relação a determinação do $\mathrm{P}$ disponível por meio de isotermas de adsorção (Morel et al., 1994; Morel et al., 1996). Salcedo et al. (1990) sugeriram a relação $r_{1} / R=0,26\left({ }^{32} P\right.$ na solução após 1 minuto da adição dele sobre o adicionado inicialmente) como um índice para separar solos baixos e altamente fixadores de P. Menor que 0,26 seriam os fixadores. Neste caso apenas o solo 3.1 (Tabela 1) não seria altamente fixador de P.

$\mathrm{O} E \mathrm{Ep}_{1 \mathrm{~min}}$ dos solos argilosos de Uberlândia e do solo argiloso da área experimental da Embrapa Cerrados foram elevados. Variaram de 17 a 173 e de 78 a 191 $\mathrm{mg} \mathrm{kg}^{-1}$ de $\mathrm{P}$, respectivamente. Nestes solos, da mesma forma que nos arenosos e arenoargilosos, houve situações de baixa e altas produtividades (Ayarza et al., 1999 Uberlândia; Vilela et al., 2001 - Embrapa Cerrados). O solo argiloso da Fazenda Rio de Janeiro apresentou valores intermediários entre os argilosos e os arenosos, devido a sua diferente composição mineralógica da fração argila (Bahia Filho et al., 1983; Ker, 1995).

\subsubsection{Fator capacidade $\left(\mathrm{FCP}=\mathrm{Ep}_{1 \mathrm{~min}} / \mathrm{Cp}\right.$ ou $\left.\mathrm{Q} / \mathrm{I}\right)$}

As bases para a conceituação e o entendimento dos três fatores: I, Q e Q/I foram desenvolvidas entre as décadas de 50 e 60 , principalmente. $O$ desenvolvimento dessa conceituação foi realizada em solos de clima temperado, com menor FCP e maior teor de $\mathrm{P}$, que os dos solos tropicais, mais intemperizados, de modo geral, o que tem causado uma série de dificuldades teóricas e práticas na utilização dessas informações sem os necessários ajustes (Novais \& Smyth, 1999).

Segundo Novais \& Smyth (1999) a determinação do FCP, é, hoje, para as nossas condições, imprescindível à comparação entre solos quanto ao "status" de P. A 
medida que, o "status" de P do solo aumenta (o solo torna-se mais rico em P), o FCP perde importância, como nos solos das regiões temperadas. Eles sugeriram uma escala hipotética de importância do FCP, como segue : FCP de solos argilosos, oxídicos, pobres em P > FCP de solos argilosos, silicatados, pobres em P > FCP de solos argilosos, oxídicos, ricos em P > FCP de solos argilosos, silicatados, ricos em P > FCP de solos arenosos, pobres em P > FCP de solos arenosos, ricos em P > FCK de solos argilosos, com 2:1 > FCK de solos argilosos, com 1:1 > FCP em solução nutritiva = FCK em solução nutritiva $=0$. Neste ponto, medidas qualitativas de adsorção, indicando a energia de ligação do $\mathrm{P}$ com o solo, trariam mais informações. $\mathrm{O}$ ideal seria poder medir as variações de energia de adsorção e, ou dessorção de $\mathrm{PO}_{4}{ }^{3-}$ em função de alterações do sistema induzidas por diversos modos de uso do solo.

O solo arenoso de Uberlândia apresentou os menores FCP, variando de 49 a 128; o areno-argiloso de Brasilândia, de 367 a 6.281, e os argilosos de Uberlândia apresentaram maior variação, entre 18.279 a 219.736, e o argiloso da Embrapa Cerrados e da Fazenda Rio de Janeiro sob diferentes sistemas agropastoris variaram entre 58.571 a 106.111 e 2.200 a 29.500 , respectivamente. Neste caso, o teor de argila associou-se aos valores de FCP (Bahia Filho \& Braga, 1975; Lopes \& Cox, 1979). Nos solos de Silvânia a variabilidade foi maior, entre 10 e 101.363 e não apresentaram boa correlação $\left(r^{2}=\right.$ 0,6) com os teores de argila (Ker, 1995). Quanto a fertilização destes solos com diferentes valores de FCP, o aumento da concentração de P-disponível, em solos com alto FCP, irá requerer doses mais elevadas de $\mathrm{P}$, em relação aos solos com baixo FCP, ambos com o mesmo teor inicial de P-disponível. Entretanto, obtida essa concentração, o solo com maior FCP irá manter o P-disponível mais constante e por períodos mais longos de cultivo.

A determinação do FCP através do valor Ep $_{\text {Imin }}$ caracteriza de melhor forma o FCP pois leva em conta o fator quantidade (isotermas) e qualidade (isotópica - energia da ligação) associados na mesma determinação. Isto fica bem caracterizado nas amostras de mesmo solo sob diferentes condições de manejo (Uberlândia - arenosos, Brasilândia, Silvânia algumas amostras; Rio de Janeiro, Embrapa Cerrados e Uberlândia - argilosos). 


\subsubsection{Biodisponibilidade de $P$ no tempo}

A análise do conjunto de solos através de estatística descritiva (Figura 4) permitiu visualizar que a biodisponibilidade potencial de $\mathrm{P}$ ao longo do tempo foi diferenciada em relação ao conteúdo de argila. Os solos arenosos apresentaram uma oferta potencial inicial muito baixa, com um aumento no período de 1 dia a 2 meses e após o decréscimo desta biodisponibilidade até o período de 1 ano (Figura 5a). Os solos areno-argilosos apresentam o mesmo comportamento, porém com biodisponibilidade potencial maior (Figura 5b). Os solos argilosos e muito argilosos apresentaram biodisponibilidade potencial de $\mathrm{P}$ inicialmente muito alta e uma queda gradativa com $\mathrm{o}$ passar do tempo, com conteúdos similares aqueles dos outros solos para o período de acima de 2 meses (Figura 5c), porém com comportamento semelhante após o período de 1 dia.

A recomendação de fertilização fosfatada para os solos do Cerrado por meio do extrator Mehlich I leva em consideração o conteúdo de argila (Novais \& Smyth, 1999; Vilela et al., 2000). Entretanto, o resultado é uma medida estática, não leva em consideração o fator tempo. Os resultados da Figura 5a,b,c demonstraram que a biodisponibilidade do $\mathrm{P}$ em função do tempo apresentou dinâmica diferente em relação ao conteúdo de argila. Outro interesse agronômico desta análise, é a possibilidade de realizar uma estimativa se a oferta do $\mathrm{P}$ do solo é suficiente para atender a demanda de $\mathrm{P}$ pela planta ao longo do seu ciclo de produção.

Nos apêndices 2 e 3 , são apresentados os resultados de dois levantamentos de análises de solo realizados no âmbito de cooperativas de produtores de leite de duas regiões do estado de Minas Gerais. A valorização destes resultados para se realizar um diagnóstico mais preciso da situação atual das pastagens, com ênfase na fertilidade química destes solos, auxiliaria numa melhor utilização e aplicação das informações conhecidas sobre o uso de fertilizantes. Estas informações poderiam ser utilizadas pelo departamento técnico das cooperativas na elaboração de estratégias mais adequadas de recuperação / renovação de pastagens. 


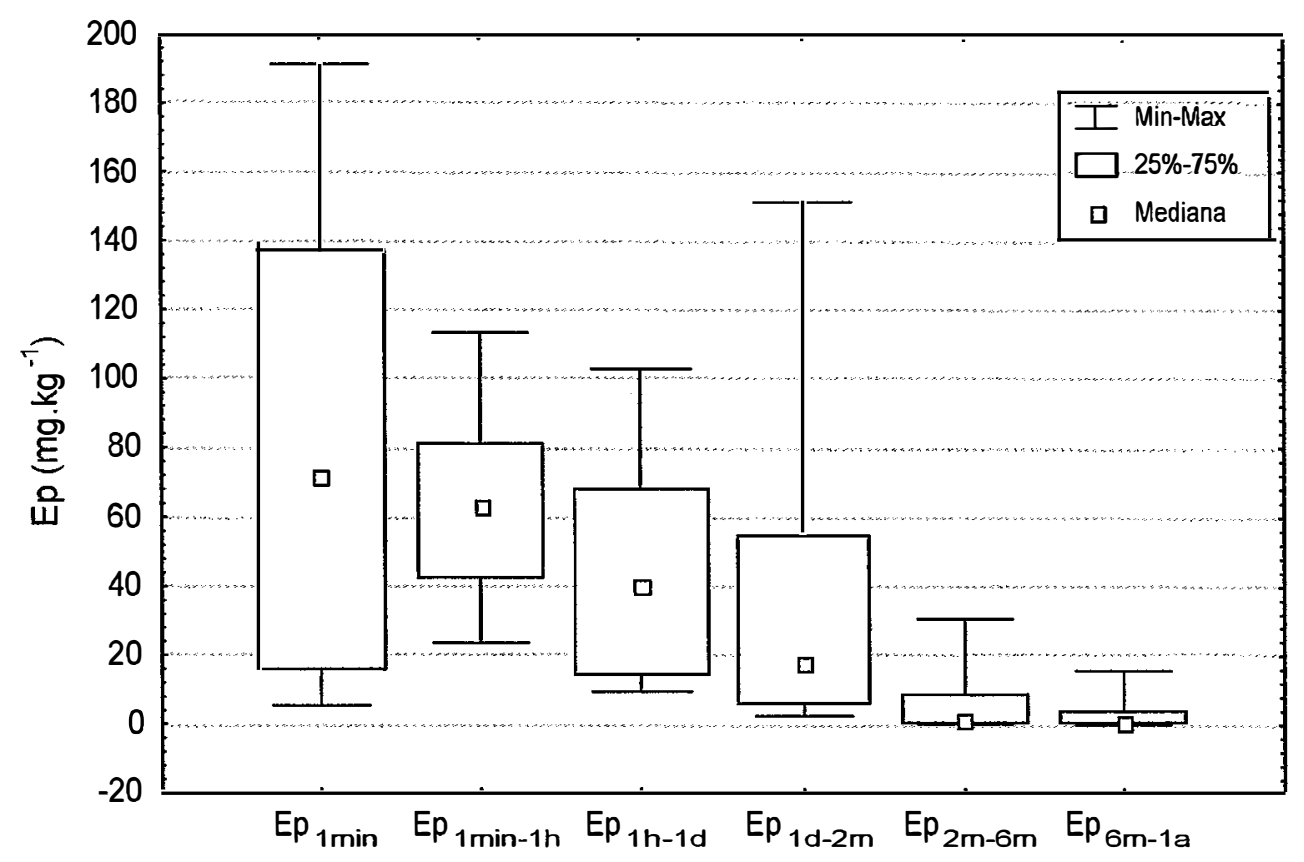

Figura 4 - Fosfato isotopicamente trocável (Ep) nos compartimentos da cinética de troca isotópica com todas as amostras.

Figura 5 a - Solos arenosos $<20 \%$ argila

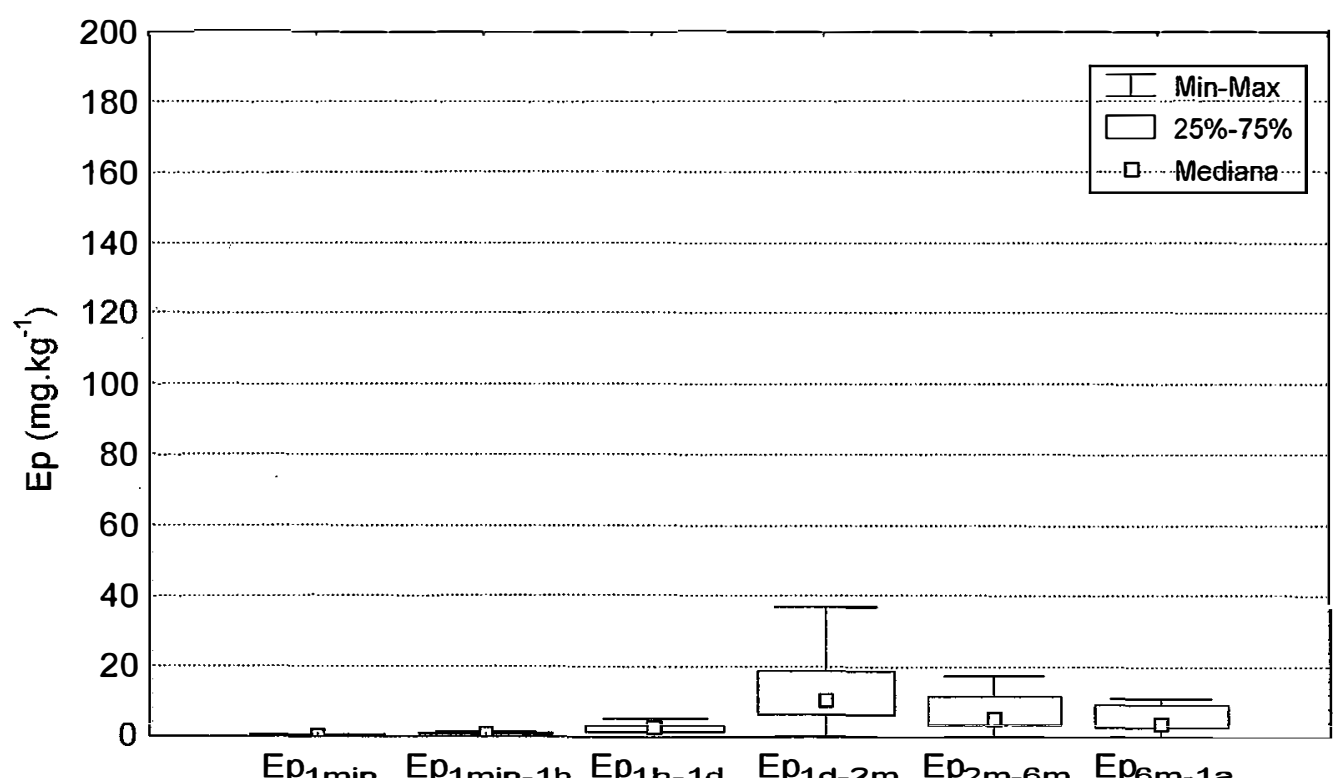


Figura 5b - Solos areno-argilosos $21-40 \%$ argila

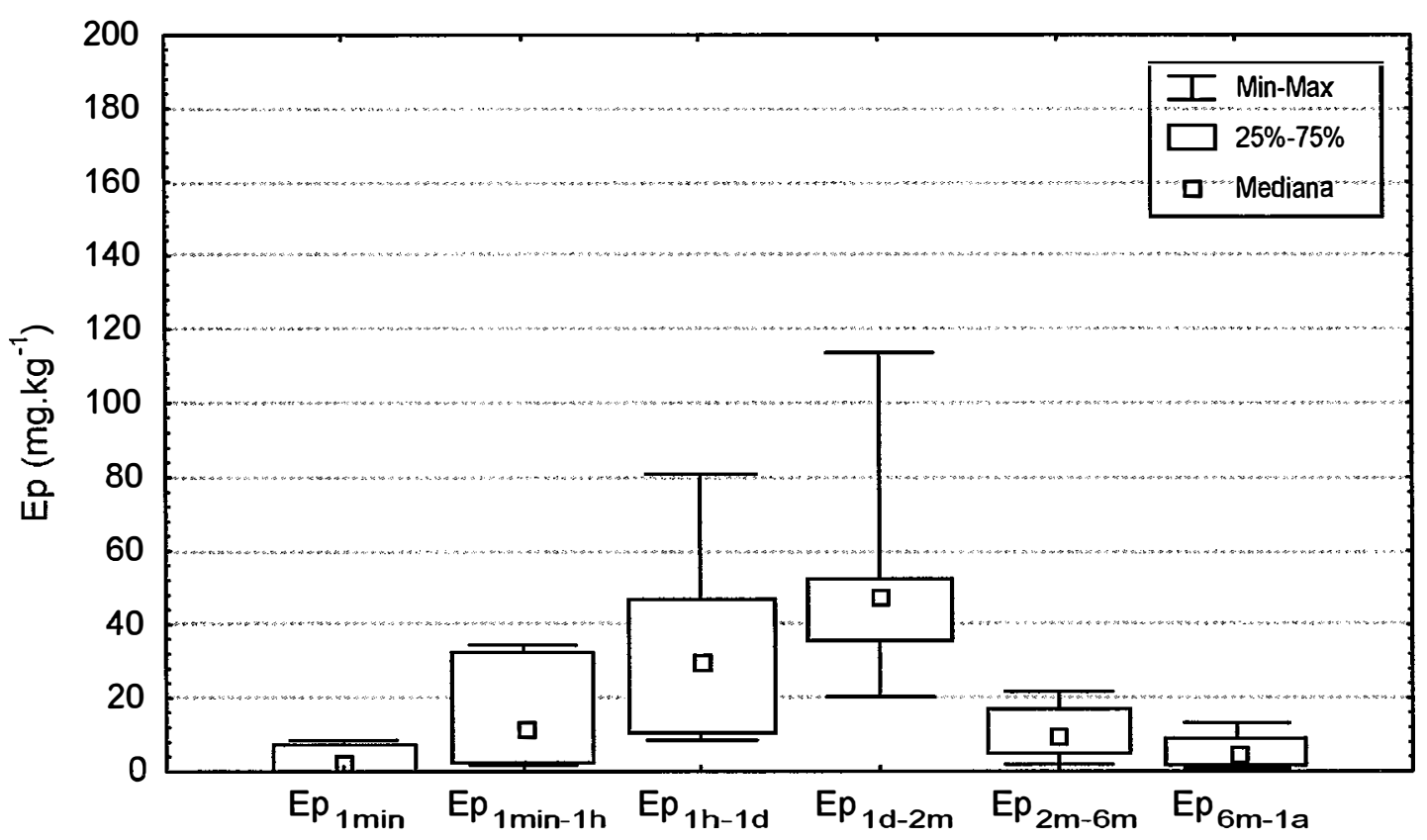

Figura $5 \mathrm{c}$ - Solos argilosos e muito argilosos $>41 \%$ argila

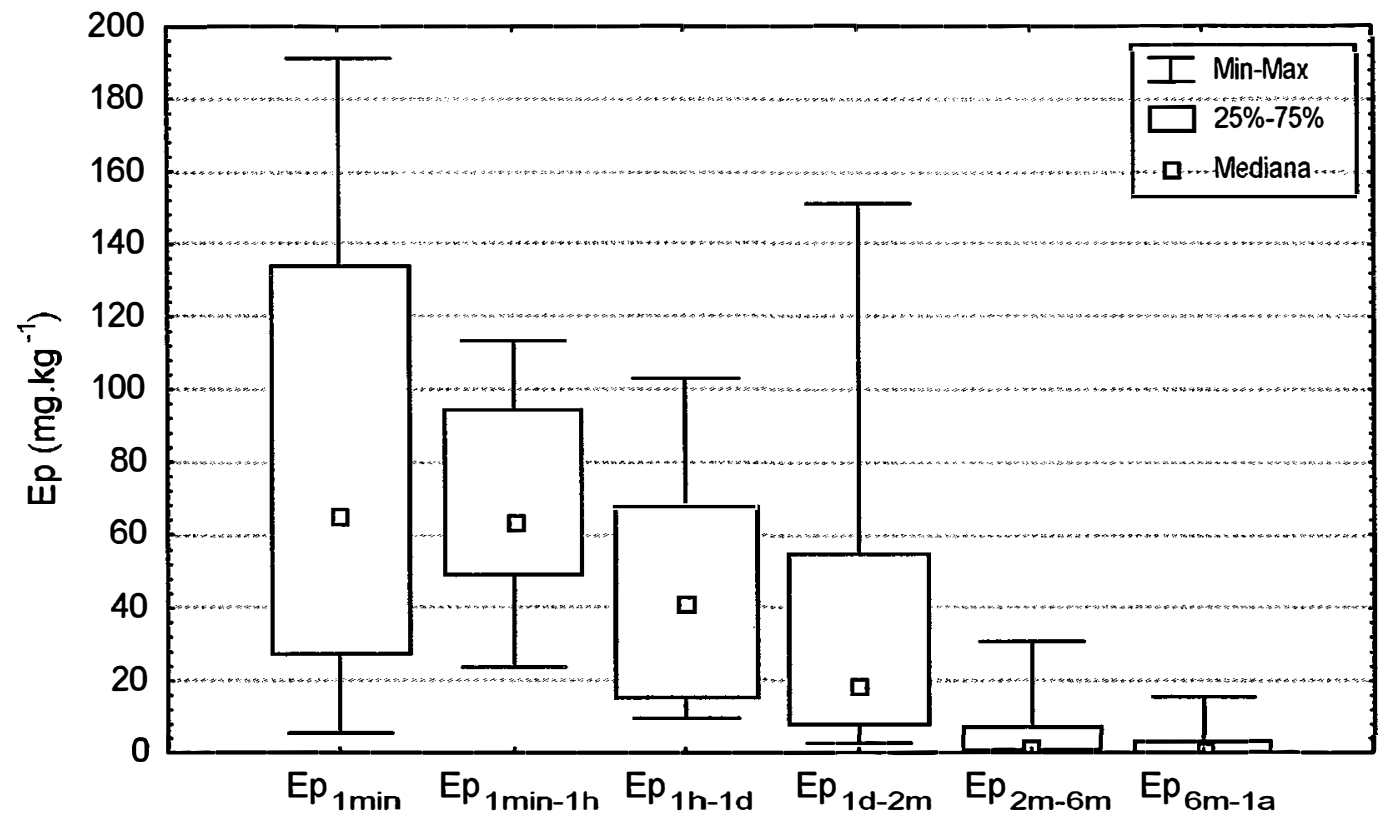

Figura 5 - Fosfato isotopicamente trocável (Ep) nos compartimentos da cinética de troca isotópica para as diferentes texturas de solo. 


\subsection{Conclusões}

A biodisponibilidade de $\mathrm{P}$ é limitante ao desenvolvimento da planta forrageira, em pastagens cultivadas da Região do Cerrado, quando não foram realizadas adubações de manutenção. Nestes solos, a determinação do $\mathrm{Ep}_{1 \min }$ forneceu a melhor estimativa do fosfato prontamente disponível para as plantas. Apesar da $\mathrm{Cp}$, concentração de fosfato na solução do solo, ser teoricamente o melhor parâmetro, ainda apresenta limitações na sua determinação devido aos baixíssimos valores de fosfato na solução do solo, o que impede a sua avaliação em análise de rotina. Este trabalho confirma a relação entre o conteúdo de argila e a biodisponibilidade do P. A distribuição do Ep segundo o tempo varia em valor absoluto segundo também os conteúdos de argila. A fertilização dos solos tropicais com fontes solúveis de fosfatos preconiza a utilização localizada para diminuir a "fixação" do solo e aumentar a eficiência do uso do P aplicado, o que foi demonstrado pelos altos valores do FCP. A utilização de fosfatos naturais reativos pode ser uma opção. A determinação das cinéticas de troca isotópica após a aplicação de doses crescentes de fosfatos nas amostras poderiam elucidar o comportamento destes solos em relação ao comportamento do fósforo advindo das fertilizações realizadas. Entretanto, algumas ponderações são necessárias, sob diferentes pontos de vista: i) solo: as quantidades para elevar a biodisponibilidade de $\mathrm{P}(\mathrm{Cp})$ são muito altas e fora da realidade econômica para o pecuarista, aos níveis atualmente considerados críticos; ii) planta: pequenas quantidades de $\mathrm{P}$ são suficientes para manter a produtividade destas pastagens a níveis aceitáveis; iii) pecuarista: embora exista a recomendação de adubações de manutenção, a adoção não é uma prática freqüente pois envolve necessidade de maior capital. Na concepção da maior parte dos pecuaristas, é mais conveniente desmatar uma nova área para formar pastagem do que recuperar/renovar a existente (onde ainda existe área de cerrado). Enfim, esta abordagem regional demonstra, mais uma vez, a necessidade de um melhor conhecimento da textura e natureza mineralógica dos solos para a adoção de técnicas modernas de cultivos. 


\section{BIODISPONIBILIDADE DE FOSFATO EM LATOSSOLO ARENO- ARGILOSO SOB Brachiaria sp. NO CERRADO ${ }^{1}$}

\section{Resumo}

$\mathrm{Na}$ região dos Cerrados o fósforo (P) é o nutriente de maior limitação para as pastagens cultivadas. A biodisponibilidade de $\mathrm{P}$ do solo nestes agroecossistemas é pouco conhecida. Avaliou-se a biodisponibilidade dos íons fosfato do solo em algumas pastagens de baixa produtividade e, em áreas renovadas. A avaliação físico-química de rotina com resina foi complementada por análises de cinética de troca isotópica (CTI) com ${ }^{32} \mathrm{P}$, possibilitando avaliar a oferta de $\mathrm{P}$ do solo no tempo. As áreas das pastagens cultivadas eram localizadas em Brasilândia (MS) sob um Latossolo Vermelho. As pastagens manejadas de forma tradicional (MTs) foram implantadas a 23 e 30 anos com Brachiaria decumbens e humidicola e as pastagens renovadas há 2 anos com Brachiaria brizantha cv. Marandu. As amostras de solo foram compostas por 30 subamostras aleatórias coletadas em três profundidades $(0-10,10-20$ e 20-30 cm), para cada tratamento. Os resultados do $\mathrm{P}$ resina correlacionaram-se com as quantidades de fosfatos aplicados e a produção de matéria verde seca nas pastagens renovadas, bem como, com as CTI para o período de 2 meses a 1 ano. Constatou-se pela análise da CTI que o conteúdo de $\mathrm{P}$ biodisponível na solução é suficiente para o desenvolvimento das plantas, mesmo nas pastagens consideradas de baixa produtividade, no primeiro período de 2 meses. Após, passa a ser limitante para as pastagens de manejo tradicional. Por outro lado, nas avaliações das pastagens renovadas, após 2 anos, a biodisponibilidade

\footnotetext{
${ }^{\text {I } A r t i g o ~ s u b m e t i d o ~ a ~ T r o p i c a l ~ G r a s s l a n d ~ e m ~ j a n e i r o ~ d e ~} 2002$.
} 
potencial de P passa a ser limitante a partir do 3 ao 4 ano de implantação, se adubações de manutenção não forem realizadas.

Palavras chaves: pastagem de baixa produtividade, cinéticas de troca isotópica, ${ }^{32} \mathrm{P}, \mathrm{P}$ resina

\section{PHOSPHATE BIOAVAILABILITY IN SANDY-CLAY FERRALSOL UNDER Brachiaria sp. IN THE CERRADO (BRAZIL)}

\section{Summary}

In Cerrado regions the soil low phosphates $(\mathrm{P})$ content is the main limitation to pastures cultivation. The bioavailability of phosphate ions in the soil of some cultivated pastures with low productivity and in renewed areas was evaluated. Routine physicochemical resin evaluation was complemented by isotopic exchange kinetic (IEK) analyses with ${ }^{32} \mathrm{P}$, which allowed for evaluation of soil $\mathrm{P}$ abundance at a defined time. The cultivated pastures were in Brasilândia, in Mato Grosso do Sul State, under a red Latossol (Ferralsol). The traditionally managed pastures (TMs) had been cultivated 23 and 30 years before with Brachiaria decumbens and humidicola and the renewed pastures had been cultivated two years before with Brachiaria brizantha cv. Marandu. The soil samples were composed of 30 random sub-samples collected at three depths (0$10,10-20$ and $20-30 \mathrm{~cm}$ ), for each treatment. The results from the resin $\mathrm{P}$ were correlated with the quantities of phosphate applied and with the production of dry green matter in the renewed pastures, as well as with the IEK for the period from two months to one year. In the IEK analysis, there was enough P bioavailability in the solution for plant development, even in the pastures considered to be of low productivity, in the first two-month period. Afterwards, it becomes limiting in the traditionally managed pastures. In contrast, in the evaluations of the renewed pastures, the potential $\mathrm{P}$ bioavailability after two years becomes limiting from the third to fourth year of planting, if fertilizer is not applied. 
Key words: low-productivity pasture, isotopic exchange kinetic, ${ }^{32} \mathrm{P}, \mathrm{P}$ resin

\subsection{Introdução}

O bioma Cerrado é uma denominação brasileira para savana. Este bioma é caracterizado por uma vegetação diversa (Ribeiro \& Walter, 1998) dependente do contexto hidrodinâmico e geoquímico local, mais relacionado com o material de origem (Furley \& Ratter, 1988; Oliveira Filho et al., 1989) e a queima (Eiten \& Sambuichi, 1996). Desde os anos 60, o bioma Cerrado foi o local de um intenso desenvolvimento de atividades agropecuárias e representou a mais importante fronteira agrícola de expansão do país (Waniez, 1992; Ker \& Resende, 1996). A fertilidade química dos solos do Cerrado é naturalmente baixa. Apresentam baixa capacidade de troca de cátions, acidez elevada, altos teores de alumínio e baixos teores de nutrientes, especialmente o P (Lopes \& Cox, 1977; Adámoli et al., 1986). Entretanto, estas áreas de Cerrado estavam em equilíbrio, onde não ocorria a exportação de nutrientes e as perdas destes eram limitadas, permitindo assim, a manutenção da vegetação natural.

O Cerrado brasileiro abrange $20710^{6}$ ha dos quais 49,5 $10^{6}$ são ocupados por pastagens cultivadas (Sano et al., 2000), na sua maioria do gênero Brachiaria, introduzidas a partir de 1970. O manejo da fertilidade do solo destas pastagens, compreendia a abertura de áreas de cerrado, correção da acidez do solo e adubação inicial com fertilizantes fosfatados (Kornelius et al., 1979). Porém, com os anos de utilização, associado ao manejo inadequado e a falta de fertilização de manutenção, a capacidade produtiva das pastagens reduziu acentuadamente.

Diferentes práticas agronômicas foram pesquisadas e difundidas para restabelecimento da capacidade produtiva destas pastagens. $\mathrm{O}$ uso do revolvimento do solo associado a correção e fertilização está sendo amplamente adotado na região. Outras alternativas recomendavam o cultivo anual associado, principalmente de milho e arroz, com pastagens. Esta tecnologia permitia o restabelecimento da pastagem e ainda a amortização parcial ou total dos custos dos insumos pela comercialização dos grãos 
(Oliveira et al., 1996). Entretanto estas práticas não foram acompanhadas pela adoção de fertilização de manutenção durante a fase de utilização, a semelhança do modelo tradicional de implantação das pastagens. Assim sendo, estes solos naturalmente deficientes em $\mathrm{P}$, dentre outros elementos, não permitiam o atendimento da exigência mínima das plantas, resultando em decréscimo acentuado da produção nos anos seguintes a recuperação ou renovação da pastagem (Euclides et al., 1997).

As análises de $\mathrm{P}$ do solo por meio de métodos de rotina podem não evidenciar esta deficiência entretanto a biodisponibilidade de $\mathrm{P}$ pode restringir e comprometer a produtividade da pastagem. A biodisponibilidade de $\mathrm{P}$ do solo pode ser definida como todo o P do solo que pode contribuir para a nutrição das plantas. Quando se realiza uma extração do fosfato disponível do solo, este é descrito simplesmente como: a quantidade de $\mathrm{P}$ extraída pelo reagente, assumindo que a disponibilidade de toda esta quantidade de P é homogênea. Porém, foi demonstrado que: (i) uma fração do fosfato do solo não disponível é geralmente extraída, ou (ii) somente uma fração do fosfato disponível é extraída (Morel \& Fardeau, 1987; Fardeau et al., 1988). Por outro lado, em solos altamente intempèrizados os métodos de rotina não acessam todas as frações de $\mathrm{P}$ (Tiessen et al., 1984; Beck \& Sanchez, 1994). A relação entre a biodisponibilidade do $P$ do solo e os íons fosfato isotopicamente trocáveis é assumida como igual por Larsen (1952) e a disponibilidade do P para as plantas é estritamente controlada pelos processos de adsorção/dessorção. White \& Beckett (1964) propuseram a caracterização da disponibilidade do fosfato do solo utilizando três fatores: i) fator intensidade que é a concentração de íons fosfato na solução do solo $\left(\mathrm{H}_{2} \mathrm{PO}_{4}{ }^{-} ; \mathrm{HPO}_{4}{ }^{-2}\right)$; ii) o fator quantidade que é representado pela quantidade de fosfato que pode ser potencialmente adsorvido pela planta, iii) a capacidade tampão que descreve a habilidade do solo para manter o fator intensidade constante quando a quantidade de $\mathrm{P}$ varia. Em análises de rotina os extratores químicos ou físico-químicos não fornecem informações sobre os fatores intensidade e capacidade. Fardeau et al., $(1977,1985)$ propuseram caracterizar a cinética de troca de fosfato entre as fases líquida e sólida do solo unicamente considerando o fator tempo. Uma das mais importantes informações do modelo funcional, fornecida 
pelos parâmetros cinéticos, é a descrição da habilidade dos íons biodisponíveis de $\mathrm{P}$ do solo saírem da fase sólida do solo para a solução do solo (Fardeau, 1996).

Este trabalho teve como objetivo avaliar a biodisponibilidade dos íons fosfato do solo em algumas pastagens de baixa produtividade e em áreas renovadas. $\mathrm{O}$ solo areno-argiloso onde o estudo foi realizado é representativo de uma importante área que compreende a região sudoeste do bioma Cerrado, onde predominam extensas áreas de pastagens cultivadas (SECRETARIA DE PLANEJAMENTO E COORDENACAO GERAL, 1989). A avaliação de rotina foi complementada por análises de cinética de troca isotópica (CTI) com ${ }^{32} \mathrm{P}$, possibilitando avaliar a oferta de $\mathrm{P}$ do solo no tempo.

\subsection{Material e Métodos}

\subsection{1 Áreas de amostragem}

A área de estudo é localizada no município de Brasilândia, no estado do Mato Grosso do Sul $\left(21^{\circ} 22,53^{\prime} \mathrm{S} 52^{\circ} 11,73^{\prime} \mathrm{E}\right)$, altitude média de $450 \mathrm{~m}$. A precipitação média anual é de $1.600 \mathrm{~mm}$. O relevo é caracterizado por uma sucessão de colinas de aproximadamente $30 / 50 \mathrm{~m}$ de altitude separadas por interflúvios de 800 a $1.500 \mathrm{~m}$. A Classe textural do solo é a franca-argilo-arenosa (Tabela 4; Lemos \& Santos, 1996) e é um Latossolo Vermelho (EMBRAPA, 1999) desenvolvido sobre materiais cretáceos altamente intemperizados (Arenito Bauru). A caulinita é o principal (18-35\%) mineral de argila associada com oxi-hidróxidos de ferro em menores proporções.

Foram consideradas as seguintes áreas de amostragem (Tabela 5):

- Área de vegetação natural, cerradão (CE) usada como referência;

- 5 pastagens manejadas de forma tradicional - MT1, MT3 e MT4, implantada a 30 anos e MT2 e MT5 a 23 anos;

- No ano agrícola de 1994/95, foram realizados tratamentos de renovação de pastagens pela implantação da Brachiaria brizantha cv. Marandu (BB) em substituição da Brachiaria humidicola $(\mathrm{BH})$, implantada a 20 anos. Cada tratamento tinha uma área de 5 ha. No período que antecedeu a implantação do experimento não foram realizadas adubações fosfatadas. Os tratamentos (Tabela 5) constituíram-se de 
renovação da pastagem, pelo estabelecimento da gramínea forrageira associada com as culturas do milho (RM), e do arroz (RA) ou direta (RD). A RM e RA seguiram as orientações preconizadas pelo Sistema Barreirão (Oliveira et. al, 1996). Foi ainda selecionada uma área experimental de 5 ha adjacente às demais para constituir o tratamento testemunha (TT), onde predominavam as espécies de BH e Brachiaria decumbens $(\mathrm{BD})$, implantadas há 20 anos.

Tabela 4. Dados físicos e químicos do solo estudado.

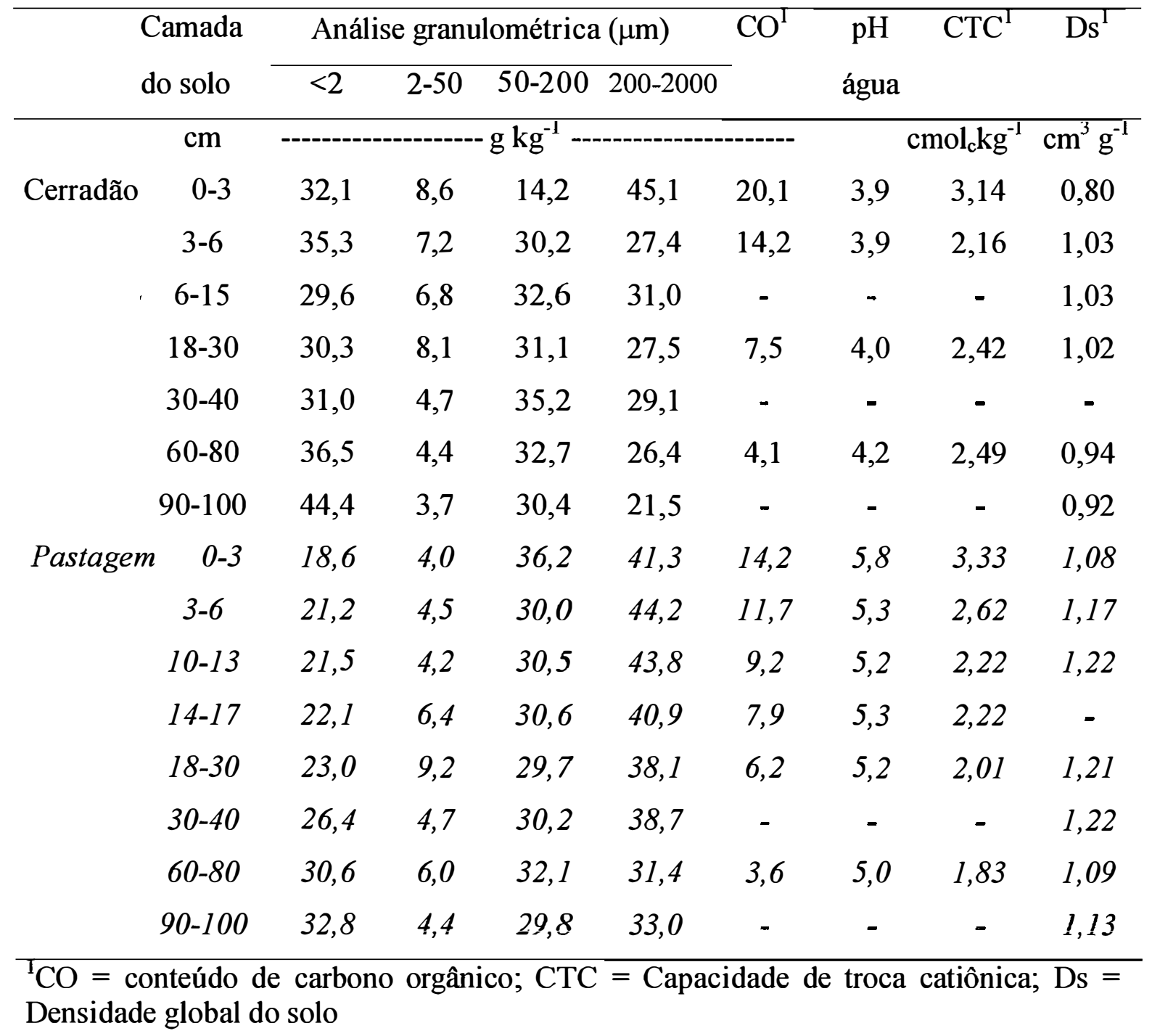







Em novembro de 1995, iniciou-se a avaliação com bovinos em sistema de pastejo rotacionado com 9 dias de pastejo e 36 dias de descanso. Adotou-se a oferta de 7 $\mathrm{kg}$ de matéria verde seca (MVS) por $100 \mathrm{~kg}$ de peso vivo por dia, representando uma pressão de pastejo (PP) de 7\% para todos os tratamentos, estimando-se a oferta de forragem por pasto por meio do corte e separação da fração verde e seca de oito unidades amostrais de $0,5 \mathrm{~m}^{2}$, antes do ingresso dos animais.

\subsubsection{Amostragens de solos}

As amostras de solo foram compostas por 30 subamostras aleatórias coletadas com trado em três profundidades $(0-10,10-20$ e 20-30 cm), para cada tratamento, dois anos após a implantação do experimento. As amostras foram secas ao ar, tamisadas a 2 $\mathrm{mm}$ para posterior análises químicas. Para as análises de $\mathrm{P}$ total $(\mathrm{Pt})$ e orgânico $(\mathrm{Po})$ uma alíquota da amostra foi finamente moída.

\subsubsection{Análises}

A extração de P-resina $(\mathrm{Pr})$, cálcio $(\mathrm{Ca})$, magnésio $(\mathrm{Mg})$ e potássio $(\mathrm{K})$ seguiram a metodologia da mistura de resina aniônica e catiônica (Raij et al., 1986). O P foi determinado por colorimetria em espectrofotômetro no comprimento de onda $882 \mathrm{~nm}$ (John, 1970), Ca e Mg por espectrofotometria de absorção atômica e o K por fotometria de chama.

O Pt foi extraído pela digestão de $0,5 \mathrm{~g}$ de solo finamente moído com uma mistura tri-ácida (ácido fluorídrico, ácido nítrico e ácido perclórico) e diluição com 50 $\mathrm{mL}$ de $\mathrm{HCl}$ 0,1 N. O Po foi determinado em duas alíquotas de $2 \mathrm{~g}$ de solo da mesma amostra, calcinando-se uma delas em mufla por 2 horas a $550{ }^{\circ} \mathrm{C}$. Adicionou-se $50 \mathrm{~mL}$ de $\mathrm{H}_{2} \mathrm{SO}_{4} 1 \mathrm{M}$ nas 2 alíquotas, agitou-se por 16 horas num agitador horizontal (Anderson, 1960). O P dos extratos foi determinado por colorimetria em espectrofotômetro (John, 1970). Obteve-se o Po pela diferença entre a amostra calcinada e não calcinada. 


\subsubsection{Determinação do fosfato isotopicamente trocável}

As análises de cinética de troca isotópica (CTI) foram conduzidas no sistema solo-solução (SSS) após as amostras atingirem o equilíbrio numa relação solo-solução 1:10 (Salcedo et al. 1990; Fardeau et al. 1991; Frossard et al., 1994). Para compor o sistema foram utilizados $10 \mathrm{~g}$ de solo, tamisados a $2 \mathrm{~mm}$ e $99 \mathrm{~mL}$ de água desionizada em um recipiente de plástico com capacidade de $250 \mathrm{~mL}$. As amostras foram agitadas durante 16 horas. A seguir, as amostras foram postas a agitar suavemente em um agitador magnético e, adicionou-se ao tempo zero $(\mathrm{t}=0), 1 \mathrm{~mL}$ de solução contendo o radioisótopo ${ }^{32} \mathrm{P}$ livre de carregador. As atividades utilizadas foram de aproximadamente $1 \mathrm{MBq} \mathrm{mL} L^{-1}$. Após $\mathrm{t}_{1}=1, \mathrm{t}_{2}=3, \mathrm{t}_{3}=10$ e $\mathrm{t}_{4}=15 \mathrm{~min}$, tomou-se uma alíquota de $\pm 8 \mathrm{~mL}$ da suspensão com uma seringa de plástico, que foi imediatamente acoplada a uma unidade de porta filtro de pressão com um filtro de membrana de $0,05 \mu \mathrm{m}$. A suspensão foi filtrada em \pm 10 segundos e desta foi utilizada uma alíquota de $0,25 \mu \mathrm{L}$, retirada com uma micropipeta, completando-se o volume a $20 \mathrm{~mL}$ para posterior determinação das contagens do ${ }^{32} \mathrm{P}$ pelo efeito Cerenkov no contador de cintilação líquida Wallac 1409. Ao final, foram utilizadas seringas de $60 \mathrm{~mL}$ para obter maior quantidade de solução para determinação da concentração de fosfato $(\mathrm{Cp})$ presente na solução do solo por colorimetria pelo método do verde malaquita (Rao et al., 1997). A concentração dos íons fosfato da solução filtrada, foi feito com peças de $3 \times 2 \mathrm{~cm}$ de resina aniônica tipo membrana, marca BDH15 1TD, como realizado por Salcedo et al. (1990). Nas condições de análises do laboratório, os valores obtidos da concentração de fosfato na solução do solo da amostra padrão apresentaram CV de 1,23 \% com 3 repetições.

\subsubsection{Cálculo da quantidade de P isotopicamente trocável (Pit) de um sistema solo solução (SSS) e da quantidade de Pit a qualquer tempo t}

As medidas de Pit no SSS devem ser conduzidas num equilíbrio (steady state), requerimento básico para a interpretação dos resultados experimentais, onde:

- R é a quantidade de radioatividade aplicada no SSS como íons $\mathrm{PO}_{4}{ }^{3-}$;

- $r_{(t)}$ é a quantidade de radioatividade presente após um tempo $t$ de troca isotópica; 
- $\mathrm{Ep}_{(\mathrm{t})}$ é a quantidade de Pit após um tempo t de troca isotópica e,

- Cp é a quantidade de $\mathrm{P}$ como íons $\mathrm{PO}_{4}{ }^{3-}$ no SSS num estado de equilíbrio.

A quantidade de Pit na solução, $E_{(t)}$, aumenta quando o tempo t aumenta, então a radioatividade $r_{(t)}$ na solução diminui com o aumento do tempo de troca. De acordo com a equação teórica a seguir (Fardeau et al., 1985):

$$
r_{(t)} / R=r_{1} / R\left[t+\left(r_{1} / R\right)^{1 / n}\right]^{-n}+r_{e q} / R
$$

Onde $r_{1}$ e $r_{\text {eq }}$ são as radioatividades em megabequerel (MBq) remanescentes na solução após o período de um minuto e no infinito, respectivamente, e n é um parâmetro obtido pelo experimento das CTI. Neste experimento, $\mathrm{n}$ é calculado como declividade da equação de regressão entre $\log \left(\mathrm{r}_{(\mathrm{t})} / \mathrm{R}\right)$ e $\log (\mathrm{t})$ (Fardeau \& Jappé, 1976). Nos cálculos para determinação do Pit são considerados os tempos de: i) 0 a 1 minuto ( $\left.E p_{1 \min }\right)$; ii) 1 minuto a 1 hora $\left(E p_{1 \min -1 \mathrm{~h}}\right)$; iii) 1 hora a 1 dia $\left(E p_{1 \mathrm{~h}-1 \mathrm{~d}}\right)$; iv) 1 dia a 2 meses $\left.\left(E p_{1 \mathrm{ld}-2 \mathrm{~m}}\right) ; \mathrm{v}\right) 2$ meses a 6 meses $\left(\mathrm{Ep}_{2 \mathrm{~m}-6 \mathrm{~m}}\right)$; vi) 6 meses a 1 ano $\left(\mathrm{Ep}_{6 \mathrm{~m}-\mathrm{la}}\right)$; vii) acima de um ano $\left(\mathrm{Ep}_{>\mathrm{la}}\right)$; viii) 0 minuto a 1 ano $\left(E p_{\Sigma<1 a}\right)$.

\subsubsection{Análise estatística}

Os efeitos dos diferentes sistemas de renovação de pastagens foram testados através do teste de Tukey com o teste da diferença mínima significativa ao nível de 5\% $(p<0,05)$ para cada profundidade amostrada. Os coeficientes de correlações foram calculados entre Pr e os compartimentos do modelo funcional (STATSOFT, 1996). As análises estatísticas foram realizadas com o programa sistema de análise estatística (SAS, 1989).

\subsection{Resultados}

\subsubsection{Conteúdo de Pt e Po nos solos}

Os conteúdos de Pt variaram entre 161 a 240, 138 a 210 e 129 a $216 \mathrm{mg} \mathrm{kg}^{-1}$ de $P$ nas camadas 0-10, 10-20 e 20-30 cm, respectivamente. O Po variou entre 57 a 115, 30 a 88 e 42 a $87 \mathrm{mg} \mathrm{kg}^{-1}$ de P respectivamente nas mesmas camadas (Tabela 6). 
Tabela 6. Conteúdos de P-total (Pt), P-orgânico (Po) e P-resina (Pr), cálcio e magnésio dos extratos resina no cerradão, pastagens renovadas e de manejo tradicional.

\begin{tabular}{|c|c|c|c|c|c|c|c|}
\hline \multirow[t]{2}{*}{ Uso $^{1}$} & \multirow{3}{*}{$\begin{array}{c}\text { Tempo } \\
\text { (ano) }\end{array}$} & \multicolumn{2}{|l|}{ P-resina ${ }^{2}$} & $\mathrm{Pt}$ & Po & $\mathrm{Ca}$ & \multirow{2}{*}{$\mathrm{Mg}$} \\
\hline & &  & $n$ & 1 & & ------- mn & \\
\hline \multicolumn{7}{|c|}{$0-10 \mathrm{~cm}$} & \\
\hline $\mathrm{CE}$ & - & $8,4 a b$ & $(0,6)$ & 210 & 88 & $2(0,9)$ & $2(0,2)$ \\
\hline RMsp & 3 & $8,9 \mathrm{a}$ & $(0,1)$ & 240 & 89 & $21(0,7)$ & $16(0,4)$ \\
\hline RM & 3 & $7,3 \mathrm{~cd}$ & $(0,4)$ & 198 & 71 & $10(2,4)$ & $7(1,3)$ \\
\hline RA & 3 & $8,0 \mathrm{~b}$ & $(0,4)$ & 221 & 86 & $7(0,8)$ & $5(0,1)$ \\
\hline $\mathrm{RD}$ & 3 & $4,8 \mathrm{f}$ & $(0,2)$ & 204 & 78 & $8(0,9)$ & $6(0,3)$ \\
\hline $\mathrm{R}$ & 3 & $6,9 \mathrm{~d}$ & $(0,1)$ & 182 & 101 & $5(1,1)$ & $5(1,3)$ \\
\hline $\mathrm{R}$ & 3 & $7,9 \mathrm{bc}$ & $(0,2)$ & 208 & 97 & $5(0,6)$ & $5(0,6)$ \\
\hline TT & 23 & $6,2 \mathrm{e}$ & $(0,1)$ & 187 & 77 & $3(0,2)$ & $3(0,1)$ \\
\hline MT1 & 30 & $5,3 \mathrm{f}$ & $(0,0)$ & 208 & 115 & $3(0,0)$ & $3(0,1)$ \\
\hline MT2 & 23 & $5,2 \mathrm{f}$ & $(0,1)$ & 180 & 89 & $4(0,3)$ & $3(0,3)$ \\
\hline MT3 & 30 & $4,7 \mathrm{f}$ & $(0,1)$ & 166 & 72 & $3(0,1)$ & $2(0,1)$ \\
\hline MT4 & 30 & $5,2 \mathrm{f}$ & $(0,1)$ & 161 & 76 & $4(1,5)$ & $2(0,0)$ \\
\hline \multicolumn{8}{|c|}{$10-20 \mathrm{~cm}$} \\
\hline CE & - & $6,4 \mathrm{a}$ & $(0,6)$ & 201 & 75 & $1(0,2)$ & $1(0,1)$ \\
\hline RMsp & 3 & $6,0 \mathrm{ab}$ & $(0,5)$ & 196 & 76 & $16(1,9)$ & $11(1,5)$ \\
\hline $\mathrm{RM}$ & 3 & 5,0 cde & $(0,1)$ & 210 & 77 & $8(2,0)$ & $5(0,9)$ \\
\hline RA & 3 & $5,5 \mathrm{bc}$ & $(0,2)$ & 194 & 88 & $4(0,1)$ & $3(0,1)$ \\
\hline $\mathrm{RD}$ & 3 & $3,3 \mathrm{i}$ & $(0,1)$ & 192 & 71 & $6(1,2)$ & $3(0,6)$ \\
\hline $\mathrm{R}$ & 3 & $5,1 \mathrm{~cd}$ & $(0,0)$ & 197 & 80 & $3(0,1)$ & $2(0,0)$ \\
\hline $\mathrm{R}$ & 3 & 4,4 efg & $(0,0)$ & 184 & 71 & $2(0,0)$ & $1(0,0)$ \\
\hline $\mathrm{TT}$ & 23 & $4,6 \mathrm{def}$ & $(0,0)$ & 194 & 67 & $2(0,4)$ & $2(0,1)$ \\
\hline MT1 & 30 & $3,4 \mathrm{i}$ & $(0,1)$ & 177 & 79 & $2(0,1)$ & $1(0,0)$ \\
\hline MT2 & 23 & $4,1 \mathrm{fgh}$ & $(0,1)$ & 162 & 78 & $2(0,2)$ & $1(0,1)$ \\
\hline MT3 & 30 & $3,6 \mathrm{hi}$ & $(0,1)$ & 154 & 54 & $2(0,1)$ & $1(0,0)$ \\
\hline MT4 & 30 & 3,9 ghi & $(0,0)$ & 138 & 58 & $2(0,1)$ & $1(0,1)$ \\
\hline MT5 & 23 & $3,3 \mathrm{i}$ & $(0,1)$ & 148 & 30 & $2(0,1)$ & $1(0,0)$ \\
\hline \multicolumn{8}{|c|}{$20-30 \mathrm{~cm}$} \\
\hline $\mathrm{CE}$ & - & $5,3 \mathrm{a}$ & $(0,3)$ & 200 & 67 & $1(0,4)$ & $1(0,1)$ \\
\hline RMsp & 3 & $3,4 \mathrm{c}$ & $(0,1)$ & 190 & 66 & $8(0,5)$ & $5(0,1)$ \\
\hline $\mathrm{RM}$ & 3 & $3,0 \mathrm{de}$ & $(0,2)$ & 201 & 61 & $4(0,4)$ & $2(0,2)$ \\
\hline RA & 3 & $4,3 \mathrm{~b}$ & $(0,1)$ & 169 & 61 & $3(0,7)$ & $2(0,3)$ \\
\hline $\mathrm{RD}$ & 3 & $2,4 \mathrm{~g}$ & $(0,1)$ & 208 & 65 & $3(0,8)$ & $2(0,1)$ \\
\hline $\mathrm{R}$ & 3 & $3,2 \mathrm{~cd}$ & $(0,0)$ & 196 & 58 & $2(0,3)$ & $1(0,2)$ \\
\hline $\mathrm{R}$ & 3 & $3,0 \mathrm{de}$ & $(0,2)$ & 190 & 87 & $2(0,2)$ & $1(0,1)$ \\
\hline TT & 23 & $3,4 \mathrm{c}$ & $(0,1)$ & 192 & 68 & $2(0,6)$ & $2(0,1)$ \\
\hline MT1 & 30 & $1,9 \mathrm{i}$ & $(0,0)$ & 216 & 76 & $2(0,2)$ & $1(0,1)$ \\
\hline MT2 & 23 & 2,8 ef & $(0,0)$ & 165 & 77 & $2(0,3)$ & $1(0,0)$ \\
\hline MT3 & 30 & $2,3 \mathrm{gh}$ & $(0,0)$ & 147 & 42 & $1(0,1)$ & $0(0,0)$ \\
\hline MT4 & 30 & $2,6 \mathrm{fg}$ & $(0,1)$ & 140 & 47 & $2(0,2)$ & $0(0,0)$ \\
\hline MT5 & 23 & $2,0 \mathrm{hi}$ & $(0,1)$ & 129 & 55 & $1(0,1)$ & $0(0,0)$ \\
\hline
\end{tabular}

${ }^{1}$ Siglas da coluna uso estão na Tabela 5. ${ }^{~}$ Médias seguidas pela mesma letra, na mesma coluna e na mesma profiundidade, não diferem entre si pelo teste de Tukey a $5 \%$. ${ }^{3}$ Valores entre parênteses referem-se ao desvio padrão. 
Na camada de 0-10 cm, o Pt apresentou uma tendência de maiores conteúdos na cerradão (CE) e nas pastagens renovadas quando comparadas as degradadas, porém com o aumento da profundidade esta tendência diminui e os conteúdos tendem a ser iguais. O Po, não apresentou diferenças. Nas diferentes camadas de solo e tratamentos, o Po variou entre 35 a 56, 20 a 48 e 28 a 47 \% dos conteúdos do Pt nas camadas de 0-10, 10-20 e 20-30 cm, respectivamente.

\subsubsection{Conteúdos de Pr, Ca e Mg}

Os conteúdos de Pr variaram entre 4,7 a 8,9,3,3 a 6,4 e 1,9 a $5,3 \mathrm{mg} \mathrm{kg}^{-1}$ de $\mathrm{P}$ nas camadas 0-10, 10-20 e 20-30 cm, respectivamente. Na camada 0-10 cm, o Pr foi estatisticamente superior no CE e pastagens renovadas quando comparadas as pastagens de manejo tradicional (MTs) (Tabela 6). Dentre as renovadas, algumas apresentaram maior Pr do que outras. Nas camadas 10-20 e 20-30 cm, os resultados de Pr seguiram a mesma tendência, com exceção do tratamento de RD que apresentou resultados sempre baixos, não sendo diferente estatisticamente das MTs. Os conteúdos de Ca e $\mathrm{Mg}$ foram maiores nas amostras renovadas, principalmente naquelas onde foi realizado a calagem (Tabela 5 e 6 ).

\subsubsection{Cinéticas de troca isotópica (CTI) e cálculo do fosfato potencialmente biodisponível}

A relação $\mathrm{R} / \mathrm{r}_{1}$ é a medida da capacidade tampão do $\mathrm{P}$ dos solos a um determinado tempo (Tran et al., 1988; Salcedo et al., 1990; Frossard et al., 1992). Os resultados de $\mathrm{R} / \mathrm{r}_{1}$ mostram que a capacidade tampão é superior a 10 nas amostras estudadas (Tabela 7). A determinação do conteúdo dos íons fosfato na solução do solo permitiu verificar que havia quantidade insuficiente para o crescimento pleno da forrageira, estando no limite de deteç̧ão do método verde malaquita (ppb). Os resultados obtidos variaram entre 0,0004 a $0,0015 \mathrm{mg} \mathrm{L}^{-1}$ e são considerados muito baixos (Tabela 7).

A análise dos compartimentos do Pit pela CTI das camadas 0-10 $\mathrm{cm}$ permitiu verificar que há uma quantidade negligenciável de $\mathrm{P}$ trocável na solução até o tempo de 
1 hora (Tabela 7), porém nos compartimentos $\mathrm{Ep}_{\mathrm{Id}-2 \mathrm{~m}}$ há maiores quantidades disponíveis. Após este compartimento, ocorre uma diminuição no $\mathrm{P}$ trocável até Ep${ }_{6 \mathrm{~m}-\mathrm{la}}$. Até um ano os solos apresentam conteúdos de Pit de $73-123 \mathrm{mg} \mathrm{kg}^{-1}$ de P. Nas amostras coletadas nas camadas de 10-20 e 20-30 cm de profundidade no CE e na MT1, as maiores quantidades de $\mathrm{P}$ trocável estão no compartimento $\mathrm{Ep}_{\mathrm{lmin}_{\mathrm{m}} \mathrm{e}} \mathrm{Ep}_{\mathrm{p}_{\text {min-lh }}}$ (Tabela 7), diminuindo drasticamente após este período.

Os conteúdos de Pr apresentaram coeficiente de correlação de Pearson significativa $(\mathrm{p}<0,05)$ com os compartimentos $E p_{1 d-2 m}, E p_{2 m-6 m}, E p_{6 m-1 a}, E p_{1 d-6 m}, E p_{2 m-1 a}$

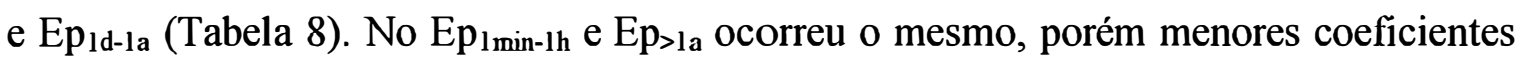
foram observados.

\subsection{Discussão}

Embora as áreas estudadas não foram delineadas para o estudo da biodisponibilidade de $\mathrm{P}$, elas são representativas do sistema pecuário atualmente utilizado.

A biodisponibilidade do $\mathrm{P}$ dos solos tropicais dependem das propriedades que regulam os processos de adsorção e dessorção, tais como a mineralogia do material de origem e textura do solo. A adsorção de fosfato é causada basicamente pelos oxihidróxidos de alumínio e ferro nos latossolos (López-Hernández \& Burnham, 1974; Le Mare, 1982; Frossard et al., 1992; Mesquita Filho \& Torrent, 1993; Fontes \& Weed, 1996). Os valores $R / r_{1}$ determinados (Tabela 7) caracterizam estes solos como altamente fixadores de íons fosfato (Frossard et al., 1994). Estes resultados corroboram com os valores muito baixos de $\mathrm{Cp}$ (Tabela 7), bem inferiores dos níveis aceitáveis, classificando a concentração de P na solução do solo como limitante ao crescimento das plantas.

Os conteúdos de Pr, Pt e Po no solo sob CE estão nos mesmos níveis daqueles encontrados nas pastagens renovadas. As diferenças com os valores das pastagens de MT podem ser explicadas através do $P$ que saiu do sistema via produção animal e perdas por erosão. Por outro lado, a grande capacidade do solo em adsorver o $\mathrm{P}$ da solução não 


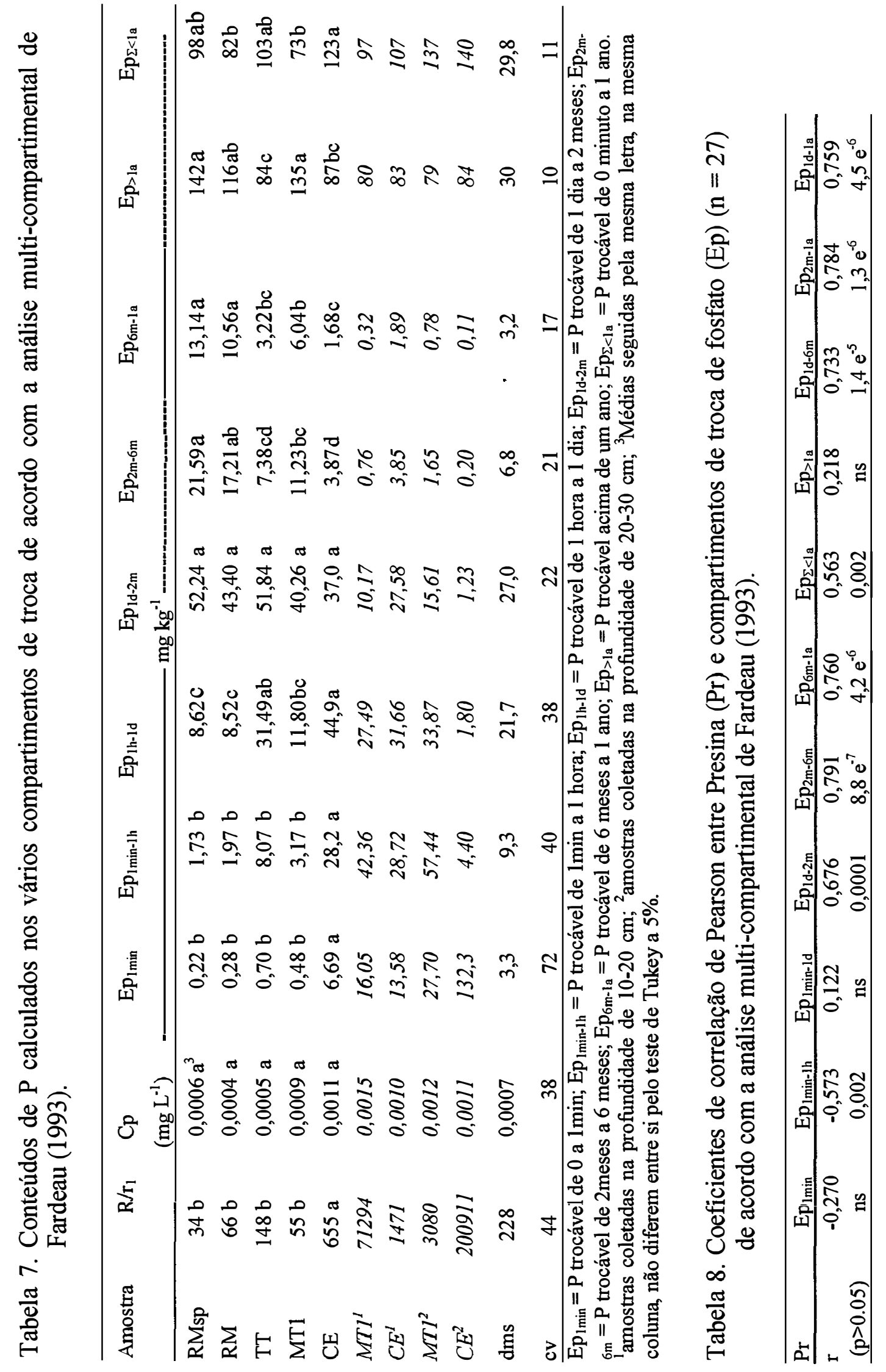


permite um desenvolvimento maior das pastagens nestes sistemas levando estas a um equilíbrio de baixa produtividade, enquanto que o $\mathrm{CE}$ se mantêm num equilíbrio em que grande parte do $\mathrm{P}$ está na biomassa.

Os conteúdos de $\mathrm{Pr}, \mathrm{Ca}$ e $\mathrm{Mg}$ das pastagens de MT e da parcela TT estão abaixo do nível crítico considerado por Vilela et al. (2000), bem como a capacidade de produção de forragem. Todavia, estas parcelas estão com a $\mathrm{BD}$ e $\mathrm{BH}$, espécies diferentes e menos exigentes em fertilidade do solo do que a BB, introduzida na renovação (Vilela et al., 2000). Com a renovação da pastagem, as produções de forragem foram superiores comparadas aos níveis de produção das pastagens de MT. Após 2 anos de implantação do experimento de renovação, os resultados obtidos pelo extrator resina $(\operatorname{Pr})$, nas diferentes profundidades (Tabela 6), são coerentes com a produção de MVS e as quantidades de fertilizantes fosfatados aplicadas na renovação (Tabela 5). A avaliação da MVS 30 dias antes da coleta das amostras de solo (resultados não apresentados), demonstrou que a parcela RM foi 81 e a RA $63 \%$ maiores do que RD.

Ainda persiste a questão quanto a biodisponibilidade potencial de $\mathrm{P}$ do solo, e se este é suficiente ou não para o crescimento da planta forrageira. As correlações obtidas entre Pr e os diferentes compartimentos de Ep trocáveis (Tabela 5), para o período de crescimento da planta, demonstram que o Pr é um bom parâmetro de determinação da biodisponibilidade de P. A Figura 6 apresenta uma estimativa da oferta potencial de $\mathrm{P}$ do solo e da demanda de $\mathrm{P}$ da planta para RM e TT levando-se em conta: i) a produção MVS da forrageira num ciclo anual (média dos dois anos de avaliação do experimento multiplicado por 2 (relação parte aérea:raiz 1:1 (Kanno et al., 1999)) multiplicado pelo conteúdo médio de $\mathrm{P}$ na MVS (Macedo et al., 1993); e, ii) a oferta de $\mathrm{P}$ do solo segundo modelo multi-comportamental na camada de $0-10 \mathrm{~cm}$. Nos primeiros 60 dias, a oferta de $\mathrm{P}$ pelo solo é muito superior a demanda pela planta, tanto para RM como TT. A partir de 80 dias, a demanda de P pela planta no TT é maior que a oferta de $\mathrm{P}$ do solo, enquanto que para a RM a oferta diminui, mas ainda é suficiente para atender as exigências da planta até o final do período estudado (Figura 6). A partir daí, começa uma demanda maior pela planta (início estação chuvosa) onde, tanto para RM como TT 
a oferta de P passa a ser limitante. Entretanto, a oferta de P pelo solo, no período de 320 dias, para RM foi de 78,0 e a demanda foi de $31,1 \mathrm{~kg} \mathrm{ha}^{-1}$ de $\mathrm{P}$, enquanto que para TT a oferta foi de 92,6 e a demanda de $20,5 \mathrm{~kg} \mathrm{ha}^{-1}$ de $\mathrm{P}$, suficientes portanto para a demanda de $\mathrm{P}$ pela planta no período analisado e, por mais 1 a 2 ciclos anuais da forrageira. Estas diferenças são devidas a oferta de $\mathrm{P}$ pelo solo que foram muito superiores a demanda pela planta, nos primeiros 60 dias, desta forma o $\mathrm{P}$ não consumido pela planta continua disponível para a planta no SSS.

Observa-se na Figura 6, que após 80 dias, a adubação inicial da RM foi suficiente para manter uma oferta de $\mathrm{P}$ superior a TT que não foi adubada. Como a produção de forragem é maior na $\mathrm{RM}$, a demanda de $\mathrm{P}$ também será, então a diferença tende a diminuir com o tempo. Dessa maneira, a realização de adubações de manutenção com P para manter os níveis de produtividade da forrageira são essenciais, pois com o tempo a disponibilidade de $\mathrm{P}$ diminui (Euclides et al., 1997).

Entretanto, algumas ponderações são necessárias com referência a algumas análises não realizadas neste experimento, tais como: i) translocação do P na planta; ii) as plantas apresentavam sistema radicular profundo e o solo uma oferta potencial de $\mathrm{P}$ de 1,9 a 6,4 $\mathrm{mg} \mathrm{kg}^{-1}$ (Tabela 6) e a provável presença de micorrizas (Vilela et al., 2001); iii) o importante retorno do P via liteira (Friesen et al., 1997; Rezende et al., 1999) e aproximadamente $80 \%$ do $\mathrm{P}$ consumido pelo animal que retorna pelas fezes dos animais (Petersen et al., 1956 a,b); iv) o Po não ter sido levado em conta no cálculo do modelo, pois ele apresenta uma fração rapidamente mineralizável (Friesen et al., 1997; ChapuisLardy et al., 2002); v) Outros nutrientes podem ter influenciado a queda da produtividade, por exemplo: o $\mathrm{N}$, que neste experimento não foi analisado. 




\subsection{Conclusões}

O objetivo deste trabalho foi avaliar a biodisponibilidade dos íons fosfato do solo em algumas pastagens de baixa produtividade e, em áreas renovadas. Os dados fornecidos pela análise da cinética de troca isotópica mostraram que há fosfato biodisponível no solo suficiente para o desenvolvimento das plantas, mesmo nas pastagens consideradas de baixa produtividade. A biodisponibilidade de $\mathrm{P}$ passa a ser limitante para as pastagens de manejo tradicional decorrido o período de dois meses após a avaliação, o que limita a produção de forragem durante a estação de crescimento. Por outro lado, nas pastagens renovadas avaliadas após 2 anos de implantação dos tratamentos, a biodisponibilidade potencial de P passa a ser limitante a partir do 3 ao 4 ano. No caso de renovação e manutenção de pastagens com gramíneas que demandam um nível de fertilidade alto, pequenas quantidades de fertilizantes fracionadas no tempo podem ser uma alternativa viável. Do ponto de vista prático, fica evidenciado que a extração com resina é o método mais adequado de avaliação do fosfato do solo. Embora esta avaliação tenha sido restrita a solos areno-argilosos duma região do Brasil, os dados obtidos apresentam relevância na medida em que latossolos de textura e mineralogia semelhantes ocorrem em diferentes ambientes tropicais. 


\section{VARIABILIDADE ESPACIAL DO FÓSFORO DO SOLO SOB Brachiaria brizantha DE BAIXA PRODUTIVIDADE ${ }^{1}$}

\section{Resumo}

$\mathrm{O}$ fósforo $(\mathrm{P})$ apresenta-se como um dos principais fatores responsáveis pela baixa produtividade das pastagens na região do Cerrado. Estudou-se a variabilidade espacial do P numa pastagem de Brachiaria brizantha cv. Marandu (BB) de baixa produtividade. O Latossolo Vermelho da área experimental de 29,11 ha vinha sendo cultivado com BB há 10 anos, sem aplicação de fertilizantes. As amostragens foram realizadas em dois momentos distintos: antes e depois da implantação do experimento. Antes da implantação, demarcou-se uma malha sistemática de 10 em 10 metros, com 98 pontos, totalizando 196 amostras (98 entre touceiras e 98 nas touceiras). No mesmo local, coletou-se uma área de $0,5 \mathrm{~m}^{2}$ da forrageira, separou-se as frações da forrageira em matéria verde (MV), matéria seca (MS) e liteira (L) em base de peso seco e determinou-se o teor de $\mathrm{N}$ e P. Após a implantação, foram coletadas amostras nos mesmos 98 pontos anteriormente amostrados e, mais 24 pontos numa malha de $2,5 \mathrm{x}$ $2,5 \mathrm{~m}$ no interior da malha de $10 \times 10 \mathrm{~m}$. A determinação do conteúdo do $\mathrm{P}$ foi realizada pelo método de resina e complementada por análises de cinética de troca isotópica com ${ }^{32} \mathrm{P}$. Análise estatística descritiva e geoestatística foram utilizadas para descrição da variabilidade espacial. Os resultados obtidos de $\mathrm{P}$ nas amostras entre as touceiras apresentaram médias e medianas menores do que as sob touceiras, aproximadamente 45 \%. Embora os valores mínimos sejam praticamente iguais, os valores máximos são 4 vezes superiores sob touceiras, demonstrando maior variabilidade. Esta maior variação

\footnotetext{
${ }^{1}$ A ser submetido em março de 2002.
} 
provavelmente está relacionada a maior concentração do sistema radicular da $\mathrm{BR}$ e matéria orgânica nestas amostras. A variabilidade espacial do $\mathrm{P}$ neste latossolo vermelho é alta e tem uma dinâmica relacionada a estrutura da comunidade das touceiras da forrageira. A análise variabilidade espacial do $\mathrm{P}$ mediante o estudo geoestatístico, revelou que essa variável não apresentou dependência espacial para uma amostragem regular de de 10 metros. Verificada a independência espacial de $\mathrm{P}$, os resultados da análise descritiva podem ser utilizados na tomada de decisão, com cuidados especiais na representatividade das recomendações no manejo de fertilizantes fosfatados na área. Ficou demonstrado a necessidade de se conhecer a variabilidade do $P$ antes da implantação de experimentos, para uma melhor definição metodológica de amostragem e aplicação de $P$.

Palavras chaves: Brachiaria brizantha, $P$ resina, fertilização, biomassa de $P$, cinéticas

\section{PHOSPHATE SPATIAL VARIABILITY UNDER BRACHIARIA LOW PRODUCTIVITY PASTURE (CERRADO, BRAZIL)}

\section{Summary}

The phosphorus is one of main factors responsible for low productivity pastures in Cerrado regions (Brazilian Savannah). Spatial variability of soil phosphorus under low productivity pasture of Brachiaria brizantha cv. Marandu (BB) was studied in 29.11 ha experimental area. The soil, dark red latosol, had been grown with BB for 10 years, without fertilizer application. The soil sampling were done twice: before and after experiment establishment. A grid of 10 to $10 \mathrm{~m}$, with a regular grid of 98 sampling points, total of 196 (98 among clump roots and 98 within the clump root) were marked at the beginning for soil sampling. In the same place, forage plants were collected from an area of $0.5 \mathrm{~m}^{2}$, proceeded by fractions of green matter (GM), dry matter (DM) and litter (L) was determined based on dry weight and $\mathrm{N}$ and $\mathrm{P}$ content determination. After establishment of the experiment, samples were taken from 98 marked points plus 24 
other points in a regular grid of 2.5 to $2.5 \mathrm{~m}$ inside the grid of 10 to $10 \mathrm{~m}$. The available P was determined by resin method and was complemented by isotopic exchange kinetic. The statistical analysis and geostatistic were utilized for the description of variability. The $\mathrm{P}$ contents in the samples among clump roots presented the mean and median smaller than of clump root, approximately $45 \%$. Although the minimum values are practically equals, the maximum values are 4 times in the clump root, showing higher variability. The higher variation is probably related to greater concentration of BR root system and organic matter in the samples. The spatial variability of $\mathrm{P}$ in this soil is high and there is a dynamic related to the structure of forage clump root community. As there was no spatial dependence for the distance greater than $10 \mathrm{~m}$, by the geostatistical analysis, the data were considered independent. Therefore, the samples may be collected randomized. The variability of $\mathrm{P}$ should be know before the establishment of the experiments to define the most adequate sampling methodology.

Key-words: Brachiaria brizantha, resin extractable $\mathrm{P}$, fertilization, biomass $\mathrm{P}$, isotopic exchange kinetic

\subsection{Introdução}

Na Região do Cerrado existem 49,5 milhões de ha de pastagens cultivadas (Sano et al., 2000), sendo que aproximadamente $80 \%$ apresentam baixa produtividade (Klutouski et al., 1999). Dentre as causas são citadas o manejo inadequado da pastagem, especialmente o sobrepastejo e a não realização de fertilizações de manutenção. A diminuição de áreas de vegetação natural para abertura e implantação de pastagens e, em contrapartida, a pressão crescente para conservação dos recursos naturais não renováveis e o desenvolvimento de tecnologias para melhor exploração das áreas que já vinham sendo cultivadas com pastagens, têm contribuído para o crescente interesse sob as pastagens cultivadas. Segundo Lopes (1997), deve-se dar prioridade à implementação de diretrizes de manejo sustentável que permitam a recuperação de áreas em fase inicial 
de degradação ou já degradada, ao invés de incentivar a simples expansão da fronteira agro-silvi-pastoril nos modelos da ocupação ocorridos até hoje.

A implementação da recuperação e/ou renovação de pastagens cultivadas prevêem o conhecimento da fertilidade do solo através da realização de análises do solo. $\mathrm{O}$ maior interesse normalmente refere-se aos conteúdos de $\mathrm{P}$ destes solos, já que é o nutriente dos mais limitantes para produção da forrageira e a sua utilização implica em custos elevados. Embora seja considerado que a variabilidade do $\mathrm{P}$ seja baixa e que não há necessidade do conhecimento dela, pois não vai fazer nenhuma diferença na estratégia de recuperação/renovação da pastagem. A variabilidade dos conteúdos de $\mathrm{P}$ nestas pastagens pode ser elevada, dependendo do manejo dado antes da amostragem do solo. A substituição da vegetação natural pela planta forrageira, o preparo do solo, a correção da acidez do solo e fertilização com P por ocasião da implantação da pastagem, são algumas práticas de manejo que influenciam na variabilidade do fosfato do solo. Por outro lado, o retorno irregular das fezes e urina (espacial e temporal) para a pastagem (Petersen et al., 1956a,b) combinado com o reduzido revolvimento e cultivo do solo comparado a solos cultivados anualmente, cria um potencial para um desenvolvimento considerável da heterogeneidade do solo com respeito a concentração de nutrientes (Fisher et al., 1998).

O suprimento heterogêneo de nutrientes no solo tem como conseqüência o crescimento das plantas em escalas variadas. Dentro do espaço de um sistema radicular definido, a proliferação de raízes e o aumento da taxa de absorção de $\mathrm{P}$ ocorre em resposta a sítios enriquecidos pelo suprimento de $\mathrm{P}$ (Jackson et al., 1990). Na escala de campo, a heterogeneidade do solo contribui para a coexistência de espécies nas pastagens, pelo intermédio de uma variedade de diferentes nichos onde espécies individualmente competem com maior sucesso (Reynolds et al., .1997). Também na escala de campo, a heterogeneidade do solo per se é considerada por favorecer localmente comunidades de plantas comparadas com plantas isoladamente (Birch \& Hutchings, 1994). Em escala superior de sistemas radiculares individuais, o P trocável do solo relaciona-se com a distribuição de muitas plantas (Tyler et al., 1996). 
O conhecimento da variabilidade espacial do fosfato em solos sob pastagens é fundamental para o estabelecimento de estratégias adequadas de recuperação e/ou renovação. Alguns autores relatam os níveis baixíssimos de fosfato nos solos sob pastagens de baixa produtividade (Oberson et al. 1999, cap. 3). Entretanto, estes resultados são de amostras compostas coletadas nestas pastagens e não de levantamentos sistemáticos para verificação da variabilidade de fosfato e outros parâmetros físico-químico dos solos.

Analisando-se a literatura sobre o assunto, verifica-se que faltam dados de campo sobre fosfato do solo sob pastagens consideradas degradadas ou de baixa produtividade na Região do Cerrado. Assim busca-se neste trabalho avaliar a variabilidade espacial do fósforo do solo numa pastagem de Brachiaria brizantha cv. Marandu (BB) de baixa produtividade visando conhecer a distribuição dos conteúdos de fosfato do solo e as possíveis relações com a nutrição da comunidade de plantas.

\subsection{Material e Métodos}

O presente trabalho foi realizado numa área experimental de 29,11 ha da Fazenda Rio de Janeiro, Planaltina-GO, $15^{\circ} \mathrm{S} 14^{\prime}$ e $47^{\circ} \mathrm{W} 42^{\prime}, 826 \mathrm{~m}$ de altitude. Esta área foi escolhida para a implantação de um experimento de recuperação de pastagens com a introdução de Stylosanthes guianensis cv. Mineirão (SG) e de duas fontes de P, o superfosfato triplo (SFT) e o fosfato reativo de gafsa (FRG). O solo é um latossolo vermelho (Tabela 9). A BB introduzida no ano de 1990, após o desmatamento da vegetação nativa apresentou baixos níveis de produtividade. A capacidade de suporte da $\mathrm{BB}$, durante a estação chuvosa, era inferior a 1 unidade animal (UA) ha ${ }^{-1}(\mathrm{UA}=450 \mathrm{~kg}$ de peso vivo). O pequeno ganho de peso na estação de chuvas e as perdas de peso na estação seca caracterizaram a baixa capacidade de produção por animal e por hectare desta pastagem.

Antes da implantação do experimento foi realizado o levantamento planialtimétrico, a localização espacial de árvores, leiras e demarcação das cercas. A área foi subdividida em seis parcelas de 4,9 ha, sendo que cada uma representa um tratamento, 
após este foi subdividido em quatro piquetes (R1, R2, R3, R4 - Figura 7a). O proprietário havia aplicado superficialmente $3 \mathrm{tha}^{-1}$ de calcário dolomítico em todas as parcelas (inclusive na testemunha).

Tabela 9. Caracterização da camada $0-10 \mathrm{~cm}$ do Latossolo Vermelho da área experimental.

\begin{tabular}{ccccccc}
\hline Argila & $\mathrm{pH} \mathrm{H}_{2} \mathrm{O}$ & Fósforo $^{(1)}$ & $\mathrm{MO}^{(2)}$ & $\mathrm{S}^{(2)}$ & $\mathrm{CTC}^{(2)}$ & $\mathrm{V}^{(2)}$ \\
\hline$--\mathrm{g} \mathrm{kg}^{-1}-$ & $(1: 2,5)$ & $--\mathrm{mg} \mathrm{L}^{-1}--$ & $--\mathrm{g} \mathrm{kg}^{-1}---$ & ---- mmol $_{\mathrm{c}} \mathrm{kg}^{-1}$ & ---- & $---\%$ \\
800 & 5,9 & 0,3 & 28 & 46 & 92 & 50
\end{tabular}

(I) Extrator mehlich; ${ }^{(2)} \mathrm{MO}=$ matéria orgânica, $\mathrm{S}=$ soma de bases, $\mathrm{CTC}=$ capacidade de troca catiônica, $\mathrm{V}=$ saturação por bases.

As amostras simples de solo foram coletadas em dois momentos distintos, antes e depois da implantação do experimento. Antes da implantação do experimento, no período de setembro a outubro de 1998, as amostras de solo foram coletadas com dois objetivos distintos: a) Foram demarcadas linhas nas divisões dos tratamentos (Figura 7a), no sentido W-E, num total de cinco, e coletadas amostras nas profundidades de 0-10, 10-20 e 20-30 cm numa distância entre os pontos de $40 \mathrm{~m}$, perfazendo 54 pontos de amostragem. b) Após um sorteio por probabilidade do tratamento seis (T6), realizou-se o mesmo sorteio para a escolha do piquete (R2) a ser realizado as amostragens, esta área foi locada com $70 \mathrm{~m}$ no sentido S-N e $140 \mathrm{~m}$ no sentido W-E e estaqueada de 10 em 10 metros, com 98 pontos de amostragens, totalizando uma área de $9.800 \mathrm{~m}^{2}$, conforme a Figura $7 \mathrm{~b}$. O sentido ascendente da pendente está no sentido da coordenada y de 0 para $130 \mathrm{~m}$, com $\pm 5 \%$ de declividade. $\mathrm{Na}$ linha marcada, há uma leira que foi construída pelo amontoamento dos restos da vegetação no momento do desmate e posterior queima. Nos 98 pontos, as amostras de solo foram coletadas na camada superficial de $0-10 \mathrm{~cm}$ de profundidade de duas maneiras: i) entre touceiras, e ii) sob touceira. No mesmo local, coletou-se uma área de $0,5 \mathrm{~m}^{2}$ da forrageira cortando-se rente ao solo, procedeu-se a separação botânica e das frações da forrageira em matéria verde (MV), matéria seca (MS) e liteira (L) em base de 
peso seco e determinou-se o teor de $\mathrm{N}$ e $\mathrm{P}$ em amostras compostas de cada linha da coordenada y, com exceção das amostras da leira.



Figura 7 - a) Croqui da área experimental com os tratamentos e respectivas subdivisões dos piquetes. b) Distribuição espacial dos 98 pontos de amostragens na área experimental. Escolhida aleatoriamente no T6 R2. 
Em fevereiro de 1999, realizou-se a implantação do experimento, com a aplicação de $40 \mathrm{~kg} \mathrm{ha}^{-1}$ de $\mathrm{P}$ na forma de superfosfato triplo a lanço e a sua incorporação com grade pesada a $\pm 10 \mathrm{~cm}$ de profundidade, após realizou-se a semeadura de Stylosanthes guianensis cv. Mineirão para o estabelecimento da pastagem consorciada com BB. Em setembro de 1999, foram coletadas amostras nos mesmos 98 pontos anteriormente amostrados e, mais 24 pontos numa malha de $2,5 \times 2,5$ m demarcados com cruzinhas (Figura 7b).

O fósforo disponível (P) foi medido através do método de resina (Raij et al., 1986) e por colorimetria. As determinações dos teores totais dos elementos na planta foram realizadas por espectrofotometria a $420 \mathrm{~nm}$ depois da oxidação com ácido nítrico /perclórico (2:1) e adição de uma solução de molibdato de amônio + metavanadato de amônio (1:1) (Adler \& Wilcox, 1985).

As análises de cinética de troca isotópica (CTI) foram conduzidas no sistema solo-solução (SSS) após as amostras atingirem o equilíbrio numa relação solo-solução 1:10 (Salcedo et al. 1990; Fardeau et al. 1991; Frossard et al., 1994). Para compor o sistema foram utilizados $10 \mathrm{~g}$ de solo, tamisados a $2 \mathrm{~mm}$ e $99 \mathrm{~mL}$ de água desionizada em um recipiente de plástico com capacidade de $250 \mathrm{~mL}$. As amostras foram agitadas durante 16 horas. A seguir, as amostras foram postas a agitar suavemente em um agitador magnético e, adicionou-se ao tempo zero $(\mathrm{t}=0), 1 \mathrm{~mL}$ de solução contendo o radioisótopo ${ }^{32} \mathrm{P}$ livre de carregador. As atividades utilizadas foram de aproximadamente $1 \mathrm{MBq} \mathrm{mL} L^{-1}$. Após $\mathrm{t}_{1}=1, \mathrm{t}_{2}=3, \mathrm{t}_{3}=10 \mathrm{e}_{4}=15 \mathrm{~min}$, tomou-se uma alíquota de $\pm 8 \mathrm{~mL}$ da suspensão com uma seringa de plástico, que foi imediatamente acoplada a uma unidade de porta filtro de pressão com um filtro de membrana de 0,05 $\mu \mathrm{m}$. A suspensão foi filtrada em \pm 10 segundos e desta foi utilizada uma alíquota de $0,25 \mu \mathrm{L}$, retirada com uma micropipeta, completando-se o volume a $20 \mathrm{~mL}$ para posterior determinação das contagens do ${ }^{32} \mathrm{P}$ pelo efeito Cerenkov no contador de cintilação líquida Wallac 1409. Ao final, foram utilizadas seringas de $60 \mathrm{~mL}$ para obter maior quantidade de solução para determinação da concentração de fosfato (Cp) presente na solução do solo por colorimetria pelo método do verde malaquita (Rao et al., 1997). A concentração dos íons fosfato da solução filtrada, foi realizada com peças de 3 
x $2 \mathrm{~cm}$ de resina aniônica tipo membrana, marca BDH15 1TD, como realizado por Salcedo et al., (1990). Nas nossas condições de análises de laboratório, os valores obtidos da concentração de fosfato na solução do solo de uma amostra padrão apresentaram coeficiente de variação de $1,23 \%$ com 3 repetições.

Foram utilizados dois procedimentos de análise estatística. O primeiro sendo uma análise descritiva geral dos resultados e correlações entre $\mathrm{P}$ do solo e variáveis da planta, sendo utilizado o "software" Statistica for Windows Statsoft (1996). O segundo, correspondeu a um estudo variográfico com finalidade de verificação da continuidade espacial das variáveis estudadas. Este estudo foi precedido por uma análise exploratória dos dados incluindo o refinamento pela mediana (Hamlett et al., 1986) para remoção do efeito variação de larga escala (tendência) da variável $\mathrm{P}$ na área experimental. A tendência verificada, negou a estacionaridade intrínseca, que é condição necessária em qualquer estudo geoestatístico. Os semavariogramas para analisar a dependência espacial entre os pontos de amostragem foram obtidos utilizando-se o "software" Variowin 2.2 (Pannatier, 1996).

\subsection{Resultados e Discussão}

Na Figura 8 são apresentados a mediana, o quartil e o valor mínimo e máximo das amostras das divisórias e isoladamente em cada profundidade (0-10, 10-20 e 20-30 $\mathrm{cm}$ ). Os conteúdos de $\operatorname{Pr}$ ficaram entre 1 e $9 \mathrm{mg} \mathrm{kg}^{-1}$, valor mínimo e máximo, respectivamente. A maior amplitude foi encontrada na profundidade $0-10 \mathrm{~cm}$. Os conteúdos de Pr apresentaram diminuição com a profundidade o que era esperado, porém está não foi brusca. As amostras na profundidade $20-30 \mathrm{~cm}$ apresentaram menor variabilidade espacial com uma distribuição muito próxima da normalidade. O estudo de dependência espacial revelou a não existência de continuidade espacial para as 54 amostras das divisórias espaçadas em 40m.

A elaboração de semivariogramas para o $\operatorname{Pr}$ de amostras de solo entre touceiras e após fertilização (malha 10m), mostraram não haver estrutura de variação no espaço. Quando se analisaram os mesmos dados, descartando-se as amostras localizadas na 
linha da leira (Figura 9) com valores superiores em média aos outros pontos, também foi verificada a independência espacial. Entretanto, para as amostras coletadas sob touceira foi observada uma tendência de diminuição dos valores de $\mathrm{P}$ no sentido ascendente da pendente (Figura 9a). Não temos argumentos para explicar está distribuição.

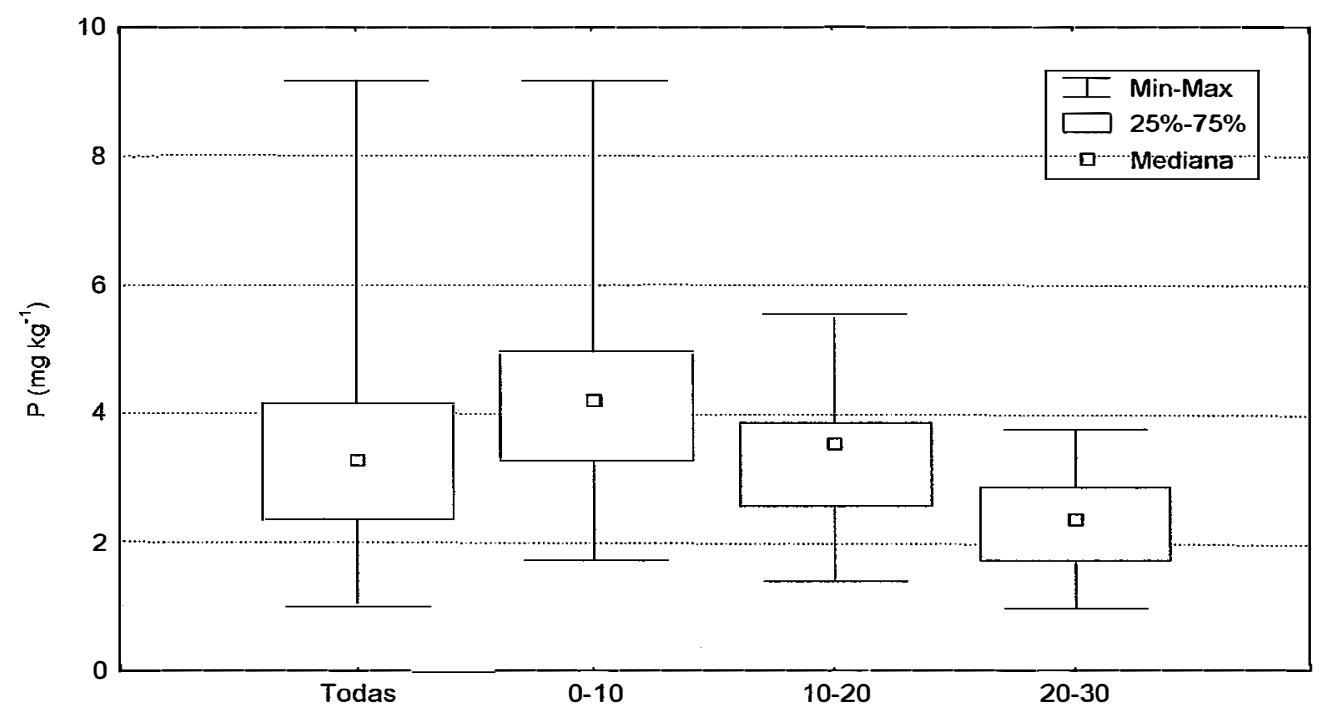

Figura 8 - "Box-plots" dos conteúdos de $\mathrm{P}$ avaliado pelo método de resina nas divisórias dos tratamentos.
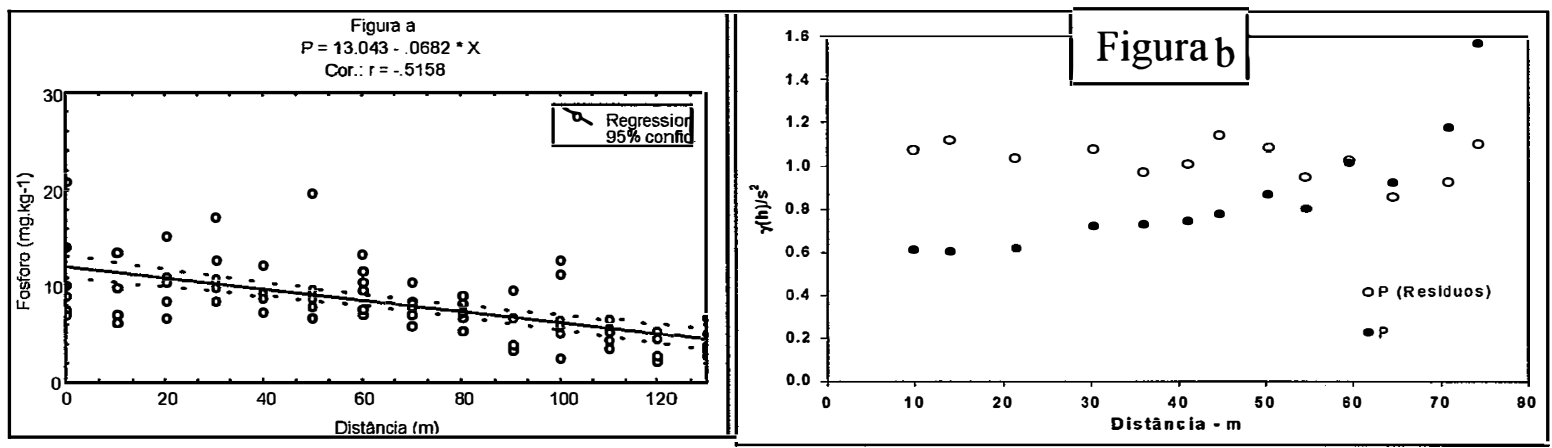

Figura 9 - Correlação do fósforo (Pr) com a pendente (a) e semivariogramas escalonados dos dados originais e resíduos (b) para o Pr sob touceira. 
O semivariograma dos resíduos do refinamento (Figura 9b) para Pr sob touceira, indica que a variável não apresenta estrutura de dependência espacial (efeito pepita puro). A tendência de crescimento nos teores de Pr com o aumento da pendente, verificada nos dados originais, comportamento linear falso do semivariograma, foi removida eficientemente com o refinamento por meio da mediana. No total, não há dependência espacial para a distância amostrada (malha sistemática $10 \times 10 \mathrm{~m}$ ) das variáveis Pr do solo entre touceiras, sob touceira e após fertilização. A amostragem realizada não foi suficiente para deteç̧ão da dependência espacial.

Comparando-se o Pr entre touceiras e sob touceira verifica-se duas situações distintas (Figura 10a): As amostras entre touceiras apresentaram média e mediana menor daquelas sob touceira, aproximadamente $45 \%$ inferiores. Embora os valores mínimos sejam praticamente iguais, o máximo foi aproximadamente 4 vezes maior sob touceira (Figura 10a), demonstrando uma maior variação dos dados (amplitude, variância e desvio padrão), no mínimo o dobro dos valores das amostras entre touceiras. Esta maior variação esta provavelmente relacionada a maior concentração do sistema radicular da planta nestas amostras. A observação de perfis do solo na área experimental, mostrou menor distribuição de raízes entre as touceiras, mesmo quando as condições de solo sob as touceiras apresentavam propriedades físicas que limitavam mais o desenvolvimento do sistema radicular.


Figura 10 - "Box-plot" dos conteúdos de fósforo (Pr) antes da fertilização (a) entre touceiras, na touceira e apos fertilização (b) em duas malhas de amostragem. 
As determinações de Pr após a aplicação do fertilizante foram superiores 6 vezes na mediana $\left(26,5 \mathrm{mg} \mathrm{kg}^{-1}\right)$ e 10 vezes na média $\left(47,4 \mathrm{mg} \mathrm{kg}^{-1}\right)$ comparados ao $\mathrm{Pr}$ entre touceiras (Figura 10b). A variabilidade aumentou significativamente. Os valores mínimos de $\operatorname{Pr}$ estão próximos daqueles anteriores à aplicação de fertilizantes, demonstrando que nestes locais não ocorreu a fertilização. Os valores máximos estão muito acima do esperado ocorrendo em algumas regiões onde foram aplicados em excesso. Em algumas amostras de solo por ocasião do preparo delas encontrou-se grãos de adubo ainda não dissolvidos. Os resultados da amostragem em malha de 2,5 m (Figura 10b) são inferiores na mediana $\left(15,8 \mathrm{mg} \mathrm{kg}^{-1}\right)$ e média $\left(19,7 \mathrm{mg} \mathrm{kg}^{-1}\right)$ comparado à amostragem em malha de $10 \mathrm{~m}$. Refletindo uma condição pontual que pode ter sido influenciada por uma aplicação desuniforme do P na área experimental, que também favoreceu a uma maior variabilidade da amostragem de toda área representada pela malha de $10 \mathrm{~m}$. Refletindo, também, a não estacionaridade da média em função da tendência verificada anteriomente, na qual ocorre a diminuição dos valores de Pr sob touceira no sentido ascendente da pendente.

A construção de uma matriz de correlação para avaliar as relações entre o Pr no solo e o P na planta indicaram não haver correlação significativa do Pr entre touceiras e o P na MV, MS e L (Figura 11a). Entretanto, foram encontradas correlações significativas entre o Pr sob touceiras e o P na planta (Figura 11b), com $r=0,76$ da regressão linear. Estes resultados confirmaram uma exploração do solo diferenciada entre touceiras e na touceira, provavelmente ligado a distribuição heterogênea do sistema radicular da BB como foi observado nos perfis do solo. A proliferação das raízes e o aumento de $\mathrm{P}$ absorvido pela forrageira ocorre em resposta a microlocais enriquecidos em oferta de P (Jackson et al., 1990). Neste trabalho, o sistema plantatouceira de nove anos tem contribuído no aumento da oferta de $\mathrm{P}$ que pode ser explicada pela reciclagem via liteira. A avaliação da MS e L após um período de diferimento da pastagem de \pm 1 ano representou $1,5 \mathrm{~kg} \mathrm{ha}^{-1}$ de $\mathrm{P}( \pm 0,5)$.

A capacidade tampão de $\mathrm{P}$ do solo $\left(\mathrm{R} / \mathrm{r}_{1}\right)$ entre touceiras foi maior do que no cerrado, na leira e sob touceira (Tabela 10). Corroborando com os resultados de $\mathrm{Pr}$ obtidos na Figura 12. Estes resultados demonstram que há diferenças de 
biodisponibilidade de $\mathrm{P}$ entre touceira e sob touceira nesta pastagem de baixa produtividade. Resultados semelhantes foram obtidos por Fisher et al. (1997) e Cross \& Schlesinger (2001). A matéria orgânica deve estar contribuindo para estes resultados (Mesquita Filho \& Torrent, 1993; McDowell \& Sharpley, 2001) e possivelmente a ciclagem da liteira.


Figura 11 - Correlações entre o fósforo (Pr) entre touceiras (a) e na touceira (b) com o P na MV da forrageira.

Tabela 10. Resultados do poder tampão do solo $\left(\mathrm{R} / \mathrm{r}_{1}\right)$, concentração de íons fosfato na solução do solo (Cp), declividade da reta (n), P-total (Pt) e P-orgânico (Po) de amostra composta por tratamento.

\begin{tabular}{|c|c|c|c|c|c|}
\hline Tratamento & $\mathrm{R} / \mathrm{r}_{1}$ & $\mathrm{Cp}$ & $\mathrm{n}$ & $\mathrm{Pt}$ & Po \\
\hline & & $\mathrm{mg} \mathrm{L}^{-1}$ & & -1-- & $1--$ \\
\hline cerrado & 3070 & 0,0014 & 0,353 & 279 & 130 \\
\hline $\mathrm{dp}^{1}$ & $(1002)$ & $(0,0003)$ & $(0,014)$ & (24) & (55) \\
\hline entre touceiras & 6980 & $\mathrm{na}^{2}$ & 0,718 & 376 & 201 \\
\hline $\mathrm{dp}$ & (1208) & & $(0,009)$ & $(12)$ & (5) \\
\hline leira & 2401 & na & 0,591 & 409 & 280 \\
\hline $\mathrm{dp}$ & $(681)$ & & $(0,076)$ & $(37)$ & (34) \\
\hline sob touceira & 454 & 0,0030 & 0,422 & 491 & 206 \\
\hline $\mathrm{dp}$ & $(150)$ & $(0,0023)$ & $(0,047)$ & $(36)$ & $(81)$ \\
\hline
\end{tabular}

$\mathrm{dp}=$ desvio padrão, resultados entre parênteses nas linhas; ' ${ }^{2}$ na $=$ não analisado. 
Assim, se a amostragem fosse realizada sob touceira, a biodisponibilidade de $\mathrm{P}$ não seria limitante ao desenvolvimento da pastagem, enquanto que entre touceiras seria limitante pela metodologia da resina (Vilela et al., 2000). Na condução de experimento nesta mesma área e em casa de vegetação (cap. 6) com o solo da área, houve resposta a fertilização com fosfatos. Contudo, há diferenças que denotam a necessidade de pesquisas futuras para o melhor entendimento da dinâmica (ciclagem de P) dentro do sistema de uma pastagem de baixa produtividade no âmbito de touceiras e entre touceiras numa comunidade de plantas que podem elucidar alguns aspectos ainda não conhecidos da ciclagem de $\mathrm{P}$.

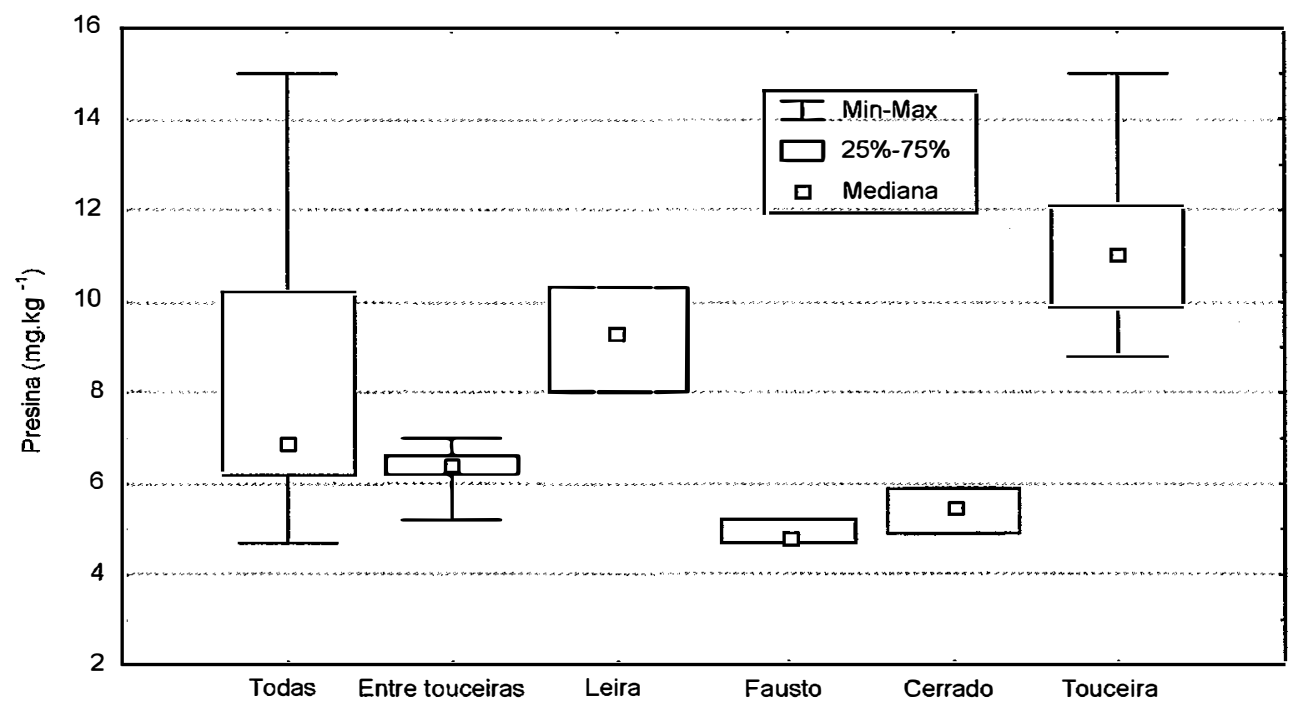

Figura 12 - "Box-plot" para P-resina (Pr) nas amostras compostas coletadas antes da implantação do experimento e de áreas adjacentes do cerrado e da fazenda vizinha (Fausto).

\subsection{Conclusões}

O pequeno número de levantamentos sistemáticos para analisar a variabilidade da biodisponibilidade de $\mathrm{P}$ em solos sob pastagens cultivadas na Região do Cerrado parte de uma pressuposição de que os níveis de $\mathrm{P}$ são baixos e por isso a variabilidade também é baixa. Entretanto, o levantamento realizado demonstrou que dependendo do 
método de coleta e da aplicação de fertilizantes a variabilidade é alta. Por outro lado, por meio da elaboração de semivariogramas não se observou dependência espacial para a malha amostrada de $10 \mathrm{~m}$.

A variabilidade da biodisponibilidade do $\mathrm{P}$ neste solo está diretamente relacionada com a estrutura das unidades de touceira da forrageira. Os resultados da cinética de troca isotópica suportam esta afirmação, pelas grandes diferenças no poder tampão do solo das amostras entre touceiras e na touceira. Neste sentido, a relação Presina e P-planta indicou uma modificação do funcionamento do solo que ressalta a necessidade de investigar as reciclagens do $\mathrm{P}$ por unidades de touceira da forrageira em pastagens de baixa produtividade.

A relação linear P-planta $=\mathrm{f}($ Pr-solo $)$ indica que a Brachiaria brizantha, nesta condição de baixa produtividade, encontra-se com demanda superior de $\mathrm{P}$ da oferta do solo. Estes resultados foram confirmados no experimento realizado em casa de vegetação (cap. 6), onde a testemunha praticamente não apresentou nenhum crescimento após o transplante. 


\section{UTILIZAÇÃO DO FÓSFORO DE FOSFATO NATURAL E SUPERFOSFATO POR Brachiaria brizantha E Stylosanthes guyanensis ${ }^{1}$}

\section{Resumo}

A maior limitação da produção de forragem nos solos ácidos do Cerrado é a baixa disponibilidade de fósforo. Um experimento em casa de vegetação foi conduzido para determinar as diferenças na absorção e utilização do $\mathrm{P}$ do solo e de diferentes fontes pela leguminosa (Stylosanthes guianenses cv. Mineirão (SG)), uma gramínea (Brachiaria brizantha cv. Marandu (BB)) e o consórcio delas. Realizou-se também um experimento de incubação com o mesmo solo e dose de adubo durante 360 dias para complementar o estudo. Utilizou-se a dose correspondente de $180 \mathrm{~kg} \mathrm{de} \mathrm{P}_{2} \mathrm{O}_{5} \mathrm{ha}^{-1}$ de superfosfato triplo (SFT), fosfato reativo de gafsa (FRG) e a mistura destes (MIS). Após 63 dias de cultivo, as plantas foram colhidas e determinou-se a produção de matéria seca e o conteúdo de P. No solo, foram avaliados o conteúdo de P-resina (Pr), P-total (Pt), Porgânico (Po) e a colonização radicular por fungos micorrízicos arbusculares (FMA). O SG cultivado no consórcio produziu menos matéria seca do que quando cultivado em monocultivo, enquanto que o $\mathrm{BB}$ manteve as produtividades. Os conteúdos de $\mathrm{P}$ na planta foram estatisticamente superiores no SG em monocultivo, independentemente da fonte de P utilizada. No experimento de incubação, o conteúdo de Pr do tratamento SFT apresentou a tendência de ser superior ao FRG.

Palavras chaves: Brachiaria sp., Stylosanthes sp., consórcio, fosfatos, latossolo, Cerrado

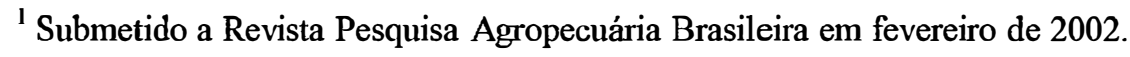


UTILIZATION OF PHOSPHATE-ROCK AND TRIPLE SUPERPHOSPHATE PHOSPHORUS BY Brachiaria brizantha AND Stylosanthes guyanensis

\section{Summary}

The most limiting factor for forage production in acid cerrado soils of Brazil is the low phosphate bioavailability. A greenhouse experiment was carried out to determine the difference in absorption and utilization of $\mathrm{P}$ from the soil and different sources by a legume (Stylosanthes guianenses cv. Mineirão (SG)), a graminae (Brachiaria brizantha cv. Marandu (BB)), and association of these crops. Triple superphosphate (TSP), gafsa rock phosphate (GRP) and TSP+GRP mixture, at rate correspondent to $180 \mathrm{~kg} \mathrm{P}_{2} \mathrm{O}_{5} \mathrm{ha}^{-1}$, were utilized. An incubation experiment with the same soil and fertilizer rate was also carried out to obtain complement the study. The plants were harvested at 63 days growth and, after weighing for dry matter determination, were analyzed for $\mathrm{P}$ content. The soils from the pots were analyzed for: available $\mathrm{P}$ (resin extractable), total $\mathrm{P}$, organic $\mathrm{P}$ and root colonization by arbuscularmycorrhizal fungi (AMF). The $\mathrm{P}$ uptake was greater in $\mathrm{SG}$ than in $\mathrm{BB}$ and in the association of these two forages. The SG grown in association produced less dry matter than when grown alone, while the $\mathrm{BB}$ maintained the productivities. The plant $\mathrm{P}$ contents were statistically higher in SG as monoculture irrespective to P source utilized. In the incubation experiment, the TSP phosphate bioavailability showed a tendency of higher values than the GRP.

Key words: Brachiaria sp., Stylosanthes sp., crop association, fertilizer, ferralsol, savannah

\subsection{Introdução}

Em pastagens cultivadas a produção animal pode ser significativamente aumentada através da implantação de leguminosa em associação com as gramíneas, 
gerando $\mathrm{N}$ pela fixação e a produção de forragem altamente nutritiva (Ayarza et al., 1999; Thomas \& Andrade, 1984; Lascano, 1991). Entretanto, o desafio no manejo do consórcio de gramíneas e leguminosas é manter um adequado balanço dos componentes ao longo do tempo. Entre os diversos fatores que interferem no balanço, a biodisponibilidade do $\mathrm{P}$ do solo é um dos mais importantes determinadores da produção, composição botânica e composição química de pastagens (Coates et al., 1990). Contudo as gramíneas tropicais são agressivas e produzem um sistema radicular abundante que compete com a leguminosa associada pela aquisição de nutrientes e água (Rao et al., 1999a).

Rao et al. (1996) demonstraram que as respostas da gramínea (Brachiaria dictyonera) e das leguminosas (Stylosanthes capitata, Arachis pintoi (AP) e Centrosema acutifolium) variaram significativamente em função dos fertilizantes fosfatados em solos ácidos. A resposta da gramínea ao suprimento de $\mathrm{P}$ foi maior do que a das leguminosas em termos da produção da parte aérea e biomassa de raízes tanto em monocultivo quanto no consórcio. Após, este incremento na resposta para o suprimento de $\mathrm{P}$ na gramínea foi associado com a maior eficiência (definida como "gramas de forragem produzida por gramas do total de P absorvida") (Rao et al., 1997). No entanto, a eficiência de absorção de $\mathrm{P}$ (definido como "miligramas de $\mathrm{P}$ absorvido na biomassa de raízes por unidade de comprimento de raiz") foi muitas vezes superior no AP (leguminosa) do que na gramínea (Rao et al., 1999b).

Numa seqüência de estudos em casa de vegetação, Rao et al. (1999a, 1999b), demonstraram que o consórcio do AP com Brachiaria dictyoneura pode aumentar a absorção total de $\mathrm{P}$ de solos ácidos de baixa fertilidade. Pelo menos três atributos da leguminosa são dados como importantes para sua eficiência na absorção de $\mathrm{P}$ de solos ácidos. Estes incluem: i) uma alta capacidade de estocar P inorgânico; ii) uma relação favorável da absorção de $\mathrm{P}$ por unidade de comprimento de raiz; iii) uma alta atividade da fosfatase ácida na raiz e a capacidade do uso de $\mathrm{P}$ de fontes orgânicas. Estes atributos da planta podem formar um autocontrole do sistema de aquisição de P do AP para solos ácidos pobres em $\mathrm{P}$. 
Embora seja tecnicamente indiscutível a necessidade de adubação fosfatada na recuperação ou renovação de pastagens, na maioria dos solos na Região do Cerrado, sua adoção esbarra no problema da baixa lucratividade de sistemas de pecuária extensiva, ainda predominantes nesta região. Os fosfatos naturais reativos (FNR) importados, com preços mais competitivos (preços da unidade de P total colocada na propriedade) em relação aos fosfatos solúveis, podem ser uma alternativa. Alguns resultados obtidos da utilização de FNRs na recuperação / renovação de pastagens apontaram que estes apresentam efeito semelhante a fontes solúveis de fosfatos (Goedert \& Lobato, 1984; Sanzonowicz \& Goedert, 1986; Soares et al., 2000). O fosfato reativo de Gafsa (FRG) é um destes fosfatos.

À solubilização do FNRs depende de fatores relacionados a sua característica intrínseca, a acidez do solo, a concentração de P e Ca no solo (Robinson \& Syers, 1990), a planta utilizada (leguminosa ou gramínea), o tempo de contato com o solo, a forma de aplicação (Soares et al., 2000) entre outros.

Este trabalho foi realizado em duas etapas. Primeiro um experimento de incubação foi realizado com o objetivo de avaliar a dissolução do FRG comparada a fonte padrão (super fosfato triplo -SFT) durante o período de um ano em condições controladas. Numa segunda fase, realizou-se um experimento em casa de vegetação com o objetivo de ampliar o conhecimento no tocante as diferenças na aquisição e utilização entre Brachiaria brizantha cv. Marandu (BB) e Stylosanthes guianensis cv. Mineirão (SG) em monocultura ou em consórcio com diferentes fontes de $\mathrm{P}$ num Latossolo Vermelho argiloso, com dois níveis de $\mathrm{P}$.

O uso de reagentes químicos como extratores de nutrientes "disponíveis" do solo normalmente provoca alterações químicas intensas nesse solo. As plantas absorvem mais P dos solos após extração do "P-disponível" pelo ácido acético ou ácido sulfúrico diluídos do que antes da extração. Há, portanto, uma profunda modificação nas características do solo causada pelos extratores o que poderia não corresponder a realidade (Novais \& Smyth, 1999). Desta maneira, escolheu-se a resina de troca aniônica considerado um método "não destrutivo" para a avaliação da biodisponibilidade do P do solo neste trabalho. 


\subsection{Material e Métodos}

\subsubsection{Experimento de incubação}

O trabalho foi realizado por um período de 360 dias, em delineamento inteiramente casualizado com três repetições. $\mathrm{O}$ experimento consistiu dos seguintes tratamentos: um solo com e sem calagem, duas fontes de $\mathrm{P}$ e as testemunhas de cada solo. O Latossolo Vermelho cultivado há dez anos com $\mathrm{BB}$, foi coletado em duas áreas adjacentes, na profundidade de $0-10 \mathrm{~cm}$, na Fazenda Rio de Janeiro em Planaltina (GO). Uma área havia recebido uma calagem na superfície. Após, procedeu-se a separação das raízes maiores e a peneiração do solo a $4 \mathrm{~mm}$, posteriormente os solos foram homogeneizados separadamente e pesados $0,5 \mathrm{~kg}$ para cada vaso que foi envolvido por um plástico preto para evitar a entrada de luminosidade. Na Tabela 1, são apresentadas as principais características deste solo.

Tabela 11. Atributos químicos e físicos do Latossolo Vermelho, na profundidade de 0$10 \mathrm{~cm}$.

\begin{tabular}{|c|c|c|c|c|c|c|c|}
\hline Argila & $\mathrm{pH}^{1}$ & $\mathrm{MO}^{2}$ & $\mathrm{P}^{3}$ & $\mathrm{Ca}$ & $\mathrm{Mg}$ & $\mathrm{H}+\mathrm{Al}^{4}$ & CTC \\
\hline $\mathrm{g} \mathrm{kg}^{-1}$ & & $\mathrm{~g} \mathrm{dm}^{-3}$ & $\mathrm{mg} \mathrm{dm}^{-3}$ & --- & $--m$ & $\mathrm{dm}^{-3}-$ & ----- \\
\hline 750 & 5,5 & 39 & 6 & 24 & 10 & 34 & 70 \\
\hline
\end{tabular}

As quantidades de fosfatos aplicados por vaso foram calculadas segundo a dose recomendada para o campo de $180 \mathrm{~kg} \mathrm{ha}^{-1}$ de $\mathrm{P}_{2} \mathrm{O}_{5}$ (equivalentes a 640 e $410 \mathrm{~kg} \mathrm{ha}^{-1}$ de FRG e SFT na superfície, respectivamente). Então, foi aplicado 0,32 g de FRG e $0,21 \mathrm{~g}$ de SFT por vaso. A aplicação e mistura do fertilizante seco foi realizada individualmente por vaso após a pesagem. Semanalmente a água destilada era adicionada para manter o solo dos vasos aproximadamente na capacidade de campo (CC). Os tempos de incubação foram 45, 90, 180 e 360 dias. Cinco dias antes de completar o período de incubação os solos eram postos para secar a sombra e peneirados a $2 \mathrm{~mm}$ para posterior 
análises por meio da extração de $\mathrm{P}$, cálcio e magnésio pela resina e a determinação do $\mathrm{pH} \mathrm{em} \mathrm{H}_{2} \mathrm{O}$.

\subsubsection{Experimento na casa de vegetação}

$\mathrm{O}$ trabalho foi realizado em delineamento inteiramente casualizado com quatro repetições. O solo utilizado foi o "com calagem" do experimento de incubação. Os tratamentos consistiram de BB (Brachiaria brizantha cv. Marandu) e SG (Stylosanthes guianensis cv. Mineirão ) e o consórcio deles. Estes foram cultivados sem fósforo (P), com SFT, com FRG e a mistura de SFT + FRG (SFTFRG) (doses equivalentes em $\mathrm{P}_{2} \mathrm{O}_{5}$ ). A unidade experimental foi composta de duas plantas de $\mathrm{SG}$, quatro plantas de $\mathrm{BB}$ e no consórcio de 2 plantas de SG mais 4 plantas de BB por vaso.

O procedimento no preparo do solo foi o mesmo do experimento de incubação, porém adicionou-se $1,5 \mathrm{~kg}$ de solo por vaso. As quantidades de fosfatos aplicados por vaso foram calculadas segundo a dose recomendada para o campo $\left(180 \mathrm{~kg} \mathrm{ha}^{-1}\right.$ de $\left.\mathrm{P}_{2} \mathrm{O}_{5}\right)$ e foram as seguintes: i) $0,52 \mathrm{~g}$ de SFT, ii) $0,82 \mathrm{~g}$ de FRG e, iii) $0,26 \mathrm{~g}$ de SFT mais 0,41 $\mathrm{g}$ de FRG por vaso na mistura. A aplicação e mistura do fertilizante seco foi realizada individualmente por vaso após a pesagem.

As sementes foram pré-germinadas num substrato de areia com água destilada. Após 9 dias o transplante foi realizado e após 14 dias do transplante foi realizado o desbaste. A água destilada foi adicionada para manter o solo dos vasos aproximadamente na capacidade de campo (CC) diariamente. Semanalmente os vaso eram mudados de local. A solução nutritiva de Johanson com macro (sem P e N) e micronutrientes foi utilizada (Epstein, 1975). O nitrogênio foi adicionado 14 dias após o transplante na dose de $20 \mathrm{mg} \mathrm{L}^{-1}$ por vaso com exceção dos quatro vasos sem plantas.

A coleta das plantas ocorreu 63 dias após o transplante. A parte aérea das plantas nos tratamentos de BB e SG foram colocadas em sacos de papel e, em seguida, foram desidratadas em estufa de ventilação forçada, a uma temperatura de $65^{\circ} \mathrm{C}$, por 48 h. No tratamento do consórcio (COM), as plantas de BB e SG foram coletadas separadamente e seguiu-se o mesmo procedimento. Uma vez desidratado, o material foi pesado e, em seguida as amostras foram moídas e armazenadas para posterior análises. 
Foram determinados os teores de $\mathrm{P}$ da parte aérea colorimetricamente pelo método do molibdato, após submeter o material vegetal à oxidação pela digestão nítrico-perclórica.

A separação das raízes foi realizada por tamisagem do solo a $4 \mathrm{~mm}$ para avaliação da matéria seca de raízes. Após a lavagem das raízes em água, subamostras radiculares foram coletadas e conservadas em solução FAA (formaldeído a 40\% + ácido acético glacial + etanol), para posterior avaliação da colonização radicular por fungos micorrízicos arbusculares (FMA) pelo método da interseção em placa reticulada (Abbott \& Robson, 1981).

Após a homogeneização do solo, retirou-se uma alíquota ( $\pm 200 \mathrm{~g}$ de solo) para compor a amostra da unidade experimental e passada em peneira de $2 \mathrm{~mm}$ para posterior análises químicas. Determinou-se o P através da extração pela resina (Raij et al., 1986) e colorimetricamente. O P-total (Pt) foi determinado após digestão com ácido fluorídrico, nítrico e perclórico. O P-orgânico foi determinado por diferença entre a alíquota da amostra calcinada em mufla a $550{ }^{\circ} \mathrm{C}$ por 2 horas e a alíquota não calcinada. O Pinorgânico obtido pela digestão em ácido sulfúrico $2 \mathrm{~N}$ das alíquotas foi determinado colorimetricamente (John 1970).

Os dados obtidos foram submetidos a análise de variância e a comparação das médias pelo teste de Tukey a 5\%.

\subsection{Resultados}

\subsubsection{Experimento de incubação}

Na Figura 13 são apresentados os conteúdos de Pr para o solo que recebeu uma calagem (RJ) e o que não recebeu nenhuma aplicação de calcário (Fa). A Figura 14 apresenta as variações de cálcio e magnésio. Até os 90 dias de incubação, o pH dos solos $\mathrm{RJ}$ e $\mathrm{Fa}$ foram iguais, porém o Fa apresentou uma tendência de diminuição dos valores. Aos 180 dias, há um decréscimo acentuado do $\mathrm{pH}$ no Fa enquanto que o RJ mantém-se estável (Figura 13). Aos 360 dias o RJ apresentou um aumento do $\mathrm{pH}$ e o Fa tendeu a estabilizar-se. Após 100 dias de incubação, o pH para os solos foi diferente. Entretanto as diferentes fontes de $\mathrm{P}$ não apresentaram influência no $\mathrm{pH}$. Os conteúdos de $\mathrm{Ca}$ e $\mathrm{Mg}$ 
foram superiores no solo RJ. O Ca apresentou maior variabilidade do que o $\mathrm{Mg}$. As diferentes fontes de $\mathrm{P}$ não influenciaram no conteúdo de Ca extraído pela resina (Figura 14).

O SFT apresentou conteúdo de Pr ligeiramente superior do que FRG em ambos os solos. Ocorreu um ligeiro aumento gradual de Pr com o decorrer do período de incubação no tratamento SFT, após uma ligeira queda inicial até 90 dias. Não se observou esse comportamento com o FRG (Figura 13).

\subsubsection{Desenvolvimento e acúmulo de matéria seca das plantas}

O crescimento das plantas após o transplante foi lento nos primeiros 20 dias de condução do experimento, característica intrínseca do SG, porém não para o BB. Após este período o desenvolvimento tendeu a ser normal. As plantas dos tratamentos sem $\mathrm{P}$ praticamente não cresceram, havendo dificuldades de se conseguir material vegetal suficiente para as análises.

A produção de matéria seca (MS) por planta variou de 0,05 a $0,10 \mathrm{~g} /$ planta para o solo SP, 0,48 a $0,79 \mathrm{~g} /$ planta para o solo com SFT, 0,42 a $0,89 \mathrm{~g}$ /planta para o solo com FRG e 0,40 a 1,50 g/planta para o solo SFTFRG (Tabela 12). A produção por planta para o consórcio (COM) sempre foi inferior a qualquer um dos monocultivos $(\mathrm{MON})$, porém foi superior quando a avaliação da produção foi por vaso ou por kg de solo. Não foram verificadas diferenças marcantes na produção de MS referente as espécies utilizadas e o seu consórcio. A tendência, para os solos com adição de $\mathrm{P}$, foi a maior produção de MS por planta para os MON e quando a avaliação não considerou a unidade planta e sim a unidade solo ou vaso, as maiores produções foram do consórcio.

\subsubsection{Conteúdos de $P$ na planta}

Os conteúdos de $\mathrm{P}$ na planta foram estatisticamente superiores no SG em monocultivo independentemente da fonte de P utilizada. Por outro lado, quando em consórcio, este não diferiu dos conteúdos apresentados pela BB (Tabela 12) e foram sempre inferiores ao SG em monocultivo. Desta maneira, as exportações de P no SG foram maiores no tratamento SFTFRG e revelaram uma tendência de serem maiores nos 
outros dois adubados (SFT e FRG). Na testemunha (SEM P), as exportações de P por planta foram iguais para todos os tratamentos.


Figura 13 - Conteúdos de P-resina ( $\mathrm{Pr}$ ) e pH $\mathrm{H}_{2} \mathrm{O}$ num período de incubação de 360 dias com superfosfato triplo (SFT) e fosfato reativo de gafsa (FRG), para os solos da Fazenda RJ (RJ) e Fazenda vizinha (Fa). 



Figura 14 - Conteúdos de cálcio e magnésio num período de incubação de 360 dias com superfosfato triplo (SFT) e fosfato reativo de gafsa (FRG) para os solos da Fazenda RJ (RJ) e Fazenda vizinha (Fa). 


\subsubsection{Conteúdos de P-resina (Pr)}

A biodisponibilidade de $\mathrm{P}$ medida pelo $\mathrm{Pr}$ não apresentou diferenças para plantas dentro de cada fonte de $\mathrm{P}$ analisada. Entretanto, quando não foi adicionado $\mathrm{P}$ a $\mathrm{BB}$ em monocultura foi inferior (Tabela 13). De maneira geral, a variabilidade das determinações analíticas foi elevada provavelmente devido a adição dos fertilizantes na forma granulada (SFT) e pó farelado (FRG). Os conteúdos de Pt e Po não apresentaram diferenças com exceção para as plantas dentro do SFT.

\subsubsection{Colonização radicular por FMA}

A colonização das raízes pelos FMA determinada pela \% de raízes infectadas foi elevada para todos os tratamentos analisados. A \% de raízes infectadas nas plantas do consórcio não foram determinadas devido a dificuldade de separação das raízes. Apenas dentro do SFTFRG o monocultivo SG foi superior ao BB (Tabela 13).

\subsection{Discussão}

A necessidade da realização de adubações de manutenção em pastagens cultivadas na Região do Cerrado para manter a produtividade a níveis compensadores já havia sido comprovada, especialmente com nitrogênio e fósforo. Entretanto, esta não é uma prática adotada pela maioria dos pecuaristas por uma série de fatores, como: disponibilidade de capital, alto custo, cultural (extrativista - mais fácil desmatar uma nova área), disponibilidade de equipamento entre outros. Desta maneira, a pesquisa buscou alternativas para manter e melhorar a produtividade destas pastagens com o consórcio com leguminosas adaptadas a solos de baixa fertilidade (Ayarza et al., 1999; Barcellos et al., 2001). 


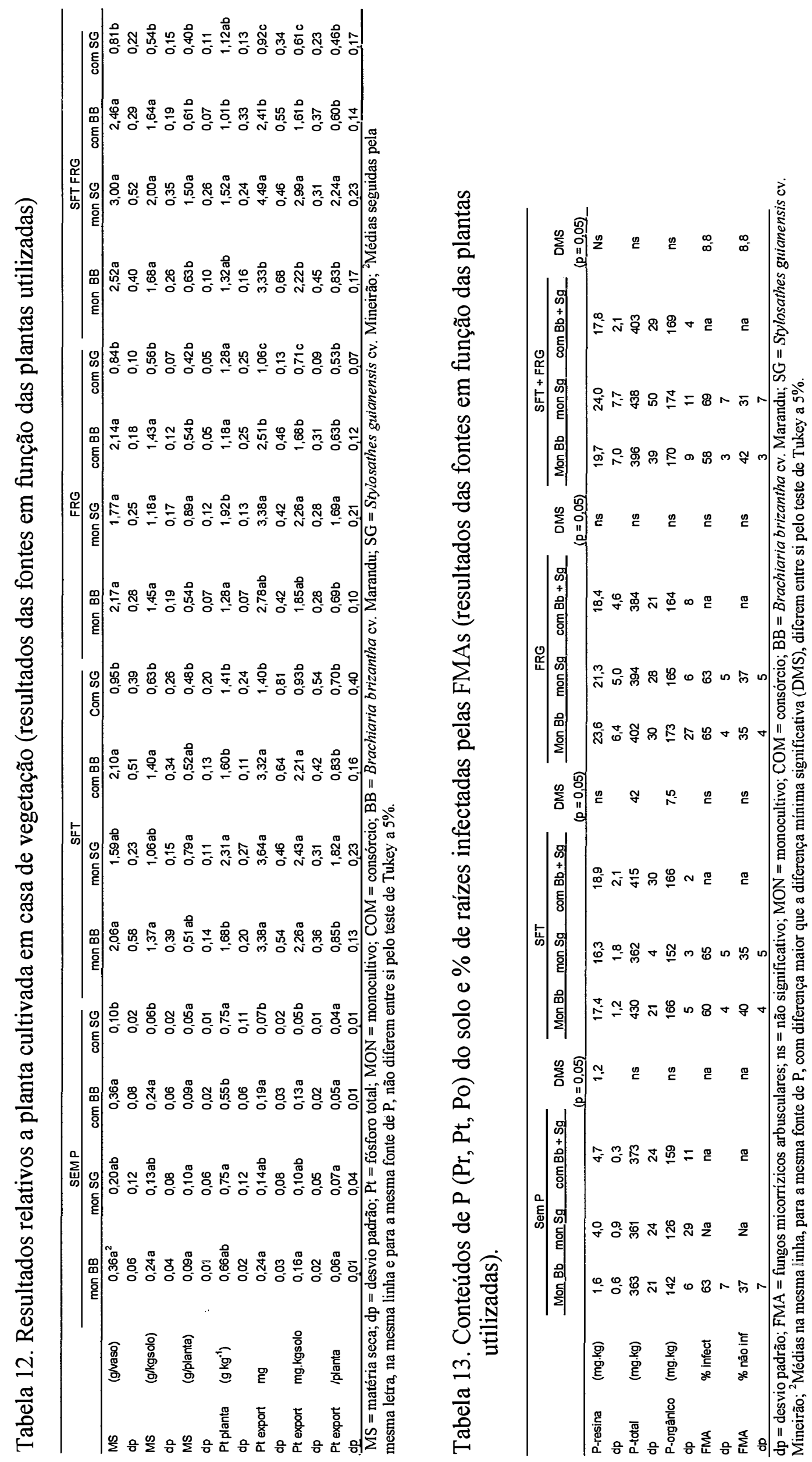


De maneira geral, as adubações com $\mathrm{N}$ beneficiam a gramínea e $\mathrm{P}$ e $\mathrm{K}$ a leguminosa no consórcio, entretanto há poucas pesquisas e muita especulação para definição dos níveis mais adequados para cada uma das culturas no consórcio para manter a longevidade do sistema no campo. Além das características relativas ao solo, existem outros fatores que influenciam, como: o manejo da pastagem, efíciência fotossintética, período de pastejo, palatabilidade, planta $\mathrm{C}_{3} \mathrm{e}_{4}$ entre outros.

Sendo o P-inorgânico pouco móvel no solo, esperava-se melhor aquisição de $\mathrm{P}$ na gramínea que apresenta o maior sistema radicular do que a leguminosa (Rao et al., 1993). Entretanto, estes resultados indicaram que o SG, com menor sistema radicular (avaliação visual), desenvolveu uma melhor capacidade para rapidamente adquirir o $\mathrm{P}$ do que o BB. De maneira geral, estas observações concordam com conclusões encontradas por outras pesquisas (Rao et al., 1997; Caradus, 1980; Evans, 1977). Dessa maneira a leguminosa parece ser mais hábil para absorver mais $\mathrm{P}$ por unidade de raiz embora a gramínea explore melhor o solo. Leguminosas com seu menor crescimento das raízes, mas com uma alta absorção de $\mathrm{P}$ por unidade de raiz, pode, possivelmente exaurir o P disponível no solo mais rapidamente. Quando crescem em consórcio, o sistema radicular da gramínea, por causa da sua agressividade e tamanho na procura (Caradus, 1980; Evans, 1977), pode ser o primeiro a absorver o $\mathrm{P}$ disponível mesmo que sua aquisição de $\mathrm{P}$ por unidade de raiz seja menor, tendência observada no consórcio. O SG cultivado no consórcio produziu menos matéria seca do que quando cultivado em monocultivo, enquanto que o BB manteve as produtividades.

Os FMAs são importantes no suprimento de P para gramíneas e leguminosas forrageiras em latossolos tropicais (Salinas et al. 1985; Carneiro et al., 1999; Souza et al., 1999b). No presente trabalho não foram encontradas diferenças na taxa de colonização radicular entre o SG e o BB após 60 dias do transplante. Souza et al. $(1999 a, b)$ verificaram maior efeito no SG, enquanto que Carneiro et al. (1999) e Rao et al. (1997) maior taxa de infecção na gramínea. Uma das possíveis explicações da superior eficiência na aquisição de $\mathrm{P}$ pelas leguminosas poderiam ser por causa das espécies de FMAs associadas as leguminosas serem mais eficientes. 
Dos parâmetros considerados do solo e da planta, Barber (1984) constatou que as predições na absorção de nutriente são mais afetadas pelas mudanças na taxa de crescimento das raízes. Mais trabalhos de pesquisa são necessários para testar as relações entre as taxas de crescimento de raízes e absorção de $\mathrm{P}$ destas espécies forrageiras em diferentes níveis de suprimento de $P$ no solo (Rao et al., 1997), principalmente no consórcio de espécies, pois este provavelmente seja um dos fatores que interfiram diretamente na longevidade da leguminosa no consórcio. Há a necessidade da realização de mais trabalhos, principalmente de campo.

Os resultados obtidos no experimento de incubação e no teste biológico com as forrageiras demonstraram que o FRG, no caso de ser incorporado ao solo, pode ser uma boa alternativa para as adubações fosfatadas de solos. A biodisponibilidade de $\mathrm{P}$ avaliada pelo Pr apresentou a tendência de ser menor, porém não foi diferente, com exceção da avaliação aos 180 dias do experimento de incubação (Figura 1). Entretanto, alguns problemas metodológicos são levantados. A utilização dos fertilizantes na forma sólida pode não ter sido avaliada de forma correta pelo $\mathrm{Pr}$, pois não há como saber se o $\mathrm{P}$ biodisponível estava no solo ou no grão. Desta forma, estes testes deveriam ser realizados também com a aplicação do radioisótopo ${ }^{32} \mathrm{P}$ que auxiliaria na elucidação destes resultados.

\subsection{Conclusões}

A biodisponibilidade de $\mathrm{P}$ do solo ácido estudado foi muito baixa, limitando o crescimento das duas espécies estudadas que são adaptadas para solos ácidos por programas de melhoramento. As fotos da testemunha sem $\mathrm{P}$ e dos tratamentos com fósforo demonstraram a falta de P biodisponível após 60 dias de cultivo (apêndice 4). Este solo vinha sendo cultivado há 10 anos com Brachiaria brizantha cv. Marandu (BB) e uma avaliação realizada definiu essa como uma pastagem de baixa capacidade produtiva (cap. 5). Desse modo, o teste biológico realizado em casa de vegetação permitiu confirmar os resultados que vinham sendo obtidos a campo. 
Os resultados revelaram que existem diferenças entre a gramínea (Brachiaria brizantha cv. Marandu) e a leguminosa (Sthylosanthes guianensis cv. Mineirão) quanto a sua habilidade de crescerem em solo ácido com pequenas quantidades biodisponíveis de $\mathrm{P}$. A leguminosa apresentou maior capacidade de aquisição de $\mathrm{P}$, porém quando foi cultivada em consórcio a gramínea foi mais eficiente na competição pelo $\mathrm{P}$ biodisponível. Estes resultados provavelmente estão associados aos diferentes tipos de sistema radicular destas plantas e a outros mecanismos que neste estudo não foram abordados. $\mathrm{O}$ experimento de incubação, a avaliação do $\mathrm{P}$ resina demonstrou que havia $\mathrm{P}$ biodisponível para a planta até o período de 360 dias, independente da fonte de fosfato utilizada. 


\section{CONCLUSÕES}

\subsection{Discussão geral}

Este trabalho tentou trazer alguns elementos de reflexão no que se refere ao conhecimento sobre o fósforo nas pastagens cultivadas do Cerrado. Mas admitimos que a origem da perda da capacidade produtiva das pastagens no Cerrado é muito mais complexa que uma simples deficiência de elementos no solo. Assim, Balbino (2001) ressaltou alguns processos físicos a serem contemplados e os problemas de manejo foram evidenciados por Costa \& Rehman (1999).

A análise da literatura enfatiza a pouca informação bem estruturada sobre as transformações do fósforo depois da implantação das pastagens cultivadas nesta região e como estas transformações afetam a biodisponibilidade e a reciclagem do P do solo. Garcia-Montiel et al. (2000) sugerem para trópicos úmidos que a disponibilidade do $\mathrm{P}$ em pastagens velhas é provavelmente mantida pela reciclagem rápida do P-orgânico e o equilíbrio entre as formas orgânicas e oclusas do $\mathrm{P}$ do solo possivelmente mediadas pela associação com FMA.

\subsubsection{A oferta de fosfato pelo solo para manter o crescimento da planta forrageira}

No capítulo 6, o experimento de casa de vegetação demonstrou que não havia biodisponibilidade de $\mathrm{P}$ suficiente para manter a produtividade da forrageira a níveis aceitáveis. Entretanto, os conteúdos de P-orgânico eram relativamente elevados, onde se esperaria uma mineralização suficiente (Garcia-Montiel et al. 2000; Chapuis-Lardy et al., 2002). A avaliação realizada a campo (cap. 5) demonstrou que a pastagem era de baixa produtividade com uma capacidade de suporte menor que uma unidade animal por 
ha. Por outro lado, em solos com alto FCP as pequenas quantidades de P mineralizado entram rapidamente no compartimento associado ao $\mathrm{P}$ inorgânico que poderá ser trocável (Frossard et al., 1996).

A variabilidade da biodisponibilidade do $\mathrm{P}$ do solo numa pastagem de baixa produtividade (cap. 5) demonstrou que a reciclagem do P neste sistema está diretamente associada à touceira da planta. No caso da Brachiaria brizantha cv. Marandu, implantada há 10 anos, ocorreu um aumento da concentração de conteúdos de $\mathrm{P}$ resina, que são suportados pelas diferenças do poder tampão do $P$ do solo $\left(R / r_{1}\right)$, das amostras "entre touceiras" e "sob touceira". Isto sugere, que a partir de um certo nível a pastagem atinja um patamar de equilíbrio da produtividade que é definido por esta reciclagem do $P$ no sistema solo-planta via touceira. Entretanto, é preciso lembrar que estas observações são válidas para as plantas forrageiras de hábito cespitoso (touceira).

\subsubsection{Oferta do $P$ do solo avaliado pela resina}

Considerando os patamares sugeridos por Vilela et al. (2000) os conteúdos de $\mathrm{P}$ resina para os diferentes solos e áreas amostrados foram considerados limitantes. Esta observação foi mais evidente nas pastagens que não recebiam nenhuma adubação de manutenção. Entretanto, por região, as pastagens renovadas de Brasilândia, sob latossolos desenvolvidos sob arenitos, apresentaram valores próximos do considerado adequado (cap. 4). As pastagens de Uberlândia (cap. 3), tanto o solo argiloso quanto o arenoso apresentaram valores abaixo do adequado. Em Silvânia (cap. 3), das nove pastagens amostradas apenas uma apresentou valor considerado adequado. No experimento na Embrapa Cerrados (cap. 3), apenas um dos tratamentos cultivados numa seqüência pastagem/lavoura/pastagem apresentou valor no limite do adequado. Na Fazenda Rio de Janeiro (cap. 5), os valores foram limitantes se considerarmos as amostras entre touceiras. Porém, a tabela dos níveis considerou amostras coletadas na profundidade 0 a $20 \mathrm{~cm}$ e as amostras comparadas foram coletadas de 0 a $10 \mathrm{~cm}$. Assim, a tendência seria de valores menores do $\mathrm{P}$ do solo dos aqui discutidos, provavelmente incluindo todos os solos como limitantes. 
A metodologia da resina utilizada neste trabalho apresentou limitações de sensibilidade, pois não discriminou pastagens consideradas de boa produtividade após a recuperação/ renovação de pastagens degradadas adjacentes as áreas. Estas plantas forrageiras são adaptadas a solos tropicais com baixa biodisponibilidade de $\mathrm{P}$ e altamente intemperizados. Desse modo, a utilização das cinéticas de troca isotópica ou o valor de $E p_{\text {lmin }}$ poderiam auxiliar na determinação de faixas mais refinadas de biodisponibilidade do $\mathrm{P}$ do solo para estas plantas forrageiras.

\subsubsection{Cinética de troca isotópica}

A visão da biodisponibilidade do $\mathrm{P}$ do solo por meio da cinética de troca isotópica, determinada no Cap. 4 para o experimento de pastagens renovadas e não renovadas, tem no componente tempo, o grande interesse da técnica. Embora, haja a necessidade de realizar a curva de demanda de $\mathrm{P}$ da planta a campo e da oferta do $\mathrm{P}$ do solo no mesmo momento, pois esta não foi experimentalmente realizada. Os dados fornecidos pela análise da cinética de troca isotópica mostraram que há fosfato biodisponível no solo suficiente para o desenvolvimento das plantas, mesmo nas pastagens consideradas de baixa produtividade. A biodisponibilidade de P passa a ser limitante para as pastagens de manejo tradicional decorrido o período de dois meses após a avaliação, o que limita a produção de forragem durante a estação de crescimento. Por outro lado, nas pastagens renovadas avaliadas após 2 anos de implantação dos tratamentos, a biodisponibilidade potencial de P passa a ser limitante a partir do 3 ao 4 ano. No caso de renovação e manutenção de pastagens com gramíneas que demandam um nível de fertilidade alto, pequenas quantidades de fertilizantes fracionadas no tempo podem ser uma alternativa viável. Com relação a técnica, acrescenta-se o interesse da realização das cinéticas de troca isotópica para pastagens fertilizadas, para se ter uma previsão do melhor momento da realização das fertilizações de manutenção. A maior sensibilidade do método em relação aos métodos convencionais (resina) pode servir como um padrão de referência ou como ferramenta na caracterização dos solos em relação ao fator quantidade $\left(\mathrm{Q}=\mathrm{Ep}_{\mathrm{lmin}_{\text {min }}}\right)$ e a capacidade tampão do $\mathrm{P}$ do solo $\left(\mathrm{R} / \mathrm{r}_{1}\right)(\mathrm{Cap}$. 
3). Esta técnica pode ser utilizada como uma ferramenta auxiliar no complemento de informações obtidas por métodos convencionais.

\subsubsection{Situação atual}

A predominância de trabalhos conduzidos em casa de vegetação tratando mais o aspecto de nutrição de plantas e de fertilidade do solo e, quando conduzidos no campo, na maioria dos casos, em parcelas experimentais, onde as avaliações são feitas através de cortes periódicos e não através do pastejo de animais, limitam alguns aspectos do estudo da ciclagem de $\mathrm{P}$ em pastagens cultivadas no Brasil. Entretanto, nestas pastagens, a produção da forragem é estacional, determin ada, principalmente pela sazonalidade anual das chuvas e temperaturas. Dessa forma, o conhecimento de alguns aspectos da fertilidade destes solos nestas situações a campo, no âmbito regional, são relevantes para a formação de estratégias que auxiliem na adoção de práticas relacionadas as pastagens que dêem maior sustentabilidade ao sistema pecuário da Região do Cerrado. As extrapolações de resultados obtidos não são cabíveis, pois os dados não apresentam uma densidade de análises suficiente no âmbito de regiões que formam o Cerrado.

Além disso, é utopia pensar que o sistema de exploração pecuária brasileira irá mudar num curto espaço de tempo. A utilização de altas quantidades de fertilizantes fosfatados neste sistema de exploração depende de vários fatores. Sendo que os problemas não são unicamente de fertilidade química, mas também de física e de manejo do solo e pastagem. De certa forma, os estudos que vem sendo realizados com leguminosas forrageiras adaptadas a estes solos, especialmente com o objetivo de realização de consórcio com as gramíneas do gênero Brachiaria spp. parecem ser mais adequados para a situação vigente (Barcellos et al., 2001).

Finalmente, há aproximadamente 39,6 milhões de hectares de pastagens cultivadas de baixa capacidade produtiva na Região do Cerrado. As consequêencias deste fato, vão além da necessidade de se ter uma percepção pelo pecuarista da necessidade de realizar a recuperação/renovação como um negócio rentável, há a necessidade de que 
todos os segmentos envolvidos elaborem programas de longo prazo para tentar reverter este cenário.

\subsubsection{Perspectivas de pesquisas futuras}

Alguns assuntos de pesquisas são levantados a seguir, que auxiliariam na compreensão dos processos que levam a perda da capacidade produtiva das pastagens no Cerrado.

Precisamos de levantamentos de campo sobre as propriedades química, física e biológica dos solos sob pastagens de baixa capacidade produtiva e em processo de recuperação/renovação para a formação de uma base de dados. Estas informações associadas a dados de experimentos de campo estudando o manejo da pastagem, a ciclagem de nutrientes ( $\mathrm{P}$ e $\mathrm{N})$ e a persistência dos componentes com base nas relações solo-planta-animal trariam subsídios importantes para o esclarecimento desta problemática.

O sistema radicular das forrageiras perenes desempenha um papel fundamental na adaptação aos solos de baixa fertilidade. A utilização do radioisótopo ${ }^{32} \mathrm{P}$ para determinar a atividade do sistema radicular, em situações de campo, poderia auxiliar na elucidação dos seguintes aspectos: i) definição da melhor zona do solo de amostragem para fins de pesquisa e de recomendação, ii) as espécies de um consórcio podem ser melhor selecionadas segundo a arquitetura radicular e a habilidade de explorar diferentes camadas do solo, utilizando melhor as reservas das camadas mais profundas, iii) evidenciar o transporte lateral do $\mathrm{P}$ aplicado numa zona de raiz de uma planta para a zona da raiz de uma outra planta vizinha resultando na sua absorção mais tarde, iv) a absorção relativa do radioisótopo aplicado em consórcio e monocultivos pode indicar a natureza e a extensão da interação, especialmente aquele da competição radicular, no crescimento e produtividade do sistema como um todo, nesta situação de estresse (Wahid, 2001).

Os microrganismos do solo são componentes integrantes do ciclo do $\mathrm{P}$ do solo e tem um importante papel afetando a disponibilidade do $\mathrm{P}$ do solo para as raízes da 
forrageira. Isto é também evidente que qualquer aperfeiçoamento na mobilização do $\mathrm{P}$ do solo necessita levar em conta os processos microbianos. No entanto, o aumento da mobilização do $\mathrm{P}$ do solo para beneficiar a produção da planta pode ser realizado através do melhor manejo da população microbiana do solo, pelo desenvolvimento de inoculantes microbianos mais efetivos, ou por meio da manipulação genética de microrganismos específicos do solo e /ou espécies de plantas (Richardson, 2001). Ficou evidenciado a falta de trabalhos de FMAs no campo para tentar compreender as relações entre as Brachiarias spp. e os fungos.

Há convincentes dados de laboratório que demonstram a secreção de ácidos orgânicos pelas plantas ou para aumentar a absorção de $\mathrm{P}$ ou para proteger suas raízes da toxicidade nos solos ácidos. Isto suporta um papel dos ânions orgânicos como o citrato, malonato, oxalato e tartarato que realçam a absorção do $\mathrm{P}$ e o malato, citrato e oxalato na tolerância ao Al. Mais trabalhos são necessários para acessar a eficácia da exsudação de ácidos orgânicos no aumento do acesso das plantas ao $\mathrm{P}$ fixado nos diferentes tipos de solos e para diferentes fontes de fertilizantes fosfatados. Ao nível agronômico, o papel das plantas que exsudam ácidos orgânicos necessita ser avaliado na economia de P nas pastagens e cultivos (Hocking, 2001).

\subsection{Conclusões}

\subsubsection{Métodos}

As faixas de disponibilidade do $\mathrm{P}$ atualmente utilizadas nas tabelas de recomendação de adubação são estreitas, principalmente para as forrageiras adaptadas a solos com baixa disponibilidade de P. Os resultados obtidos nos capítulos 3, 4 e 5 com o método da resina permitiram demonstrar esta problemática. Demonstrou-se que a extração pela resina não consegue ter sensibilidade suficiente para diferenciar um solo de baixa e de boa biodisponibilidade de P para o crescimento da planta. Desta forma, há a necessidade de se buscar métodos com maior sensibilidade, ou a determinação de outros mecanismos que auxiliem na diferenciação dos níveis críticos de disponibilidade de $\mathrm{P}$ dos solos com maior exatidão. Os dados de literatura demonstraram que está 
problemática é mais grave com o Mehlich I quando comparado a resina. Porém, afora os problemas levantados neste trabalho, a resina é o melhor método de rotina para a realização destas avaliações.

A concentração de íons fosfato na solução aquosa $(\mathrm{Cp})$ foi muito baixa, apresentaram-se no limite de detecção. Todos os solos analisados foram limitantes quanto a Cp. Entretanto, está metodologia necessita de estudos em solos tropicais, provavelmente com o avanço da tecnologia encontre-se metodologias mais refinadas para a sua determinação com uma boa confiabilidade. Para solos tropicais cultivados com alta adição de fertilizantes fosfatados pode ser uma boa alternativa.

A capacidade tampão do solo $\left(R / r_{1}\right)$ medida por meio de técnicas isotópicas permitiu identificar os solos com maior capacidade de fixação.

A determinação da $\mathrm{Cp}$ e do $\mathrm{Ep}_{\text {lmin }}$ permitiram o cálculo dos fatores intensidade (I), quantidade (Q) e capacidade (FCP) conforme modelo conceitual proposto por Beckett \& White (1964).

As cinéticas de troca isotópica (CTI) permitiram uma avaliação da oferta (biodisponibilidade) do $\mathrm{P}$ do solo no tempo, complementando a informação da análise de P-resina, considerando a planta e suas exigências.

\subsubsection{Escala}

A abordagem regional demonstrou que a biodisponibilidade do $\mathrm{P}$ variou entre os diferentes tipos de solos, principalmente em relação a textura. A modelagem dos dados de CTI permitiram observar uma variação da biodisponibilidade do $\mathrm{P}$ em função do tempo de oferta considerado.

No estudo em Brasilândia, numa escala de experimento sob pastejo, as pastagens renovadas apresentaram biodisponibilidade do $\mathrm{P}$ superior das não renovadas. Entretanto, as faixas de biodisponibilidade foram muito estreitas.

A abordagem em parcela de campo, demonstrou variabilidade do $\mathrm{P}$ do solo e os cuidados que devemos ter ao realizar uma amostragem de solo sob pastagem de baixa produtividade. No âmbito de uma área de 30 ha a variabilidade foi baixa numa amostragem em malha irregular de aproximadamente $40 \times 100 \mathrm{~m}$. No entanto, na área de 
1 ha, na amostragem em malha sistemática de $10 \times 10 \mathrm{~m}$ a variabilidade foi elevada principalmente após a aplicação dos fertilizantes. Na mesma malha, a biodisponibilidade do P na amostragem entre touceiras e sob touceira passaram do nível baixo para o nível adequado.

Os resultados da biodisponibilidade do $\mathrm{P}$ do solo entre e sob touceira demonstraram que o funcionamento do solo ocorre no domínio de touceira da planta, ressaltando a necessidade de se investigar a reciclagem do $\mathrm{P}$ por unidades de touceira.

O estudo em vasos demonstrou a baixa biodisponibilidade do $\mathrm{P}$ do solo.

\subsubsection{Resultados agronômicos}

A utilização de pequenas quantidades de fertilizantes fosfatados na renovação/ recuperação da pastagem associado a aplicações de manutenção anuais são essenciais para manutenção da capacidade produtiva das pastagens. Pode-se associar esta prática ao cultivo de culturas anuais para a amortização do custo inicial da renovação / recuperação.

A aplicação de fertilizantes fosfatados aumentou a variabilidade do $\mathrm{P}$ do solo, pela distribuição desuniforme. Com isso, a produtividade da forrageira será diferenciada. A amostragem de solo e da planta deve levar em conta este fato.

$\mathrm{O}$ conhecimento mais profundo da textura e mineralogia dos solos numa escala regional mais detalhada pode auxiliar na utilização de práticas mais racionais de adubações fosfatadas. 


\section{REFERÊNCIAS BIBLIOGRÁFICAS}

ABBOT, L.K.; ROBSON, A.D. Infectivity and effectiveness of five Endomycorrhizal fungi: competition with indigenous fungi in field soils. Australian Journal of Agricultural Research, v. 32, p. 612-630, 1981.

ADÁMOLI, J.; MACEDO, J.; AZEVEDO, L. G.; NETTO, J.M. Caracterização da região dos cerrados. In: GOEDERT, W.J. (Ed.). Solos dos cerrados: tecnologias e estratégias de manejo. Planaltina: EMBRAPA-CPAC; São Paulo: Nobel, 1986. cap.2, p.33-74.

ADLER, P.R.; WILCOX, G.E. Rapid perchloric acid digest methods for analysis of major elements in plant tissue. Communications in Soil Science and Plant Analysis, v. 16, n. 11, p. 1153-1163, 1985.

ALMEIDA NETO, J.X.; BRASL SOBRINHO, M.O.C. Fixação de fósforo em três solos sob Cerrado de Goiás. Revista Brasileira de Ciência do Solo, v. 1, p. 12-15, 1977.

AMER, F.; MAHDI, S.; ALRADI, A. Limitations in isotopic measurements of labile phosphate in soils. Journal Soil Science, v. 20, p. 91-100, 1969.

ANDERSON, G. Factors affecting the estimation of phosphate-esters in soils. Journal of the Science of Food and Agricultural, v. 11, p. 497-503, 1960.

ARAÚJO, A.G.; AYARZA; M.A.; FRIESEN, D.K.; VILELA, L. Fraç̃os orgânicas e inorgânicas de fósforo em um solo de cerrado sob diferentes sistemas de manejo. In: SIMPÓSIO SOBRE O CERRADO, 8.; INTERNATIONAL SYMPOSIUM ON TROPICAL SAVANNAS, 1., Brasília, 1996. Biodiversidade e produção sustentável de alimentos e fibras nos cerrados/ Biodiversity and sustainable production of food and fibers in the Tropical Savannas. Anais/proceedings. Planaltina: EMBRAPACPAC, 1996. p.319-322.

ASSAD, E.D.; SANO, E.E.; MASUTOMO, R.; CASTRO, L.H.R.; SILVA, F.M. Veranicos na região dos cerrados brasileiros: freqüência e probabilidade de ocorrência. Pesquisa Agropecuária Brasileira, v. 28, p. 993-1002, 1993. 
AYARZA, M.A.; VILELA, L.; PIZARRO, E.A.; COSTA, P.H. da. Agropastoral systems based on legumes: an alternative for sustainable agriculture in the Brazilian cerrados. In: THOMAS, R.; AYARZA, M.A. (Ed.). Sustainable land management for the oxisols of the Latin American savannas: dynamics of soil organic matter and indicators of soil quality. Cali: CIAT, 1999. p. 22-36.

BAHIA FILHO, A.F.C.; BRAGA, J.M. Fósforo em latossolos do Estado de Minas Gerais. I. Intensidade e capacidade tampão de fósforo. Experentiae, v. 19, p. 17-32, 1975.

BAHIA FILHO, A.F.C.; VASCONCELLOS, C.A.; SANTOS, H.L.; MENDES, J.F.; PITTA, G.V.E.; OLIVEIRA, A.C. Relação entre adsorção de fósforo e componentes mineralógicos da fração argila de Latossolos do Planalto Central. Revista Brasileira de Ciência do Solo, v. 7, p. 221-226, 1983.

BALBINO, L.C. Évolution de la structure et des propriétés hydrauliques dans des Ferralsols mis en prairie pâturée (Cerrado, Brésil). Paris, 2001. 153 p. Thèse (Doctorat) - Institut National Agronomique, Paris-Grignon.

BALBINO, L.C.; BRUAND, A.; BROSSARD, M.; GRIMALDI, M.; HAJNOS, M.; GUIMARÃES, M.F. Changes in porosity and microaggregation clayey Ferralsols of the Brazilian Cerrado on clearing for pasture. European Journal of Soil Science, $v$. 53. No prelo.

BARBER, S.A. Soil nutrient bioavailability: a mechanistic approach. New York: John Wiley, 1984. 398p.

BARCELLOS, A.O. Sistemas extensivos e semi-intensivos de produção: pecuária bovina de corte nos Cerrados. In : SIMPÓSIO SOBRE O CERRADO, 8.; INTERNATIONAL SYMPOSIUM ON TROPICAL SAVANNAS, 1., Brasília, 1996. Biodiversidade e produção sustentável de alimentos e fibras nos cerrados/ Biodiversity and sustainable production of food and fibers in the Tropical Savannas: anais/ proceedings. Planaltina: EMBRAPA,CPAC, 1996. p. 130-136.

BARCELLOS, A. de O.; ANDRADE, R.P. de; KARIA, C.T.; VILELA, L. Potencial e uso de leguminosas forrageiras dos gêneros Stylosanthes, Arachis e Leucaena. In: PEIXOTO, A. M.; PEDREIRA, C. G. S.; MOURA, J. C. de; FARIA, V. P. F. (Ed.) SIMPOSIO SOBRE MANEJO DA PASTAGEM, 17., Piracicaba, 2001. A planta forrageira no sistema de produção. 2. ed. Piracicaba: FEALQ, 2001. p. 365-425.

BARCELLOS, A.O.; VILELA, L.; LUPINACCI, A.V. Produção animal a pasto: desafios e oportunidades. In: ENCONTRO NACIONAL DO BOI VERDE, 3., Uberlândia, 2001. A pecuária sustentável: Anais. Uberlândia: Sindicato Rural de Uberlândia: ABCZ: CNPC: Embrapa: FAEMG, 2001. p. 27-64. 
BECK, M.A.; SANCHEZ, P.A. Soil phosphorus fraction dynamics during 18 years of cultivation on a typic paleudult. Soil Science Society of America Journal, v. 58, n. 5, p. 1424-1431, 1994.

BECKETT, P.H.T.; WHITE, R.E. Studies on phosphate potentials of soils. Part III. The pool of labile inorganic phosphate. Plant and Soil, v. 21, p. 253-282, 1964.

BECKWITH, R.S. Sorbed phosphate at standard supernatant concentration as na estimate of the phosphate needs of soils. Australian Journal of Experimental Agriculture and Animal Husbandry, v. 5, p. 52-58, 1965.

BENNEMA J.; LEMOS, R.C.; VETTURS, L. Latosols in Brazil. In: Inter-Africain Soils Conference. Dalaba, 1959. V. I, 273-281, 1959.

BIRCH, C.P.D.; HUTCHINGS, M.J. Exploitation of patchily distributed soil resources by the clonal herb Gleuchoma hederacea. Journal of Ecology, v. 82, p. 653-664, 1994.

BOWMAN, R.A.; COLE, C.V. Transformations of organic phosphorus substrates in soils as evaluate by $\mathrm{NaHCO}_{3}$ extraction. Soil Science, v. 125, p. 49-54, 1978.

CAMARGO, M.N.; KLAMT, E.; KAUFFMAN, J.H. Sistema brasileiro de classificação de solos. Boletim Informativo da Sociedade Brasileira de Ciência do Solo, v. 12, n. 1, p. 11-33, 1987.

CARADUS, J.R. Distinguishing between grass and legume species for efficiency of phosphorus use. New Zealand Journal of Agriculture Research, v. 23, p. 75-81, 1980.

CARNEIRO, M.A.C.; SIQUEIRA, J.O.; CURI, N.; MOREIRA, F.M.S. Efeitos da inoculação de fungos micorrízicos arbusculares e da aplicação de fósforo no estabelecimento de forrageiras em solo degradado. Pesquisa Agropecuária Brasileira, v. 34, n. 9, p. 1669-1677, 1999.

CARVALHO, S.I.C.; VILELA, L.; SPAIN, J.M.; KARIA, C.T. Recuperação de pastagens degradadas de Brachiaria decumbens cv. Basilik na região dos Cerrados. Pasturas Tropicales, v. 12, n. 2, p. 24-28, 1990.

CATTANI, R.A.; PELLEGRINO, D. A fixação do fósforo em alguns solos do Estado de São Paulo, estudada com o auxílio do fósforo radioativo. Revista de Agricultura, v. 32, p. 237-252, 1957. 
CHAPUIS-LARDY, L.; BROSSARD, M.; QUIQUAMPOIX, H. Assessing organic phosphorus status of Cerrado oxisols (Brazil) using ${ }^{31} \mathrm{P}-\mathrm{NMR}$ spectroscopy and phosphomonoesterase activity measurement. Canadian Journal of Soil Science, v. 81, p. 591-601, 2001.

CHAPUIS-LARDY, L.; BROSSARD, M.; ASSAD, M.L.L.; LAURENT, J.Y. Carbon and phosphorus stocks in clayey Ferralsols (Cerrados, Brazil). Agriculture Ecosystems and Environment, 2002. No prelo.

CONDRON, L.M.; MOIR,J.O.; TIESSEN, H.; STEWART, J.W.B. Critical evaluation of methods for determining total organic phosphorus in tropical soils. Soil Science Society of American Journal, v. 54, p. 1261-1266, 1990.

CORREA, L. de A.; HAAG, H.P. Níveis críticos de fósforo para o estabelecimento de gramíneas forrageiras em Latossolo Vermelho-Amarelo, álico: I: Ensaio em casa de vegetação. Scientia Agricola, v. 50, n. 1, p. 99-108,.1993a.

CORREA, L. de A.; HAAG, H.P. Níveis críticos de fósforo para o estabelecimento de gramíneas forrageiras em Latossolo Vermelho-Amarelo, álico: II: Experimento de campo. Scientia Agricola, v. 50, n. 1, p. 109-116, 1993 b.

COATES, D.F.; KERRIDGE, P.C.; MILLER, C.P.; WINTER, W.H. Phosphorus and beef production in Northern Austrália. 7. The effect of phosphorus on the composition, yield and quality of legume based pasture and their relation to animal production. Tropical Grasslands, v. 24, p. 209-220, 1990.

COSTA F.P.; REHMAN, T. Exploring the link between farmers' objectives and the phenomenon of pasture degradation in the beef production systems of Central Brazil. Agricultural Systems, v. 61, p. 135-146, 1999.

CROSS, A.F.; SCHLESINGER, W.H. Biological and geochemical controls on phosphorus fractions in semiarid soils. Biogeochemistry, v. 52, p. 155-172, 2001.

DECKERS, F.O.; NACHTERGAELE, F.O.; SPAARGAREN, O.C. World Reference Base for Soil Resources: Introduction. Leuven: ISRIC-FAO-ISSS-Acco, 1998. $88 \mathrm{p}$.

EITEN G.; SAMBUICHI R.H.R. Effect of long-term periodic fire on plant diversity in a Cerrado region. In: SIMPÓSIO SOBRE O CERRADO, 8.; INTERNATIONAL SYMPOSIUM ON TROPICAL SAVANNAS, 1., Brasília, 1996. Biodiversidade e produção sustentável de alimentos e fibras nos cerrados/ Biodiversity and sustainable production of food and fibers in the Tropical Savannas, Anais/ Proceedings. Planaltina: EMBRAPA-CPAC, 1996. p. 46-55. 
EMPRESA BRASILEIRA DE PESQUISA AGROPECUÁRIA. Centro Nacional de Pesquisa de solos (Rio de Janeiro, RJ). Manual de métodos de análises de solos. 2. ed. Rio de Janeiro: EMBRAPA-CNPS, Rio de Janeiro, 1997. 212 p.

EMPRESA BRASILEIRA DE PESQUISA AGROPECUÁRIA. Centro Nacional de Pesquisa de Solos (Rio de Janeiro, RJ). Sistema Brasileiro de classificação de solos. Brasília: Embrapa Produção de Informação; Rio de Janeiro: Embrapa Solos, 1999. 414p.

EPSTEIN, E. Nutrição mineral de plantas: princípios e perspectivas. Rio de Janeiro: Livros Técnicos e Científicos, 1975. 341 p.

EUCLIDES, V.P.B.; MACEDO, M.C.M.; OLIVEIRA, M.P. Desempenho animal em pastagens de gramíneas recuperadas com diferentes níveis de fertilização. In: REUNIAO ANUAL DA SOCIEDADE BRASILEIRA DE ZOOTECNIA, 34., Juiz de Fora, 1997. Anais. Juiz de Fora: SBZ, 1997. p. 201-203.

EVANS, P.S. Comparative root morphology of some pasture grasses and clovers. New Zealand Journal of Agricultural Research, v. 20, p. 331-335, 1977.

FARDEAU, J.C. Le phosphore assimilable des sols: sa représentation par un modèle fonctionnel à plusieurs compartiments. Agronomie, v. 13, p. 317-331, 1993.

FARDEAU, J.C. Dynamics of phosphate in soils. An isotopic outlook. Fertilizer Research, v. 45, p. 91-100, 1996.

FARDEAU, J.C.; JAPPÉ, J. Nouvelle méthod de détermination du phosphore assimilable du sol par les plantes: Extrapolation des cinétiques de dilution isotopique. Comptes Rendus de l'Académie des Sciences, v. 282 D, p. 1137-1140, 1976.

FARDEAU, J.C.; CHABOUIS, C.; HETIER, J.M. Méthode des cinétiques de dilution isotopique des ions $\mathrm{PO} 4$ et $\mathrm{Ke}$ : application à l'analyse des modifications de fertilité dans les essais de très longue durée. Bulletin de l'Association Française pour l'Étude du Sol, v. 2, p. 111-121, 1977.

FARDEAU, J.C.; MOREL, C.; BONIFACE, R. Cinétiques de transferts des ions phosphate du sol vers la solution du sol: paramètres caractéristiques. Agronomie, v. 11, p. 787-797, 1991.

FARDEAU, J.C.; MOREL, C.; JAPPÉ, J. Cinétique d'echange des ions phosphate dans les systèmes sol-solution. Vérification expérimentale de l'équation théorique. Comptes Rendus de l'Académie des Sciences, t. 300, série III, v. 8, p. 371-376, 1985. 
FARDEAU, J.C.; MOREL, C.; BONIFACE, R. Pouquoi choisir la méthode Olsen pour estimer le phosphore "assimilable" des sols? Agronomie, v. 8, n. 7, p. 577-584, 1988.

FIGUIÉ, M. La construction sociale d'un savoi sur la dégradation des ressources naturelles: le cas des pâturages dans les exploitations agricoles familiales de la commune de Silvânia au Brésil. Paris, 2001. 326 p. Thèse (Doctorat) - Institut National Agronomique, Paris-Grignon.

FISHER, E.; THORNTON, B.; HUDSON, G.; EDWARDS, A.C. The variability in total and extractable soil phosphorus under a grazed pasture. Plant and Soil, v. 203, p. 249-255, 1998.

FONSECA, D.M.; GOMIDE, J.A.; ALVAREZ, V.H.; NOVAIS, R.F. Fatores que influenciam os níveis críticos de fósforo para o estabelecimento de gramíneas forrageiras. I. Casa de vegetação. Revista Brasileira de Ciência do Solo, v. 21, p. 27-34, 1997a.

FONSECA, D.M.; GOMIDE, J.A.; ALVAREZ, V.H.; NOVAIS, R.F. Fatores que influenciam os níveis críticos de fósforo para o estabelecimento de gramíneas forrageiras. II. Em campo. Revista Brasileira de Ciência do Solo, v. 21, p. 35-40, 1997b.

FONTES, M.P.F.; WEED, S.B. Phosphate adsorption by clays from Brazilian Oxisols: relationships with specific surface area and mineralogy. Geoderma, v. 72, p. 37-51, 1996.

FOX, R.L.; KAMPRATH, E.J. Phosphate sorption isotherms for evaluating the phosphate requirements of soils. Soil Science Society of American Proceedings, v. 34, p. 902-907, 1970.

FRIESEN, D.K.; RAO, I.M.; THOMAS, R.J.; OBERSON, A.; SANZ, J.I. Phosphorus acquisition and cycling in crop and pasture systems in low fertility tropical soils. Plant and Soil, v. 196, n. 2, p. 289-294, 1997.

FROSSARD, E.; BROSSARD, M.; HEDLEY, M.J.; METHERELL, A. Reactions controlling the cycling of $\mathrm{P}$ in soils. In: TIESSEN, H. (Ed.). Phosphorus in the global environment: transfers, cycles and management. Chichester: John Wiley, 1995. cap.7, p. 107-137.

FROSSARD, E.; FARDEAU, J.C.; BROSSARD, M.; MOREL, J.L. Soil isotopically exchanbeable phosphorus: A comparison between E and L values. Soil Science Society of America Journal, v. 58, p. 846-851, 1994. 
FROSSARD, E.; FARDEAU, J.C.; OGNALAGA, M.; MOREL, C. Influences of agricultural pratices, soil properties and parent material on the phosphate buffering capacity of cultivated soils developed in temperate climates. European Journal of Agronomy, v.1, n.1, p.45-50, 1992.

FROSSARD, E.; LÓPEZ-HERNÁNDEZ, D.; BROSSARD, M. Can isotopic exchange kinetics give valuable information on the rate of mineralization of organic phosphorus in soils? Soil Biology Biochemistry, v. 28, n. 7, p. 857-864, 1996.

FROSSARD, E.; SINAJ, S.; MÄCHLER, F. Interferences of colloidal particles in the determination of orthophosphate concentrations in soil water extracts. (compact disk) In: WORLD CONGRESS OF SOIL SCIENCE, 16., Montpellier, 1998. France. Proceedings. Montpellier: ISSS, 1998.

FURLEY, P.A.; RATTER J.A., Soil ressources and plant communities of the central Brazilian cerrado and their development. Journal of Biogeography, v. 15, p. 97 108, 1988.

GARCIA, E.A.C. Desenvolvimento econômico sustentável do Cerrado. Pesquisa Agropecuária Brasileira, v. 30, n. 6, p. 759-774, 1995.

GARCIA-MONTIEL, D.C.; NEILL; C.; MELILLO, J; THOMAS, S.; STEUDLER, P.A.; CERRI, C.C. Soil phosphorus transformations following forest clearing for pasture in the Brazilian Amazon. Soil Science Society of American Journal, v. 64, n. 5 , p. 1792-1804, 2000.

GOEDERT, W.J. Management of the cerrado soils of Brazil: a review. Journal of Soil Science, n. 3, p. 405-428, 1983.

GOEDERT, W.J.; LOBATO, E. Avaliação agronômica de fosfatos em solo de cerrado. Revista Brasileira de Ciência do Solo, v. 8, p. 97-102, 1984.

GUERRA, J.G.M.; ALMEIDA, D.L.; SANTOS, G.A.; FERNANDES, M.S. Conteúdo de fósforo orgânico em amostras de solos. Pesquisa Agropecuária Brasileira, v. 31, n. 4, p. 291-299, 1996.

HAMLETT, J.M.; HORTON, R.; CRESSIE, N.A.C. Resistant and exploratory techniques for use in semivariogram analyses. Soil Science Society of America Journal, v. 50, p. 868-875, 1986.

HARRISON, A.F. Soil organic phosphorus: a review of world literature. Oxon: CAB International, 1987. $257 \mathrm{p}$. 
HEDLEY, M.J.; STEWART, J.W.B.; CHAUHAN, B.S. Changes in inorganic and organic soil phosphorus fractions induced by cultivation practices and by laboratory incubations. Soil Science Society of American Journal, v. 46, p. 970-976, 1982.

HOCKING, P.J. Organic acids exuded from roots in phosphorus uptake and aluminum tolerance of plants in acid soils. Advances in Agronomy, v. 74, p. 63-97, 2001.

INTERNATIONAL ATOMIC ENERGY AGENCY. Use of isotope and radiation methods in soil and water management and crop nutrition: manual. Vienna, 2001a. p.178-180: Bioavailable phosphorus in soils - introduction to the isotopic exchange kinetics (IEK) method. (Training Courses Series, 14).

INTERNATIONAL ATOMIC ENERGY AGENCY. Use of isotope and radiation methods in soil and water management and crop nutrition: manual. Vienna, 2001b. p.180-194: Isotopic exchange kinetics (IEK) - reference method for the assessment of bioavailable soil P. (Training Courses Series, 14).

JACKSON, R.B.; MANWARING, J.H.; CALDWELL, M.M. Rapid physiological adjustment of roots to localized soil enrichment. Nature, v. 344, p. 58-60, 1990.

JOHN, M.K. Colorimetric determination of phosphorus in soil and plant materials with ascorbic acid. Soil science, v. 109, n. 4, p. 214-220, 1970.

KANNO, T.; MACEDO, M.C.M.; EUCLIDES, V.B.P.; BONO, J.A.M.; SANTOS JÚNIOR, J.D.G.; CORREAA, R.M.; BERETTA, L.G. Root biomass of five tropical grass pastures under continuos grazing in Brazilian Savannas. Grassland Science, v. 45, n. 1, p. 9-14, 1999.

KER, J.C. Mineralogia, sorção e dessorção de fosfato, magnetização e elementos traços de Latossolos do Brasil. Viçosa, 1995. 181 p. Tese (Doutorado) Universidade Federal de Viçosa.

KER, J.C.; RESENDE, M. Recursos edáficos dos Cerrados: ocorrência e potencial. In: SIMPÓSIO SOBRE O CERRADO, 8.; INTERNATIONAL SYMPOSIUM ON TROPICAL SAVANNAS, 1., Brasília, 1996. Biodiversidade e produção sustentável de alimentos e fibras nos cerrados/ Biodiversity and sustainable production of food and fibers in the Tropical Savannas, Anais. Planaltina: EMBRAPA-CPAC, 1996. p. 15-19.

KLAMT E.; VAN REEUWIJK, L.P. Evaluation of morphological, physical and chemical characteristics of ferralsols and related soils. Revista Brasileira de Ciência do Solo, v. 24, p. 573-587, 2000. 
KLUTHCOUSKI, J.; OLIVEIRA, I.P.; YOKOYAMA, L.P.; DUTRA, L.G.; PORTES, T.A.; SILVA, A.E.; PINHEIRO, B.S.; FERREIRA, E.; CASTRO, E.M.; GUIMARÃES, C.M.; GOMIDE, J.C.; BALBINO, L.C. Sistema Barreirão: recuperación/renovación de pasturas degradadas utilizando cultivos anuales. In: GUIMARÃES, E.P.; SANS, J.I.; RAO, I.M.; AMÉZQUITA, M.C.; AMÉSQUITA, E. (Ed.). Sistemas agropastoriles en sabanas tropicales de America Latina. Cali: CIAT; Brasília: Embrapa, 1999. cap.15, p. 195-231.

KORNELIUS, E.; SAUERESSING, M.G.; GOEDERT, W.J. Pasture establishment and management in the Cerrado of Brazil. In: SANCHEZ, P.A.; TERGAS, L.E. (Ed.). Pasture production in acid soils of the tropics. Cali: CIAT, 1979. p. 147-166.

LARSEN, S. The use of ${ }^{32} \mathrm{P}$ in studies on the uptake of phosphorus by plants. Plant and Soil, v. 4, p. 1-10, 1952.

LASCANO, C.E. Managing the grazing resource for animal production in savannas of tropical America. Tropical Grasslands, v. 25, p. 66-72, 1991.

LE MARE, P.H. Sorption of isotopically exchangeable and non-exchangeable phosphate by some soils of Colombia and Brazil, and comparisons with soils of southern Nigeria. Journal of Soil Science, v. 33, p. 691-7.07, 1982.

LEMOS, R.C. de; SANTOS, R.D.dos. Manual de descrição e coleta de solo no campo. 3.ed. Campinas: Sociedade Brasileira de Ciência do Solo, 1996. 83p.

LILIENFEIN, J.; WILCKE, W.; AYARZA; M.A.; VILELA, L.; LIMA, S.C.; ZECH, W. Chemical fractionation of phosphorus, sulphur, and molybdenum in Brazilian savannah Oxisols under different land use. Geoderma, v. 96, p. 31-46, 2000.

LOBATO, E.; KORNELIUS, E.; SANZONOWICZ, C. Adubação fosfatada em pastagens. In: SIMPÓSIO SOBRE ADUBAÇÃO E CALAGEM DE PASTAGENS, 1., Nova Odessa, 1985. Calagem e adubação de pastagens. Piracicaba: POTAFOS, 1986. p. 145-174.

LOPES, A.S. Available water, phosphorus fixation, and zinc levels in Brazilian cerrado soils in relation to their physical, chemical, and mineralogical properties. Raleigh, 1977. 189 p. Thesis (PhD). North Caroline State University.

LOPES, A.S. Diretrizes para o manejo sustentável dos solos brasileiros - região dos Cerrados.In: CONGRESSO BRASILEIRO DE CIÊNCIA DO SOLO, 26., Rio de Janeiro, 1997. Informação, globalização, uso do solo: Anais. Rio de Janeiro:SBCS, 1997. p. $65-80$.

LOPES, A.S.; COX, F.R. A survey of the fertility status of surface soils under "cerrado" vegetation in Brazil. Soil Science Society of American Journal, v. 41, p. 742-747, 1977. 
LOPES, A.S.; COX, F.R. Relação de características físicas, químicas e mineralógicas com fixação de fósforo em solos sob Cerrados. Revista Brasileira de Ciência do Solo, v. 3, p. 82-88, 1979.

LOPES, A.S.; GOEDERT, W.J. Phosphorus status and agronomic efficiency of phosphate fertilizers in the Cerrado region of Brazil. In: PHOSPHORUS CYCLES IN TERRESTRIAL AND AQUATIC ECOSYSTEMS: REGIONAL WORKSHOP 3: SOUTH AND CENTRAL AMERICA. Maracay, 1989. Proceedings. Saskatoon: Saskatchewan Institute of Pedology, 1991. p. 203-220.

LÓPEZ-HERNÁNDEZ, D.B.; BURNHAM, C.P. The covariance of phosphate sorption with other soil properties in some British and Tropical soils. Journal of Soil Science, v. 25, p. 195-206, 1974.

MACEDO, J. Pastagens no ecossistema Cerrados: pesquisas para o desenvolvimento sustentável. In: SIMPOSIO SOBRE PASTAGENS NOS ECOSSISTEMAS BRASILEIROS; REUNIAO ANUAL DA SOCIEDADE BRASILEIRA DE ZOOTECNIA, 32., Brasilia, 1995. Pesquisas para o desenvolvimento sustentavel: Anais. Brasília: SBZ, 1995. p. 28-62.

MACEDO, M.C.M.; EUCLIDES, V.P.B.; OLIVEIRA, M.P. Seasonal changes in the chemical composition of cultivated tropical grasses in the savannas of Brazil. In: INTERNATIONAL GRASSLAND CONGRESS, 17., Rockhampton, 1993. Proceedings. Palmerston North: New Zealand Grassland Association, 1993. p. 20002002.

MACEDO, M.C.M.; ZIMMER, A.H. Sistema pasto-lavoura e seus efeitos na produtividade agropecuária. In: SIMPOSIO SOBRE ECOSSISTEMA DE PASTAGENS, 2., Jaboticabal, 1993. Anais. Jaboticabal: FUNEP, 1993. p. 216-245.

MALAVOLTA, E.; PELLEGRINO, D. Nota sobre algumas transformações do superfosfato radioativo em terra roxa. Revista de Agricultura, v. 29, p. 317-323, 1954.

McAULIFFE, C.D.; HALL, N.S.; DEAN, L.A.; HENDRICKS, S.B. Exchange reactions between phosphates and soils: Hydroxylic surfaces of soil minerals. Soil Science Society of American Proceedings, v. 12, p. 119-123, 1948.

McDOWELL, R.W.; SHARPLEY, A.N. Soil phosphorus fractions in solution: influence of fertiliser and manure, filtration and method of determination. Chemosphere, $v$. 45, n. 6-7, p. 737-748, 2001.

MEHLICH, A. Determination of $\mathbf{P}, \mathbf{C a}, \mathbf{M g}, \mathbf{K}, \mathbf{N a}$, and $\mathbf{N H}_{4}$. Raleigh: North Carolina Soil Test Div., 1953. (não publicado) 
MESQUITA FILHO, M.V.; TORRENT, J. Phosphate sorption as related to mineralogy of a hydrosequence of soils from the cerrado region (Brazil). Geoderma, v. 58, p. 107-123, 1993.

MOREL, C.; FARDEAU, J.C. Le phosphore assimilable des sols intertropicaux : ses relations avec le phosphore extrait par deux méthodes chimiques. L'agronomie Tropicale, v. 42, n. 4, p. 248-257, 1987.

MOREL, C.; PLECHETTE, C. Is the isotopically exchangeable phosphate of a loamy soil the plant-available P? Plant and Soil, v. 158, p. 287-297, 1994.

MOREL, C.; TIESSEN, H.; STEWART, J.W.B. Phosphorus transformations and availability due to crop rotations and mineral fertilization assessed by the isotopic exchange method. Soil Science Society of American Journal, v. 58, p. 1439-1445, 1994.

MOREL, C.; TIESSEN, H.; STEWART, J.W.B. Sensitivity to equilibration periods of phosphate sorption and isotopic exchange methods assessing Q/I relationships in soils. Soil Science, v. 161, n. 7, p. 459-467, 1996.

NEUFELDT, H.; SILVA, J.E.; AYARZA, M.A.; ZECH, W. Land-use effects on phosphorus fractions in Cerrado oxisols. Biology and Fertility of Soils, v. 31, p. 30$37,2000$.

NORTHUP, B.K.; BROWN, J.R.; HOLT, J.A. Grazing impacts on the spatial distribution of soil microbial biomass around tussock grasses in a tropical grassland. Applied Soil Ecology, v. 13, p. 259-270, 1999.

NOVAIS, R.F.de; SMYTH, T.J. Fósforo em solo e planta em condições tropicais. Viçosa, MG: UFV, 1999. 399p.

OBERSON, A.; FRIESEN, D.K.; TIESSEN, H.; MOREL, C.; STAHEL, W. Phosphorus status and cycling in native savanna and improved pastures on an acid low-P Colombian Oxisol. Nutrient Cycling in Agroecosystems, v. 55, p. 77-88, 1999.

OLIVEIRA FILHO, A.T., SHEPHERD G.J.; MARTINS F.R.; STUBBLEBINE W.H. Environmental factors affecting physionomy and floristic variation in an area of Cerrado in central Brazil. Journal of Tropical Ecology, v. 5, p. 413-431, 1989.

OLIVEIRA, I.P.; KLUTHCOUSKI, J.; YOKOYAMA, L.P.; DUTRA, L.G.; PORTES, T.A.; SILVA, A.E.; PINHEIRO, B.S.; FERREIRA, E.; CASTRO, E.M.; GUIMARÃES, C.M.; GOMIDE, J.C.; BALBINO, L.C. Sistema Barreirão: recuperação/renovação de pastagens degradadas em consórcio com culturas anuais. Goiânia: EMBRAPA-CNPAF, 1996. 90p. (EMBRAPA-CNPAF. Documentos, 64). 
PANNATIER, Y. Variowin: software for spatial data analysis in 2D, V.2.2. New York: Springer-Verlag, 1996, 93p.

PETERSEN, R.G.; LUCAS, H.L.; WOODHOUSE, W.W. The distribution of excreta by freely grazing cattle and its effect on pasture fertility. I. Excretol distribution. Agronomy Journal, v. 48, p. 440-444, 1956 .

PETERSEN, R. G.; WOODHOUSE, W.W.; LUCAS, H.L. The distribution of excreta by freely grazing cattle and its effect on pasture fertility. II. Effect of returned excreta on the residual concentration of some fertilizer elements. Agronomy Journal, v. 48, p. $444-449,1956 b$.

RAJAN, S.S.S. Phosphorus adsorption characteristics of Hawaiian soils and their ralationships to equilibrium phosphorus concentrations required for maximum growth of millet. Plant and Soil, v. 39, p. 519-532, 1973.

RAIJ, B. van; QUAGGIO, J.A.; SILVA, N.M. Extraction of phosphorus, potassium, calcium and magnesium from soils by an ion-exchange resin procedure. Communications in Soil Science and Plant Analisis, v. 17, p. 544-566, 1986.

RAO, A.S.; REDDY, K.S.; TAKKAR, P.N. Malachite green method compared to ascorbic acid for estimating small amounts of phosphorus in water, $0.01 \mathrm{M}$ calcium chloride, and Olsen soil extracts. Communications in Soil Science and Plant Analisis, v. 28, n. 6/8, p. 589-601, 1997.

RAO, I.M.; AYARZA, M.A.; GARCIA, R. Adaptive attributes of tropical forage species to acid soils I. Differences in plant growth, nutrient acquisition and nutrient utilization among C4 grasses and C3 legumes. Journal of Plant Nutrition, v. 18, $\mathrm{n}$. 10, p. 2135-2155, 1995.

RAO, I.M.; BORRERO, V.; RICAURTE, J.; GARCIA, R.; AYARZA, M.A. Adaptive attributes of tropical forage species to acid soils II. Differences in shoot growth responses to varying phosphorus supply and soil type. Journal of Plant Nutrition, v. 19, n. 2 , p. $323-352,1996$.

RAO, I.M.; BORRERO, V.; RICAURTE, J.; GARCIA, R.; AYARZA, M.A. Adaptive attributes of tropical forage species to acid soils III. Differences in phosphorus acquisition and utilization as influenced by varying phosphorus supply and soil type. Journal of Plant Nutrition, v. 20, n. 1, p. 155-180, 1997.

RAO, I.M.; BORRERO, V; RICAURTE, J; GARCIA, R Adaptive attributes of tropical forage species to acid soils. IV. Differences in shoot and root growth responses to inorganic and organic phosphorus sources. Journal of Plant Nutrition, New York, v. 22, n. 7 , p. 1153-1174, 1999a. 
RAO, I.M.; BORRERO, V; RICAURTE, J; GARCIA, R Adaptive attributes of tropical forage species to acid soils. V. Differences in phosphorus acquisition from less available inorganic and organic sources of phosphate. Journal of Plant Nutrition, $v$. 22 , n. 7, p. 1175-1196, 1999b.

RAO, I.M.; ZEIGLER, R.S.; VERA, R.; SARKARUNG, S. Selection and breeding for acid soil tolerance in crops: Upland rice and tropical forage as case studies. Bio Science, v. 43, p. 454-465, 1993.

REIS, C.; FABRIS, J.D.; NOVAIS, R.F.; BAHIA FILHO, A.F.C.; SANTANA, D.P.; CURI, N.; COEY, J.M.D. Cinética de sorção de fósforo em alguns solos de Minas Gerais. Revista Brasileira de Ciência do Solo, Campinas, v. 19, p. 337-344, 1995.

REYNOLDS, H.L.; HUNGATE, B.A.; CHAPIN, III, F.S.; D'ANTONIO, C.M. Soil heterogeneity and plant competition in an annual grassland. Journal of Ecology, v. 78, p. 2076-2090, 1997.

REZENDE, C. de P.; CANTARUTTI, R.B.; BRAGA, J.M.; GOMIDE, J.A.; PEREIRA, J.M.; FERREIRA, E.; TARRÉ, R.; MACEDO, R.; ALVES, B.J.R.; URQUIAGA, S.; CADISH, G.; GILLER, K.E.; BODDEY, R.M. Litter deposition and disappearance in Brachiaria pastures in the Atlantic forest region of the South of Bahia, Brazil. Nutrient Cycling in Agroecosystems, v. 54, p. 99-112, 1999.

RIBEIRO, J.F., WALTER, B.M.T. Fitofisionomias do bioma Cerrado. In: SANO, S.M.; DE ALMEIDA, S.P. (Ed.). Cerrado: ambiente e flora. Planaltina: Embrapa-CPAC, 1998. cap. 3, p. 87-166.

RICHARDSON, A.E. Prospects for using soil microorganisms to improve the acquisition of phosphorus by plants. Australian Journal of Plant Physiology, v. 28, p. 897-906, 2001.

ROBINSON, J.S.; SYERS, J.K. A critical evaluation of the factors influencing the dissolution of Gafsa phosphate rock. Journal of Soil Science, v. 41, p. 597-605, 1990.

ROCHA, C.M.C. da; MADEIRA NETO, J. da S. Recuperation and development of acid soils in the Brazilian "Cerrados". WORKSHOP TO DEVELOP A STRATEGY FOR COLLABORATIVE RESEARCH AND DISSEMINATION OF TECHNOLOGY IN SUSTAINABLE CROP PRODUCTION IN ACID SAVANNAS AND OTHER PROBLEM SOILS OF THE WORLD. West Lafayette, 1998. Procedings. West Lafayette: Purdue University, 1998. p.13-26. 
SALCEDO, I.H.; BERTINO, F.; SAMPAIO, E.V.S.B. Reactivity of phosphorus in Northeastern Brazilian soils assessed by isotopic dilution. Soil Science Society America Journal, v. 55, p. 140-145, 1990.

SALINAS, J.G.; SANZ, J.I.; SIEVERDING, E. Importance of VA mycorrhizae for phosphorus supply to pasture plants in tropical soils. Plant and Soil, v. 87,p. 347$360,1985$.

SANO, E.E.; BARCELLOS, A.O.; BEZERRA, H.S. Assessing the spatial distribution of cultivated pastures in the Brazilian savanna. Pasturas Tropicales, v. 22, n. 3, p. 2$15,2000$.

SANZONOWICZ, C.; GOEDERT, W.J. Uso de fosfatos naturais em pastagens. Planaltina, DF: Embrapa-CPAC, 1986. 33p. (Embrapa-CPAC, Circular técnica ,21).

SAS INSTITUTE (Cary, NC). SAS/STAT: user's guide, version 6. 4.ed. Cary, NC, 1989. 943p. v.1.

SAVIDAN Y.; JANK, J.; DE SOUZA, F.H.D. de; BOOK, A. Preliminary evaluation of Panicum maximum germplasm in Brazil. In: INTERNATIONAL GRASSLAND CONGRESS, 15., Kyoto, 1985. Proceedings. Japan: The Science Council of Japan/ The Japanese Society of Grassland Science, 1985. p.117-118.

SECRETARIA DE PLANEJAMENTO E COORDENACAO GERAL (CAMPO GRANDE, MS). Macrozoneamento geoambiental do Estado de Mato Grosso do Sul. Campo Grande: SEPLAN-MS/IBGE, 1989. 242p. (Projeto Estudos Integrados do Potencial de Recursos Naturais. A obra inclui 1 Atlas Multirreferencial do Estado do Mato Grosso do Sul).

SHARPLEY, A.N. Phosphorus cycling in unfertilized agricultural soils. Soil Science Society of American Journal, v. 49, n. 4, p. 905-91 1, 1985.

SILVA, F.C.; RAIJ, B. van. Disponibilidade de fósforo em solos avaliada por diferentes extratores. Pesquisa Agropecuária Brasileira, v. 34, n. 2, p. 267-288, 1999.

SMYTH, T.J.; SANCHEZ, P.A. Níveis críticos de fósforo para arroz de sequeiro em um latossolo dos cerrados. Revista Brasileira de Ciência do Solo, v. 4, p. 88-92, 1980.

SOARES, W.S.; LOBATO, E.; SOUSA, D.M.G. de; REIN, T.A. Avaliação do fosfato natural de gafsa para recuperação de pastagem degradada em Latossolo VermelhoEscuro. Pesquisa Agropecuária Brasileira, v. 35, p. 819-825, 2000. 
SOARES, W.S.; MACEDO, M.C.M.; VILELA, L.; SOUZA, O.C. Resposta da Brachiaria decumbens cv. Basilisk ao fósforo e níveis críticos de $P$ num Latossolo Roxo. Planaltina: Embrapa Cerrados. 1999. 25p. (Embrapa Cerrados: Boletim de Pesquisa, 4).

SOUZA, R.F.; PINTO, J.C.; SIQUEIRA, J.O.; REZENDE, V.F. Micorriza e fósforo no crescimento de Brachiaria brizantha e Stylosanthes guianenses em solo de baixa fertilidade. 1. Produção de matéria seca e proteína bruta. Pasturas Tropicales, v. 21, n. 3, p. 19-23, 1999a.

SOUZA, R.F.; PINTO, J.C.; SIQUEIRA, J.O.; REZENDE, V.F. Micorriza e fósforo no crescimento de Brachiaria brizantha e Stylosanthes guianenses em solo de baixa fertilidade. 2. Acúmulo de minerais. Pasturas Tropicales, v. 21, n.3, p. 24-30, 1999b.

SPAD versão 3.5. Logiciel d'Analyse des Données. (Centre International de Statistique e d'Informatique Appliquées) CISIA-CERESTA. 1998.

STATSOFT. Statistica for windows V.6.0. Tulsa: Statsoft, 1996.

THOMAS, D.; ANDRADE, R.P.de. The persistence of tropical grass-legume associations under grazing in Brazil. Journal of Agricultural Science, v. 102, p. 257-263, 1984.

TIESSEN, H.; MOIR, J.O. Characterization of available P by sequential extraction. In: CARTER, M.R. (Ed.). Soil sampling and methods of analysis. Boca Raton, FL: Canadian Society Of Soil Science, 1993. cap. 10, p. 75-86.

TIESSEN, H.; SALCEDO, I.H.; SAMPAIO, E.V.S.B. Nutrient and soil organic matter dynamics under shifting cultivation in semi-arid Northeastern Brazil. Agriculture Ecosystem and Environment, v. 38, p. 139-151, 1992.

TIESSEN, H.; STEWART, J.W.B.; COLE, C.V. Pathways of phosphorus transformations in soils of different pedogenesis. Soil Science Society of America Journal, v. 48, p. 853-858, 1984.

TRAN, T.S.; FARDEAU, J.C.; GIROUX, M. Effects of soil properties on plantavailable phosphorus determined by the isotopic dilution phosphorus-32 method. Soil Science Society America Journal, v. 52, p. 1383-1390, 1988.

TYLER, G. Cover distributions of vascular plants in relation to soil chemistry and soil depth in a granite rock ecosystem. Vegetatio, v. 27, p. 215-223, 1996.

VAN WAMBEKE, A. Oxisols: soils of the tropics properties and appraisal. New York: Mc Graw-Hill, 1992. 392 p. 
VILELA, L.; AYARZA, M.A.; MIRANDA, J.C.C. de. Agropastoral systems: activities developed by cerrados agricultural research center (EMBRAPA Cerrados). In: KANNO, T.; MACEDO, M.C.M. (Ed.). JIRCAS / EMBRAPA gado de corte international joint workshop on agropastoral system in South America. Tsukuba: JIRCAS, 2001. p.19-33. (JIRCAS Working Report, 19). EMBRAPACNPGC and JIRCAS joint International Workshop on Agrospatoral System in South America, held in Campo Grande, MS, Brazil, 1999.

VILELA, L.; SOARES, W.V.; SOUSA, D.M.G.; MACEDO, M.C.M. Calagem e adubação para pastagens na região do cerrado. Planaltina: Embrapa Cerrados. 2000. 15 p. (Embrapa Cerrados. Circular Técnica, 37).

WAHID, P.A. Radioisotope studies of root activity and root-level interactions in treebased productions systems: a review. Applied Radiation and Isotopes, v. 54, p.715$736,2001$.

WALWORTH, J.L.; SUMNER, M.E. The diagnosis and recommendation integrated system (DRIS). Advances in Soil Science, v. 6, p. 149-188, 1987.

WANIEZ, P. Les Cerrados: un "espace frontière" brésilien., Montpellier: G.I.P. RECLUSORSTOM, 1992.344 p.

WHITE, R.E.; BECKETT, P.H.T. Studies on phosphate potentials of soils. Part I. The measurement of phosphate potential. Plant and Soil, v. 20, p. 1-16, 1964.

WOLF, A.M., BAKER, D.E.; PIONKE, H.B. The measurement of labile phosphorus by the isotopic dilution and anion resin methods. Soil Science, v. 141, n. 1, p. 60-69, 1986.

YOKOYAMA， L.P.; KLUTHCOUSKI， J.; OLIVEIRA， I.P.D.; DUTRA， L.G.; GOMIDE, J.C.; BUSO, L.H. Sistema Barreirao: análise de custo/benefício e necessidade de máquinas e implementos agrícolas. Goiânia: EMBRAPA-CNPAF, 1995. 31p. (EMBRAPA-CNPAF. Documentos, 56).

YOST, R.S.; KAMPRATH, E.J.; LOBATO, E.; NADERMAN, G. Phosphorus response of corn on an Oxisol as influenced by rates and placement. Soil Science Society of America Journal, v. 43, p. 338-343, 1979.

ZIMMER, A.H.; CORREA, E.S. A pecuária nacional, uma pecuária de pasto? In: ENCONTRO SOBRE RECUPERACAO DE PASTAGENS, 1., Nova Odessa, 1993. Anais. Nova Odessa: Instituto de Zootecnia, 1993. p.1-25.

ZIMMER, A.H.; EUCLIDES FILHO, K.P. As pastagens e a pecuária de corte brasileira. In: SIMPÓSIO INTERNACIONAL SOBRE PRODUÇÃO ANIMAL EM PASTEJO, Viçosa, 1997. Anais. Viçosa: UFV, 1997. p. 350-379. 


\section{APÊNDICES}




\section{APÊNDICE 1}

\section{LEVANTAMENTO BIBLIOGRÁFICO DOS ARTIGOS DA}

REVISTA BRASILEIRA DE CIÊNCIA DO SOLO 1978-2000 RELATIVOS AO FÓSFORO DO SOLO 


\section{Levantamento bibliográfico dos artigos da Revista Brasileira de Ciência do Solo 1978-2000 relativos ao fósforo do solo.}

Abichequer, A.D.; Bohnen, H. Eficiência de absorção, translocação e utilização de fósforo por variedades de trigo. R. Bras. Ci. Solo, v. 22, p. 21-26, 1998.

Alcarde, J.C.; Ponchio, C.O. A ação solubilizante das soluções de citrato de amônio e de ácido cítrico sobre fertilizantes fosfatados. R. Bras. Ci. Solo, v. 3, p. 173-178, 1979.

Alcarde, J.C.; Malavolta, E. Solubilidade de um fosfato natural de araxá parcialmente acidulado, nos extratores químicos de avaliação do fósforo em fertilizantes. R. Bras. Ci. Solo, v. 6, p. 59-62, 1982.

Almeida Neto, J.X.; Brasil Sobrinho, M.O.C. Fixação de fósforo em três solos sob Cerrado de Goiás. R. Bras. Ci. Solo, v. 1, p. 12-15, 1977.

Alves, V.C.M.; Magalhães, J.V.; Vasconcellos, C.A.; et al. Acúmulo de nitrogênio e de fósforo em plantas de milho afetadas pelo suprimento parcial de fósforo às raízes. R. Bras. Ci. Solo, v. 23, p. 299-305, 1999.

Ambrosano, E.J.; Corsi, M.; Trivelin, P.C.O.; et al. Aproveitamento do nitrogênio do sulfato de amônio (15N) pelo capim colonião em sucessivos cortes e diferentes épocas de adubação. R. Bras. Ci. Solo, v. 20, p. 277-282, 1996.

Araújo, M.S.B.; Salcedo, I.H. Formas preferenciais de a cumulação de fósforo em solos cultivados com canade-açúcar na Região Nordeste. R. Bras. Ci. Solo, v. 21, p. 643-650, 1997.

Bahia $\mathrm{F}^{\mathrm{o}}$, A.F.C.; Vasconcellos, C.A.; Santos, H.L.; et al. Formas de fósforo inorgânico e fósforo "disponível" em um latossolo vermelho-escuro, fertilizado com diferentes fosfatos. R. Bras. Ci. Solo, v. 6, p. 99-104, 1982.

Bahia Fo, A.F.C.; Vasconcellos, C.A.; Santos, H.L.; et al. Relação entre adsorção de fósforo e componentes mineralógicos da fração argila de Latossolos do Planalto Central. R. Bras. Ci. Solo, v. 6, p. 99-104, 1983.

Barbosa $F^{\circ}$, M.P.; Kinjo, T.; Muraoka, T. Relações entre fósforo "extraível", frações inorgânicas de fósforo e crescimento de arroz em função de fontes de fósforo, calagem e tempo de incubação. R. Bras. Ci. Solo, v. 11, p. 147-155, 1987.

Berg, M.; Klamt, E. Variabilidade espacial de características de solos na Região do Planalto Médio, RS: I. Análise de variância por amostragem aninhada. R. Bras. Ci. Solo, v. 21, p. 393-399, 1997.

Berg, M.; Klamt, E. Variabilidade espacial de características de solos na Região do Planalto médio, RS: II. Análise da semivariância e da variância. R. Bras. Ci. Solo, v. 21, p. 401-408, 1997.

Berton, R.S.; Pratt, P.F. Evaluation of phosphorus requirement by the sorption isotherm technique in soils amended with organic materials. R. Bras. Ci. Solo, v. 21, p. 199-206, 1997.

Berton, R.S.; Pratt, P.F.; Frankenberger Jr., W.T. Phosphorus availability in soils amended with organic materials, estimated by three chemical methods and two enzyme activities. R. Bras. Ci. Solo, v. 21, p. 617-624, 1997.

Boschetti, A.N.G.; Quintero, G. C.E.; Benavidez, Q.R.A. Caracterização do fator capacidade de fósforo em solos de Entre Ríos, Argentina. R. Bras. Ci. Solo, v. 22, p. 95-99, 1998.

Braga, N.R.; Mascarenhas, H.A.A.; Feitosa, C.T.; et al. Efeitos de fosfatos sobre o crescimento e produção de soja. R. Bras. Ci. Solo, v. 4, p. 36-39, 1980.

Braga, N.R.; Mascarenhas, H.A.A.; Bulisani, E.A. Eficiência agronômica de nove fosfatos em quatro cultivos consecutivos de soja. R. Bras. Ci. Solo, v. 15, p. 315-319, 1991.

Braida, J.A.; Camargo, F.O.A.; Rosso, I.J.; et al. Comparação de métodos de determinação da disponibilidade de fósforo do solo para as plantas. R. Bras. Ci. Solo, v. 20, p. 345-347, 1996.

Brasil, E.C.; Muraoka, T. Extratores de fósforo em solos da Amazônia tratados com fertilizantes fosfatados. R. Bras. Ci. Solo, v. 21, p. 599-606, 1997.

Cabala, P.; Santana, M.B.M. Disponibilidade e diagnose de fósforo pela análise química do solo com referência ao Brasil. R. Bras. Ci. Solo, v. 7, p. 109-1 18, 1983.

Camargo, O.A. O papel do íon fluoreto na adsorção, dessorção e movimento de fósforo em Alfisol. R. Bras. Ci. Solo, v. 3, p. 141-144, 1979.

Camargo, O.A.; Biggar, J.W.; Nielsen, D.R. Efeito do cálcio ou do potássio na adsorção e movimento do fósforo em um Alfisol. R. Bras. Ci. Solo, v. 3, p. 8-13, 1979.

Cantarutti, R.B.; Braga, J.M.; Novais, R.F.; et al. Época de aplicação de fosfato natural em relação à calagem, num solo com elevado teor de alumínio trocável. R. Bras. Ci. Solo, v. 5, p. 129-133, 1981. 
Carvalho, M.M.; Saraiva, O.F.; Oliveira, F.T.T.; et al. Respostas de leguminosas forrageiras tropicais à calagem e ao fósforo, em casa de vegetação. R. Bras. Ci. Solo, v. 12, p. 153-159, 1988.

Carvalho, M.M.; Saraiva, O.F.; Verneque, R.S. Níveis críticos externos e internos de fósforo de duas leguminosas tropicais em um solo ácido. R. Bras. Ci. Solo, v. 13, p. 311-314, 1989.

Carvalho, M.M.; Martins, C.E.; Verneque, R.S.; et al. Resposta de uma espécie de braquiária à fertilização com nitrogênio e potássio em um solo ácido. R. Bras. Ci. Solo, v. 15, p. 195-200, 1991.

Carvalho, ${ }^{a}$ M.; Fageria, N.K.; Oliveira, I.P.; et al. Reposta do feijoeiro à aplicação de fósforo em solos dos Cerrados. R. Bras. Ci. Solo, v. 19, p. 61-67, 1995.

Carvalho, R.; Furtini Neto, ${ }^{a}$ E.; Curi, N.; et al. Dessorção de fósforo por silício em solos cultivados com eucalipto. R. Bras. Ci. Solo, v. 24, p. 69-74, 2000.

Casagrande, J.C.; Camargo, O.A. Adsorção de fosfato em solos com caráter ácrico avaliada por um modelo de complexação de superficie. R. Bras. Ci. Solo, v. 21, p. 353-360, 1997.

Cordeiro, D.S.; Pöttker, D.; Borkert, C.M.; et al. Efeito de níveis e fontes de fósforo na produção e no rendimento econômico da soja na Região de Dourados (MS). R. Bras. Ci. Solo, v. 3, p. 100-105, 1979.

Delazari, P.C.; Braga, J.M.; Novais, R.F.; et al. Disponibilidade de fósforo em solos do estado do Espírito Santo. R. Bras. Ci. Solo, v. 4, p. 149-153, 1980.

Delazari, P.C.; Braga, J.M.; Novais, R.F. Parâmetros de fósforo em função de características químicas e físicas de solos. R. Bras. Ci. Solo, v. 7, p. 55-60, 1983.

Dynia, J.F.; Camargo, O.A. Adsorção e movimento de sulfato em latossolo de Cerrado submetido a calagem e adubação fosfatada. R. Bras. Ci. Solo, v. 19, p. 249-253, 1995.

Ernani, P.R.; Figueiredo, O.R.A.; Becegato, V.; et al. Decréscimo da retenção de fósforo no solo pelo aumento de pH. R. Bras. Ci. Solo, v. 20, p. 159-162, 1996.

Ernani, P.R.; Nascimento, J.L.A.; Campos, M.L.; et al. Influência da combinação de fósforo e calcário no rendimento de milho. R. Bras. Ci. Solo, v. 24, p. 537-544, 2000.

Faquin, V.; Hoffmann, C.R.; Evangelista, A.R.; et al. O potássio e o enxofre no crescimento da braquiária e do colonião em amostras de um latossolo da Região Noroeste do Paraná. R. Bras. Ci. Solo, v. 19, p. 8794, 1995.

Fernandes, S.B.V.; Kaminski, J. Efeito de níveis de acidulação do fosfato-de-araxá no suprimento de fósforo à sucessão sorgo-soja-aveia, em dois solos. R. Bras. Ci. Solo, v. 11, p. 157-160, 1987.

Fernandes, M.F.; Ruiz, H.A.; Neves, J.C.L.; et al. Crescimento e absorção de fósforo em plantas de Eucalyptus grandis associadas a fungos micorrizicos em diferentes doses de fósforo e potencias de água no solo. R. Bras. Ci. Solo, v. 23, p. 617-626, 1999.

Fernandes, M.F.; Faquin, V.; Furtini Neto, E.; et al. Frações de fósforo e atividade da fosfatase ácida em plantas de feijoeiro cultivadas em solos de várzea. R. Bras. Ci. Solo, v. 24, p. 561-571, 2000.

Ferreira, T.N.;Kaminski, J. Eficiência agronômica dos fosfatos naturais de Patos-deMinas e gafsa puros e modificados por acidulação e calcinação. R. Bras. Ci. Solo, v. 3, p. 158-162, 1979.

Fonseca, D.M.; Alvarez, V.H.; Neves, J.C.L.; et al. Níveis críticos de fósforo em amostras de solos para o estabelecimento de Andropogon gayanus, Brachiaria decumbens e Hyparrhenia mufa. R. Bras. Ci. Solo, v. 12 , p. $49-58,1988$.

Fonseca, D.M.; Gomide, J.A.; Alvarez, V.H.; et al. Fatores que influenciam os níveis críticos de fósforo para o estabelecimento de gramíneas forrageiras: I. casa de vegetação. R. Bras. Ci. Solo, v. 21, p. 27-34, 1997.

Fonseca, D.M.; Gomide, J.A.; Alvarez, V.H.; et al. Fatores que influenciam os níveis críticos de fósforo para o estabelecimento de gramíneas forrageiras: II. em campo. R. Bras. Ci. Solo, v. 21, p. 35-40, 1997.

Freire, F.M.; Novais, R.F.; Braga, J.M.; et al. Adubação fosfatada para a cultura da soja (Glicine max (L.) Merril) baseada no fósforo "disponível" em diferentes extratores químicos e no "fator capacidade". $\mathbf{R}$. Bras. Ci. Solo, v. 3, p. 105-111, 1979.

Freire, F.M.; Braga, J.M.; Martins $\mathrm{F}^{\circ}$, C.A.S . Valor fertilizante de fosfatos solúveis, araxá e parcialmente acidulado. R. Bras. Ci. Solo, v. 7, p. 65-68, 1983.

Galrão, E.; Volkweiss, S.J. Disponibilidade de fósforo do solo para as plantas. R. Bras. Ci. Solo, v. 5, p. 114$118,1981$.

Galrão, E.; Andrade, R.P.; Vilela, L. Efeito de micronutrientes, cobalto e enxofre no rendimento de matéria seca do estilosantes em solo sob cerrado. R. Bras. Ci. Solo, v. 16, p. 75-78, 1992.

Goedert, W.J.; Lobato, E. Avaliação agronômica de fosfatos em solo de cerrado. Rev. Bras. de Ci. do Solo, v. 8, p. 97-102, 1984. 
Goedert, W.J.; Sousa, D.M.G. de. Avaliação preliminar da eficiência de fosfatos com acidulação parcial. Rev. Bras. de Ci. do Solo, v. 10, p. 75-80, 1986.

Goedert, W.J.; Rein, T.A.; Sousa, D.M.G. de. Eficiência agronômica de um fosfato parcialmente acidulado em solo de cerrado. R. bras. Ci. Solo, v. v.12, p. p.179-183, 1988.

Gonçalves, J.L.M.; Firme, D.J.; Novais, R.F.; et al. Cinética de adsorção de fósforo em solos de Cerrado. R. Bras. Ci. Solo, v. 9, p. 107-111, 1985.

Gonçalves, J.L.M.; Novais, R.F.; Barros, N.F.; et al. Cinética de transformação de fósforo-lábil em não-lábil, em solos do cerrado. R. Bras. Ci. Solo, v. 13, p. 13-24, 1989.

Grande, M.A.; Curi, N.; Quaggio, J.A. Disponibilidade de fósforo pelos extratores de Mehlich e resina, em solos cultivados com arroz irrigado. R. Bras. Ci. Solo, v. 10, p. 45-50, 1986.

Guilherme, L.R.G.; Curi, N.; Silva, M.L.N.; et al. Adsorção de fósforo em solos de várzea do estado de Minas Gerais. R. Bras. Ci. Solo, v. 24, p. 27-34, 2000.

Hernández, J.; Meurer, E.J. Adsorção de fósforo e sua relação com formas de ferro em dez solos do Uruguai. R. Bras. Ci. Solo, v. 22, p. 223-230, 1998.

Hernández, J.; Meurer, E.J. Disponibilidade de fósforo em seis solos do Uruguai afetada pela variação temporal das condições de oxirredução. R. Bras. ci. Solo, v. 24, p. 19-26, 2000.

Hoffimann, C.R.; Faquin, V.; Guedes, G.A.A.; et al. O nitrogênio e o fósforo no crescimento da braquiária e do colonião em amostras de um latossolo da Região Noroeste do Paraná. R. Bras. Ci. Solo, v. 19, p. 79$86,1995$.

Lemos, C.A.S.; Anghinoni, I.; Volkweiss, S.J. Efeito residual do fósforo e sua relação com a granulação do superfosfato triplo e com o revolvimento do solo. R. Bras. Ci. Solo, v. 11, p. 161-166, 1987.

Longo, R.M.; Espíndola, C.R. C-orgânico, N-total e substâncias húmicas sob influência da introdução de pastagens (Brachiaria sp.) em áreas de cerrado e floresta amazônica. R. Bras. Ci. Solo, v. 24, p. 723-730, 2000.

Lopes, A.S.; Cox, F.R. Relação de características fisicas, químicas e mineralógicas com fixação de fósforo em solos sob Cerrados. R. Bras. Ci. Solo, v. 3, p. 82-88, 1979.

Macedo, W.S.L.; Gonçalves, J.O.N. Resposta da cultura de trevo-branco (Trifolium repens L.) cv. Bagé à calagem e a adubação fosfatada e potássica. R. Bras. Ci. Solo, v. 4, p. 39-44, 1980.

Magalhães, J.C.A.J.de; Lobato, E.; Rodrigues, L.H. Calagem e adubacao fosfatada para dois cultivares de trigo em solo de cerrado. R. Bras. Ci. solo, v. 4, p. 160-164, 1980.

Magalhães, J.C.A.J.de; Vieira, R.F.; Pereira, J.; et al. Efeito da adubação verde na disponibilidade de fósforo de fosfatos, numa sucessão de culturas, em solo de Cerrado. R. Bras. Ci. Solo, v. 15, p. 329-337, 1991.

Melloni, R.; Nogueira, M.A.; Freire, V.F.; et al. Fósforo adicionado e fungos micorrízicos arbusculares no crescimento e nutrição mineral do limoeiro-cravo [Citrus limonia (L.) Osbeck]. R. Bras. Ci. Solo, v. 24, p. 767-776, 2000.

Miranda, L.N.; Volkweiss, S.J. Relações entre a resposta da soja à adubação fosfatada e alguns parâmetros do solo. R. Bras. Ci. Solo, v. 5, p. 58-63, 1981.

Moreira, J.F.; Barros, N.F.; Novais, R.F.; et al. Efeito do tempo de contato do fósforo com o solo sobre sua disponibilidade para mudas de eucalipto. R. Bras. Ci. Solo, v. 15, p. 303-308, 1991.

Morelli, J.L.; Nelli, E.J.; Baptistella, J.R.; et al. Termofosfato na produtividade da cana-de-açúcar e nas propriedades químicas de um solo arenoso de baixa fertilidade. R. Bras. Ci. Solo, v. 15, p. 57-61, 1991.

Muniz, A.S.; Novais, R.F.; Barros, N.F.; et al.Nível crítico de fósforo na parte aérea de soja como variável do fator capacidade de fósforo do solo. R. Bras. Ci. Solo, v. 9, p. 237-243, 1985.

Nogueira, M.A.; Cardoso, E.J.B.N. Produção de micélio externo por fungos micorrízicos arbusculares e crescimento da soja em função de doses de fósforo. R. Bras. Ci. Solo, v. 24, p. 329-338, 2000.

Novais, R.F.; Kamprath, E.J. Parâmetros das isotermas de adsorção de fósforo como critério de recomendação de adubção fosfatada. R. Bras. Ci. Solo, v. 3, p. 37-41, 1979.

Novais, R.F.; Kamprath, E.J. Fósforo recuperado em três extratores químicos como função do fósforo aplicado no solo e do "fator capacidade". R. Bras. Ci. Solo, v. 3, p. 41-46, 1979.

Novelino, J.O.; Novais, R.F.; Neves, J.C.L.; et al. Solubilização de fosfato-de-araxá, em diferentes tempos de incubação, com amostras de cinco latossolos, na presença e na ausência de calagem. R. Bras. Ci. Solo, v. 9, p. 13-22, 1985.

Oliveira, E.L.; Muzilli, O.; Igue, K.; et al. Avaliação da eficiência agronômica de fosfatos naturais. R. Bras. Ci. Solo, v. 8, p. 63-67, 1984. 
Pavan, M.A.; Chaves, J.C.D. Alterações nas frações de fósforo no solo associadas com a densidade populacional de cafeeiros. R. Bras. Ci. Solo, v. 20, p. 251-256, 1996.

Raij, B. van. Seleção de métodos de laboratório para avaliar a disponibilidade de fósforo em solos. R. Bras. Ci. Solo, v. 2, p. 1-9, 1978.

Raij, B. van. Condições mínimas de eficiência para fosfatos alternativos ao superfosfato. R. Bras. Ci. Solo, v. 10, p. 235-239, 1986

Ramos, M.G. Avaliação da eficiência de oito fosfatos para as culturas de trigo e soja em um latossolo vermelho-escuro argiloso. R. Bras. Ci. Solo, v. 6, p. 38-42, 1982.

Rein, T.A.; Feitosa, C.T.; Goedert, W.J.; et al. Avaliação agronômica do concentrado fosfático de Patos de Minas tratado com bissulfato de amônio. R. Bras. Ci. Solo, v. 12, p. 171-177, 1988.

Reis, C.; Fabris, J.D.; Novais, R.F.; et al. Cinética de sorção de fósforo em alguns solos de Minas Gerais. R. Bras. Ci. Solo, v. 19, p. 337-344, 1995.

Rheinheimer, D.S.; Emani, P.R.; Santos, J.C.P.; et al. Influência da micorriza no crescimento do Trifolium riograndense e na predição da absorção de fósforo por um modelo mecanístico. R. Bras. Ci. Solo, v. 21, p. 191-197, 1997.

Rheinheimer, D.S.; Anghinoni, I.; Kaminski, J. Depleção do fósforo inorgânico de diferentes frações provocada pela extração sucessiva com resina em diferentes solos e manejos. R. Bras. Ci. Solo, v. 24, p. 345-354, 2000.

Rheinheimer, D.S.; Anghinoni, I.; Conte, E. Fósforo da biomassa microbiana em solos sob diferentes sistemas de manejo. R. Bras. Ci. Solo, v. 24, p. 589-598, 2000.

Rheinheimer, D.S.; Santos, E.J.S.; Kaminski, J.; et al. Alterações de atributos do solo pela calagem superficial e incorporada a partir de pastagem natural. R. bras. Ci. Solo, v. 24, p. 797-806, 2000.

Rodrigues, A.N.A.; Volkweiss, S.J.; Anghinoni, I. Efeitos imediatos e residuais do superfosfato triplo sobre o rendimento de matéria seca e absorção de fósforo por aveia forrageira em solo podzólico vermelho-escuro. R. Bras. Ci. Solo, v. 9, p. 219-224, 1985.

Ruiz, H.A.; Fernandes, B.; Novais, R.F.; et al. Efeito da pressão osmótica da solução nutritiva sobre a absorção de fósforo por plantas de soja. R. bras. Ci. Solo, v. 11, p. 295-297, 1987.

Ruiz, H.A.; Fernandes, B.; Novais, R.F.; et al. Efeito do conteúdo de água sobre os níveis críticos de fósforo em dois latossolos. R. Bras. Ci. Solo, v. 12, p. 43-48, 1988.

Ruiz, H.A.; Fernandes, B.; Novais, R.F.; et al. Efeito da umidade do solo sobre o volume e o conteúdo de fósforo no exsudato xilemático de soja. R. Bras. Ci. Solo, v. 12, p. 39-42, 1988.

Santos, H.L.; Vasconcellos, C.A. Determinação do número de amostras de solo para análise química em diferentes condições de manejo. R. Bras. Ci. Solo, v. 11, p. 97-100, 1987.

Schlindwein, J.A.; Anghinoni, I. Variabilidade horizontal de atributos de fertilidade e amostragem do solo no sistema plantio direto. R. Bras. Ci. Solo, v. 24, p. 85-91, 2000.

Scivittaro, W.B.; Boaretto, A.E.; Muraoka, T. Eficiência agronômica de fertilizantes fosfatados fluídos e sólidos. R. Bras. Ci. Solo, v. 21, p. 505-511, 1997.

Sfredo, G.J.; Borkert, C.M.; Cordeiro, D.S.; et al. Comparação de cinco extratores de fósforo do solo, considerando-se o tempo de incorporação de três adubos fosfatados. R. Bras. Ci. Solo, v. 3, p. 111-115, 1979.

Sfredo, G.J.; Paludzyszyn $\mathrm{F}^{\mathrm{o}}$, E.; Gomes, E.R.; et al. Resposta da soja a fósforo e a calcário em podzólico vermelho-amarelo de balsas, MA. R. Bras. Ci. Solo, v. 20, p. 429-432, 1996.

Silva, N.M.; Ferraz, C.A.M.; Campana, M.P. Competição entre superfosfatos simples e

termofosfatos, em ensaio permanente com algodoeiro. Rev. Bras. Ci. Solo, v. 1, p. 34-38, 1977.

Silva, E.M.R.; Almeida, D.L.; Franco, A.A.; et al. Adubação verde no aproveitamento de fosfato em solo ácido. R. Bras. Ci. Solo, v. 9, p. 85-88, 1985.

Silva, F.L.I.M.; Magalhães, J.R. Análise de sensibilidade dos parâmetros utilizados na simulação de absorção de fósforo pelo tomateiro, com o modelo matemático de Cushman-Barber. R. Bras. Ci. Solo, v. 13, p. 315-320, 1989.

Silva, F.C.; Raij, B. van. Avaliação da disponibilidade de fósforo, por diversos extratores, em amostras de solos cultivados com cana-de-açúcar. R. Bras. Ci. Solo, v. 20, p. 83-90, 1996.

Silva, R.B.; Lima, J.M.; Dias Junior, M.S. Efeito da adsorção de fosfato em parâmetros físicos e na compressibilidade de solos tropicais. R. Bras. Ci. Solo, v. 23, p. 219-226, 1999. 
Silva Filho, G.N.; Vidor, C. Solubilização de fosfatos por microrganismos na presença de fontes de carbono. R. Bras. Ci. Solo, v. 24, p. 311-319, 2000.

Smyth, T.J.; Sanchez, P.A. Níveis críticos de fósforo para arroz de sequeiro em um latossolo dos cerrados. R. Bras. Ci. Solo, v. 4, p. 88-92, 1980.

Sousa, D.M.G. de; Volkweiss, S.J. Efeito residual do superfosfato triplo aplicado em pó e em grânulos no solo. R. Bras. Ci. Solo, v. 11, p. 141-146, 1987.

Sousa, D.M.G. de; Volkweiss, S.J. Reações do superfosfato triplo em grânulos com solos. R. Bras. Ci. Solo, v. 11, p. 133-140, 1987.

Sousa, D.M.G. de; Volkweiss, S.J. Rendimento de matéria seca e conteúdo de fósforo da parte aérea de milho influendiados pela adubação com superfosfato triplo em pó e em grânulos. R. Bras. Ci. Solo, v. 11, p. 127-132, 1987.

Souza, L.S.; Cogo, N.P.; Vieira, S.R. Variabilidade de fósforo, potássio e matéria orgânica no solo em relação a sistemas de manejo. R. Bras. Ci. Solo, v. 22, p. 77-86, 1998.

Sparovek, G.; Camargo, O.A. Sampling strategies for tropical forest nutrient cycling studies: a case study in São Paulo, Brazil. R. Bras. Ci. Solo, v. 21, p. 635-642, 1997.

Tanaka, R.T.; Bahia, V.G.; Coelho, A.M.; et al. Seleção de extratores de fósforo do solo em função das respostas das plantas de milho (Zea mays L.) e da adubação com fosfato Patos-de-Minas em condiões de casa de vegetação.R. Bras. Ci. Solo, v.5, p.38-42, 1981.

Vale, F.R.; Novais, R.F.; Sant'anna, R.; et al. Absorção e translocação de fosfato em milho suprido com nitrato ou amônio e pré-tratado com alumínio. R. Bras. Ci. Solo, v. 8, p. 219-222, 1984.

Vilela, L.; Anghinoni, I. Morfologia do sistema radicular e cinética da absorção de fósforo em cultivares de soja afetados pela interação alumínio-fósforo. R. Bras. Ci. Solo, v. 8, p. 91-96, 1984. 


\section{APÊNDICE 2}

\section{VARIABILIDADE QUÍMICA DAS CAMADAS SUPERFICIAIS DE SOLOS DO MUNICÍPIO DE UNAÍ (MG).}

$27^{\circ}$ Congresso Brasileiro de Ciência do Solo, Brasília, 11-16 de julho de 1999. SBCSEmbrapa Cerrados, CD-rom. 


\section{VARIABILIDADE QUÍMICA DAS CAMADAS SUPERFICIAIS DE SOLOS DO MUNICIPIO DE UNAI}

(MG)

Edemar Joaquim CORAZZA ${ }^{1}$, Michel BROSSARD ${ }^{2}$ \& Alécio Faria OLIVEIRA ${ }^{3}$. 1. Doutorando ESALQ-USP, bolsista IRD-Orstom, Projeto Embrapa Cerrados IRD (França), CP 08223, 73301-970 Planaltina-DF, ecorazza@carpa.ciagri.usp.br. 2. IRD-Orstom/Embrapa Cerrados. 3. CAPUL, Unaí, MG.

Num estudo de diagnóstico de solos sob pastagens, construiu-se uma base de dados com resultados de análises de solos de propriedades afiliadas à cooperativa agropecuária Unaí (CAPUL), Unaí (MG). Selecionou-se 115 amostras de solo, sendo $48 \%$ de pastagens de Brachiaria spp. (BR), Panicum maximum (PM) e Andropogon gayanus (AG) , $17 \%$ de áreas sob cultivos diversos (CD) e $35 \%$ de áreas não identificadas com precisão, porém todas estavam sob pastoreio. A amostragem não foi controlada. As amostras foram analisadas num mesmo laboratório privado avaliando-se as seguintes propriedades químicas: $\mathrm{pH}, \mathrm{CTC}, \mathrm{Ca}, \mathrm{Mg}$, $\mathrm{K}$, Al, P extraível, matéria orgânica (MO). A variabilidade dos dados foi determinada por métodos estatísticos não paramétricos (centil, quartil, mediana).

As amostras analisadas apresentam-se como ácidas a neutras. A mediana do $\mathrm{pH}$ água é de $5,2\left(\mathrm{pHCaCl}_{2}\right.$ $=4,4)$, sendo que $5 \%$ das amostras apresentam valores inferiores a $4,7(\mathrm{pH} \mathrm{CaCl}=4)$ e $5 \%$ delas superiores a $6\left(\mathrm{pHCaCl}_{2}=5,3\right)$. Alguns solos podem ser considerados álicos. A mediana dos valores de Al trocável é $0,4 \mathrm{cmol}_{\mathrm{c}} / \mathrm{dm}^{3} \mathrm{com}$ amplitude de 0 a $3,3 \mathrm{cmol}_{\mathrm{C}} / \mathrm{dm}^{3}$, sendo que apenas $5 \%$ das amostras tem valores de Al superiores a $2,5 \mathrm{cmol}_{\mathrm{c}} / \mathrm{dm}^{3}$, e $75 \%$ delas situam-se entre 0,1 e $1,4 \mathrm{cmol}_{\mathrm{c}} / \mathrm{dm}^{3}$. A amplitude da saturação de alumínio (m) é de 0 a $87 \%$, com mediana de $11,3 \%$. Observa-se que $43 \%$ das amostram apresentam $\mathrm{m}$ superiores à $20 \%$ (limite toxidez do Al). Nas amostras sob BR a mediana de $m$ é de $32 \%$, sendo reduzida a $2,4 \%$ sob PM e AG, e a $1 \%$ sob $C D$.

Os conteúdos de $\mathrm{MO}$ podem ser considerados médios: mediana de $2,4 \%$ com uma amplitude de 1,1 a $6,3 \%$. Sob as BR, $75 \%$ das amostras estão entre 1,9 e $2,9 \%$ (mediana $2,5 \%$ ), sendo que sob $\mathrm{PM}$ e $\mathrm{AG}$ e $\mathrm{CD}$ observam-se medianas mais elevadas $(2,8$ e $2,7 \%$, respectivamente). A participação da MO na troca de cátions é ilustrada pelos coeficientes de correlação positivos significativos a $1 \%$ : MO-Ca $\mathrm{r}^{2}=0,672$; $\mathrm{MO}-\mathrm{K} \mathrm{r}^{2}=$ 0,$418 ; \mathrm{MO}-\mathrm{Mg} \mathrm{r}^{2}=0,492$.

A CTC efetiva apresenta uma mediana de 7,8 cmol ${ }^{\prime} / \mathrm{dm}^{3}$ com amplitude de 3,3 a $17,6 \mathrm{cmol}_{\mathrm{C}} / \mathrm{dm}^{3}$. $75 \%$ das amostras apresentam valores entre $6,3 \mathrm{e}$ $10,1 \mathrm{cmol}_{\mathrm{c}} / \mathrm{dm}^{3}$. Sob as BR esta amplitude é reduzida e os valores são mais baixos, 5,9 e 7,6
$\mathrm{cmol}_{\mathrm{C}} / \mathrm{dm}^{3}$, o que é coerente com os valores de $\mathrm{MO}$ sob essas pastagens. A CTC da fase mineral, situase entre 2,8 e $3,1 \mathrm{cmol} / \mathrm{cdm}^{3}$ de solo. Observando-se os parâmetros para cátions, os fatos mais relevantes são: $\mathrm{Ca}$, mediana $1,9 \mathrm{cmol}_{\mathrm{c}} / \mathrm{dm}^{3}$ com amplitude de 0,1 a $10,7 \quad \mathrm{cmol}_{\mathrm{C}} / \mathrm{dm}^{3} ; \mathrm{Mg}$, mediana 1,1 cmol $_{\mathrm{c}} / \mathrm{dm}^{3}$ com amplitude de 0 a $2,8 \mathrm{cmol}_{\mathrm{C}} / \mathrm{dm}^{3} ; \mathrm{K}$, mediana de 0,3 $\mathrm{cmol}_{\mathrm{c}} / \mathrm{dm}^{3}$, amplitude de 0,05 a 1,02 $\mathrm{cmol}_{\mathrm{c}} / \mathrm{dm}^{3}$. Não foram observadas variações de conteúdos de $\mathrm{K}$ segundo a origem das amostras. Entretanto, as diferenças são relevantes para $\mathrm{Ca}$ e $\mathrm{Mg}$, e as amostras das áreas de BR apresentaram valores mais baixos comparadas às áreas de $\mathrm{CD}$ e de $P M$ e $A G$, atingindo níveis considerados limitantes à produtividade (mediana $\mathrm{Ca}=0,8$ $\mathrm{cmol}_{\mathrm{C}} / \mathrm{dm}^{3}$; mediana $\mathrm{Mg}=0,6 \mathrm{cmol}_{\mathrm{C}} / \mathrm{dm}^{3}$ ).

A mediana do PMehlich é de $3 \mathrm{mgP}_{\mathrm{dm}^{3}}$.com amplitude entre 1 e $48 \mathrm{mgP} / \mathrm{dm}^{3}$. Ressalta-se os baixos valores observados sob as pastagens de BR, mediana de $2 \mathrm{mgP} / \mathrm{dm}^{3}, 75 \%$ da população entre 1 e $3 \mathrm{mgP} / \mathrm{dm}^{3}$. As pastagens de PM e AG (mediana de $3 \mathrm{mgP} / \mathrm{dm}^{3}$ ) e CD (mediana de $5 \mathrm{mgP} / \mathrm{dm}^{3}$ ) já mostram valores mais elevados indicando uma possível estratégia de fertilização.

Os solos sob BR estavam com os níveis nutricionais abaixo dos demais. Isso poderia significar: manejo inadequado do solo na época do preparo e na condução da pastagem. Estas informações de um diagnóstico, de maneira geral, são importantes na definição de estratégias de recuperação ou renovação de pastagens por parte de cooperativas, associações e municípios.

A a nálise dos dados existentes fornece indicações da variabilidade de propriedades de solos em grandes áreas, valoriza resultados coletados no decorrer do tempo a fim de observar flutuações, permite preparar estratégias de amostragem em função de objetivos específicos, e fornece dados sintéticos aos técnicos. 


\section{APÊNDICE 3}

\section{CARACTERÍSTICAS QUÍMICAS DE SOLOS SOB PASTAGENS DE BAIXA PRODUTIVIDADE: CONTRIBUIÇÃO PARA UMA ABORDAGEM REGIONAL NO CERRADO.}

Abstracts International Symposium Soil functioning under pastures in intertropical areas. Brasilia, Brazil, October 16-20, 2000. CD-rom Embrapa Cerrados/IRD, Ed. Soil Pasture Project. 
Características químicas de solos sob pastagens de baixa produtividade: contribuição para uma abordagem regional no Cerrado.

E.J. Corazza ${ }^{1}$, M. Brossard ${ }^{2} \&$ V. C. Dias $^{3}$

1. Graduate student (Doctor degree - IRD Scholarship) at ESALQ/USP (University of São Paulo, Brazil), CP 96, Lab. of Soil Fertility/CENA, 13400-970 - Piracicaba, SP Brazil (ecorazza@carpa.ciagri.usp.br)

2. IRD/Embrapa Cerrados, caixa postal 7091, 71619-970 Brasília, DF, Brazil

3. Eng ${ }^{\circ}$ Agrônomo Cooprata, R. Pe. Angelo Fel 8, 38140-000 Prata, MG, Brazil

\begin{abstract}
Soil chemical characteristics under low productivity pastures: a contribution to a regional approach in the Cerrado region.

It is estimated that approximately 49 millions ha of cultivated pastures of Cerrado Region are in degradation process. The objective of this paper was to determine some indicators for pastures degradation level evaluation through the chemical variability of soil surface layers. A data base was elaborated with 771 routine soil analysis from an area of approximately $1000 \mathrm{~km}^{2}$. The data was analysed by descriptive and no-parametric statistics. The pastures were below their productivity potential on soils developed on sandstone materials. They main limiting factors were related to acidity and low levels of available phosphorus and soil organic matter. For this database, the soils under Brachiaria presented the strongest nutritional limitation for the plants. In this typical region of the Cerrado, it could be concluded that the soil chemical characteristics had contributed to the pastures degradation processes.
\end{abstract}

Key-words: routine soil analysis, soil variability, phosphorus, organic matter, degradation process

\title{
INTRODUÇÃO
}

Estima-se que cerca de $80 \%$ das pastagens cultivadas, atualmente implantadas, estejam em processos de degradação. Este total soma algo em torno de 49 milhões de hectares, constituindo-se um dos maiores problemas ambientais e econômicos da região do Cerrado. Levantamentos a nível de propriedades, associações de produtores, cooperativas e empresas de assistência técnica são escassos e quando realizados poucos são realizados de modo ordenado, facilitando a compilação dos dados e a análise destes de maneira conjunta. $\mathrm{O}$ objetivo deste trabalho foi determinar alguns indicadores de níveis de degradação de pastagens a partir da variabilidade química das camadas superficiais de solos e valorizar os resultados para elaboração de estratégias de recuperação e/ou renovação de pastagens por parte de cooperativas, associações de produtores e municípios.

\section{MATERIAL E MÉTODOS}

No âmbito de um estudo de diagnóstico de solos sob pastagens, uma base de dados foi construída com resultados de análises de solos de propriedades afiliadas à Cooperativa dos Produtores Rurais do Prata (Cooprata) do Município de Prata (MG). Foram selecionadas 771 análises de amostras de solo (75 sob Brachiaria spp. (BR), 46 sob Panicum spp. (PA), 78 sob cana, 161 sob pastagens diversas (PD), 69 sob cultivos diversos (CD) e 342 não identificadas (NI)). A área abrange aproximadamente $1000 \mathrm{~km}^{2}$. A estratégia de amostragem não foi controlada. Uma amostra analisada resulta da mistura de vários pontos amostrados da camada superficial $( \pm 0-20 \mathrm{~cm})$ da mesma parcela feita pelo agricultor ou pelo técnico da cooperativa. As amostras foram analisadas num mesmo laboratório privado. Foram determinados características químicas usuais $\left(\mathrm{pH}\right.$ em $\mathrm{H}_{2} \mathrm{O}, \mathrm{CTC}$ efetiva, $\mathrm{Ca}, \mathrm{Mg}, \mathrm{K}, \mathrm{Al}, \mathrm{P}$ extraível, matéria orgânica (MO)) e utilizado estatísticas descritivas para a análise dos dados.

\section{RESULTADOS}

A CTC efetiva apresentou mediana de $2,0 \mathrm{cmol}_{\mathrm{c}} \mathrm{dm}^{-3}$ e amplitude de 0,4 a $18,0 \mathrm{cmol}_{\mathrm{c}} \mathrm{dm}^{-3} .75 \%$ das amostras apresentaram valores inferiores $3,4 \mathrm{cmol}_{\mathrm{c}} \mathrm{dm}^{-3}$, sendo esta amplitude reduzida e os 
valores muito baixos. Sob Brachiaria, os valores foram ainda mais baixos, 75 \% das amostras estavam abaixo de 2,3 $\mathrm{cmol}_{\mathrm{c}} \mathrm{dm}^{-3}$ (mediana 1,48), o que foi coerente com os valores de MO sob essas pastagens. A CTC da fase mineral, situou-se em torno de $2,0 \mathrm{cmol}_{c} \mathrm{dm}^{-3}$ de solo indicando que a maioria das amostras são oriundas de solos desenvolvidos sob arenitos.

As amostras analisadas apresentaram-se como ácidas a neutras. A mediana do $\mathrm{pH}$ em água foi de 5,4 , sendo que $75 \%$ das amostras apresentaram valores inferiores a 5,7. Uma parte dos solos podem ser considerados álicos. A mediana dos valores de Al trocável foi $0,2 \mathrm{cmol}_{\mathrm{c}} \mathrm{dm}^{-3}$, a amplitude de 0 a $2,7 \mathrm{cmol}_{\mathrm{c}} \mathrm{dm}^{-3}$, apenas $25 \%$ das amostras tem valores de Al superiores a $0,5 \mathrm{cmol}_{\mathrm{c}} \mathrm{dm}^{-3}$, e $75 \%$ delas situam-se entre 0,0 e $0,5 \mathrm{cmol}_{\mathrm{c}} \mathrm{dm}^{-3}$. A amplitude da saturação de alumínio foi de 0 a $92,8 \%$, com mediana de 7,7 \%. Observou-se que $45 \%$ das amostras apresentaram valores "m" superiores à $20 \%$ (limite de toxidez do Al). Quando selecionadas amostras sob Brachiaria a mediana foi de 29,5\%, sendo reduzida a $0,0 \%$ sob Panicum, 4,9 \% sob cana, $16 \%$ sob pastagens diversas e a 3,8 \% sob cultivos diversos. Demonstrando que, com exceção das áreas sob Brachiaria, em grande parte das áreas amostradas foi realizada uma correção da acidez do solo através da calagem.

Os conteúdos de MO podem ser considerados baixos: mediana de 1,5 dag kg-1 (menos de 1,5 CFSEMG, 1978) com amplitude de 0,2 a 12,3 dag kg ${ }^{-1}$. Sob Brachiaria, $75 \%$ das amostras estão entre 0,4 a 1,6 dag kg ${ }^{-1}$ (mediana 1,3), sob Panicum 75\% das amostras estão entre 0,8 a 2,1 dag kg (mediana 1,4), sob cana $75 \%$ das amostras estão entre 0,7 a 1,8 dag kg$^{-1}$ (mediana 1,5), sob pastagens diversas $75 \%$ das amostras estão entre 0,3 a 2,0 dag kg $^{-1}$ (mediana 1,5) e sob cultivos diversos $75 \%$ das amostras estão entre 0,2 a $1,9 \mathrm{dag} \mathrm{kg}^{-1}$ (mediana 1,6). Lopes (1984) em trabalho realizado com 514 amostras sob cerrado encontrou mediana de $2,2 \mathrm{dag} \mathrm{kg}^{-1}$ com $60 \%$ delas apresentando valores entre 1,5 e 3,0 dag $\mathrm{kg}^{-1}$ de MO níveis considerados médios. Verifica-se a tendência nas amostras analisadas de perda da MO com o cultivo, principalmente quando sob pastagens cultivadas sem correções da fertilidade do solo, pois $50 \%$ das amostras encontrava-se com teores menores que $1,5 \mathrm{dag} \mathrm{kg}^{-1} \mathrm{de} \mathrm{MO}_{\text {. }}$

$\mathrm{Na}$ análise dos valores de cátions, os fatos mais relevantes observados foram: $\mathrm{Ca}$, mediana 1,2 $\mathrm{cmol}_{\mathrm{c}} \mathrm{dm}^{-3}$, amplitude de 0,1 a 15,6 $\mathrm{cmol}_{\mathrm{c}} \mathrm{dm}^{-3} ; \mathrm{Mg}$, mediana $0,5 \mathrm{cmol}_{\mathrm{c}} \mathrm{dm}^{-3}$, amplitude de 0 a 5,4 $\mathrm{cmol}_{\mathrm{c}} \mathrm{dm}^{-3} ; \mathrm{K}$, mediana de $0,12 \mathrm{cmol}_{\mathrm{c}} \mathrm{dm}^{-3}$, amplitude de 0,002 a $0,85 \mathrm{cmol}_{\mathrm{c}} \mathrm{dm}^{-3}$. Não se observou variações de conteúdos de $\mathrm{K}$ segundo a origem das amostras, mas as diferenças ocorreram para $\mathrm{Ca} \mathrm{e}$ $\mathrm{Mg}$, pois as amostras das parcelas de Brachiaria apresentaram valores mais baixos comparadas às áreas de Panicum e cultivos diversos, sendo considerados limitantes à produtividade (mediana Ca 0,6

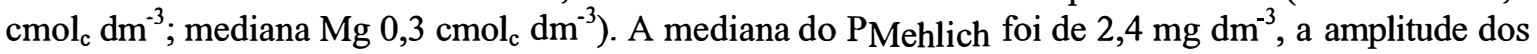
resultados situou-se entre 0 e $168 \mathrm{mg} \mathrm{dm}^{-3}, 75 \%$ das amostras apresentaram valores inferiores a $5,9 \mathrm{mg}$ $\mathrm{dm}^{-3}$. Ressalta-se os baixos valores observados sob as pastagens de Brachiaria, mediana de 1,8 mg

$\mathrm{dm}^{-3}, 75 \%$ da população entre 0,2 e $4,3 \mathrm{mg} \mathrm{dm}^{-3}$ e pastagens diversas com mediana de $2 \mathrm{mg} \mathrm{dm}^{-3}$. As pastagens de Panicum (mediana de $5 \mathrm{mg} \mathrm{dm}^{-3}$ ) mostraram valores mais elevados que traduzem uma estratégia de fertilização. Entretanto, as amostras sob pastagens não identificadas e cultivos diversos apresentaram valores intermediários tendendo a baixos (mediana $2,7 \mathrm{mg} \mathrm{dm}^{-3}$ ) demonstrando que a fertilização destas áreas nem sempre é realizada conforme as recomendações técnicas.

\section{CONCLUSÕES}

As análises demonstraram que as pastagens estão aquém do potencial produtivo, pois apresentaram fatores limitantes ligados a falta da correção acidez do solo e baixos níveis de $\mathrm{P}$ e MO em grande parte das análises. Dentro dos grupos estudados, os solos sob Brachiaria estavam com maiores limitações químicas em relação à oferta de nutrientes para as plantas. Pode se concluir com este levantamento que os fatores químicos do solo contribuíram para o processo de degradação das pastagens.

CFSEMG - Comissão estadual de fertilidade do solo do Estado de Minas Gerais. Recomendações para o uso de corretivos e fertilizantes em Minas Gerais - $3^{a}$ aproximação. EPAMIG, Belo Horizonte. 1978. 80p.

Lopes, A.S. Solos sob "Cerrado": características, propriedades e manejo. Associação brasileira para pesquisa da Potassa e do Fosfato, Piracicaba, 2a ed., 1984. 162 p. 


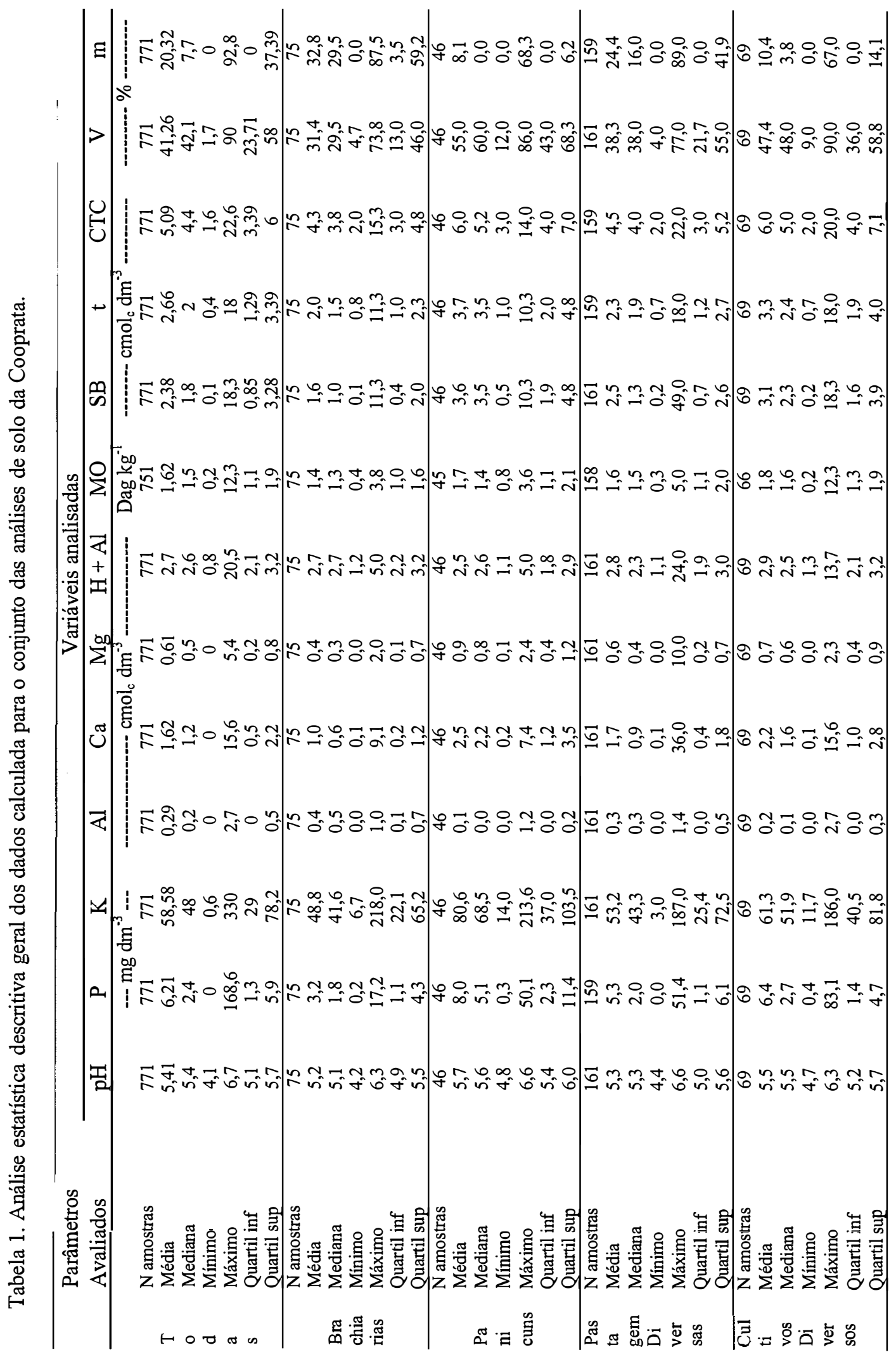


APÊNDICE 4

IMAGENS DOS CULTIVOS EM VASO, CAPÍTULO 6. 


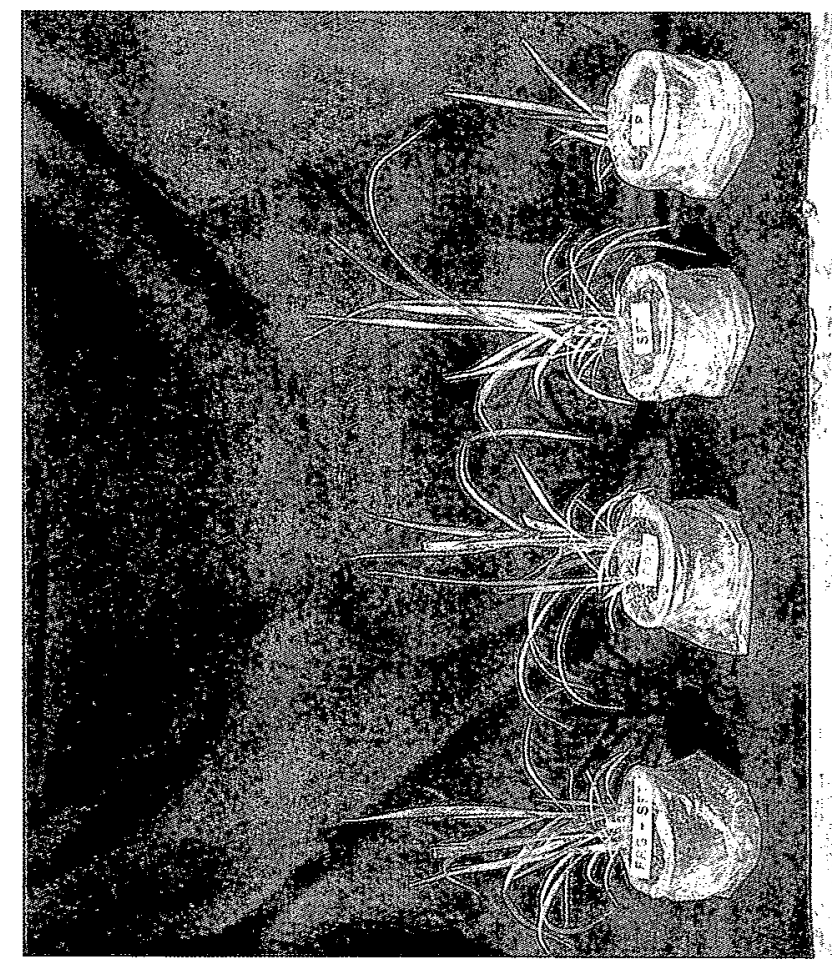

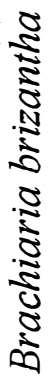
